\title{
„denn der tragende Gehalt der Kultur ist die Religion und die notwendige Form der Religion ist die Kultur". Considerações sobre os fundamentos teórico-conceituais e sistemáticos da teologia da cultura de Paul Tillich
}

\author{
Fábio Henrique Abreu*
}

Dedico esse texto à memória de meu Doktorvater Zwinglio Mota Dias (1941-2021), cujo testemunho de vida continua a encantarme enquanto expressão fidedigna do princípio protestante.

\section{RESUMO}

Esse artigo reconstrói a teologia da cultura de Paul Tillich de forma sistemática. A tese apresentada afirma que o modo da relação entre religião e cultura no programa teológico-cultural de Tillich é não apenas mediado por uma filosofia do espírito e do sentido, como também reivindica uma teoria dos símbolos plenamente delineada. A análise da filosofia do espírito e do sentido de Tillich é desenvolvida na primeira parte da presente exposição. A partir da elucidação de sua filosofia do espírito e do sentido, o conceito de religião, enquanto direcionamento ao incondicionado, é apresentado em sua natureza mais própria. A tarefa de exposição do conceito de religião compreende o conteúdo da segunda parte desse estudo. Na terceira e última parte da presente exposição, uma análise da função do conceito de símbolo para uma delimitação mais precisa da teologia da cultura de Tillich é oferecida. Como se tornará perceptível, é a partir do conceito de símbolo que a forma própria do

\footnotetext{
* Doutor em Ciência da Religião pelo Programa de Pós-graduação em Ciência da Religião da Universidade Federal de Juiz de Fora (PPCIR-UFJF). Pós-doutor em Filosofia da Religião pelo PPCIR-UFJF e pela Evangelisch-Theologische Fakultät, Universität Wien. Atualmente desenvolve pesquisa de habilitação em Teologia Sistemática pela Universität Wien, sob a supervisão do Prof. Dr. habil. Christian Danz.
} 
relacionamento entre religião e cultura, i.e., entre o condicionado e o incondicionado, é articulada.

Palavras-chave: teologia da cultura; filosofia do espírito e do sentido; símbolo; religião e cultura.

\title{
„denn der tragende Gehalt der Kultur ist die Religion und die notwendige Form der Religion ist die Kultur". Considerations on the Theoretical- Conceptual and Systematic Foundations of Paul Tillich's Theology of Culture.
}

\begin{abstract}
This article reconstructs Paul Tillich's theology of culture in a systematic way. The thesis presented asserts that the mode of the relationship between religion and culture in Tillich's theological-cultural program is not only mediated by a philosophy of spirit and meaning, but also claims a fully delineated theory of symbols. The analysis of Tillich's philosophy of spirit and meaning is developed in the first part of this study. From the elucidation of his philosophy of spirit and meaning, the concept of religion, as directedness towards the unconditioned, is presented in its most proper nature. The task of presenting the concept of religion comprises the content of the second part of this investigation. In the third and last part of the present study, an analysis of the role of the concept of symbol for the delineation of Tillich's theology of culture is offered. As will become transparent, it is from the concept of symbol that the proper form of the relationship between religion and culture, i.e., between the conditioned and the unconditioned, is articulated.
\end{abstract}

Keywords: theology of culture; philosophy of spirit and meaning; symbol; religion and culture.

Que a busca de sentido seja uma necessidade básica de toda vida consciente; que o manejo do sentido seja uma das tarefas centrais dos sistemas sociais; e que a religião, tanto em sua forma individual quanto pública, tenha participação em ambas; é, hoje em dia, quase um lugar-comum. Isso nem sempre foi assim. Devemos a primeira construção do conceito de religião baseado numa teoria do sentido a Paul Tillich. Dessa forma, ele estabeleceu padrões de importância 
duradoura para o tratamento cultural-científico, sociológico, filosófico-religioso e teológico-sistemático do conceito de sentido. ${ }^{1}$

\section{Introdução}

"A religião é o direcionamento ao incondicionado [Richtung auf das Unbedingte]". ${ }^{2}$ Essa sentença, escrita por Tillich na segunda versão de sua famosa palestra Über die Idee einer Theologie der Kultur, proferida em 1919 e publicada de forma revisada em 1921, é frequentemente citada para marcar o centro de seu programa teológico-cultural. Trata-se, sem dúvidas, de uma de suas mais famosas formulações. Essa sentença configura, de acordo com Trutz Rendtorff, uma espécie de "melodia de reconhecimento [Erkennungsmelodie]", uma "trilha sonora", que, onde quer que soe, se torna "inconfundivelmente reconhecível: aqui fala Paul Tillich". ${ }^{3}$ A concisão da fórmula, no entanto, oblitera o fato de que ela é, como corretamente aponta Georg Neugebauer, extremamente hermética e dificilmente compreensível quando tomada em si mesma. ${ }^{4}$ Os conceitos que são fundamentais para a teologia da cultura - como forma (Form), conteúdo (Inhalt), substância (Gehalt/Substanz), autonomia, heteronomia, teonomia, síntese cultural (Kultursynthese) -, por Tillich mesmo inseridos esquematicamente no centro de seu programa, tendem a conferir uma falsa ideia de que é possível reconstruir sua Kulturtheologie tão somente através de uma análise desses conceitos. ${ }^{5}$ Tal procedimento, entretanto, perde o foco

\footnotetext{
${ }^{1}$ BARTH, U. Die sinntheoretischen Grundlagen des Religionsbegriffs. Problemgeschichtliche Hintergründe zum frühen Tillich. In: Religion in der Moderne. Tübingen: J. C. B. Mohr (Paul Siebeck), 2003, p. 89. [Todas as traduções são nossas = FHA.]

${ }^{2}$ TILLICH, P. Über die Idee einer Theologie der Kultur. In: RADBRUCH, G.; TILLICH, P. (Hg.). Religionsphilosophie der Kultur. Zwei Entwürfe von Gustav Radbruch und Paul Tillich. Darmstadt: Wissenschaftliche Buchgesellschaft, 1968, p. 27-52, aqui, p. 35. Para a primeira versão da Kulturvortrag, proferida no âmbito da Sociedade Kantiana de Berlim, em 1919, cf. TILLICH, P. Über die Idee einer Theologie der Kultur. (1919). In: PALMER, M. (Hg.). Main Works - Hauptwerke. Band 2: Kulturphilosophische Schriften. Berlin; New York: Walter de Gruyter; Evangelisches Verlagswerk, 1990, p. 69-85.

${ }^{3}$ RENDTORFF, T. In Richtung auf das Unbedingte. Religionsphilosophie der Postmoderne. In: FISCHER, H. (Hg.). Paul Tillich: Studien zu einer Theologie der Moderne. Frankfurt am Main: Athenäum Verlag GmbH, 1989, p. 335. Como Rendtorff afirma nessa mesma página: „So lautet die Erkennungsmelodie, die, wo sie ertönt, unverwechselbar zu erkennen gibt: Hier spricht Paul Tillich. In vielen Variationen kehrt dieser Grundton immer wieder: Denken und Reden ,in Richtung auf das Unbedingte'. Dieser Grundton hat dem Werk Tillichs sein eingentümliches Gepräge gegeben. Im System der Wissenschaften von 1923 liest man, der ,Wille zum Unbedingten" liege allem geistigen zu Grunde“.

${ }^{4}$ NEUGEBAUER, G. Die geistphilosophischen Grundlagen der Kulturtheologie Tillichs vor dem Hintergrund seiner Schelling- und Husserlrezeption. In: DANZ, C.; SCHÜßLER, W. (Hg.). Paul Tillichs Theologie der Kultur: Aspekte, Probleme, Perspektiven. Berlin; Boston: Walter de Gruyter GmbH \& Co. KG, 2011, p. 38.

${ }^{5}$ NEUGEBAUER, G. Die geistphilosophischen Grundlagen der Kulturtheologie Tillichs vor dem Hintergrund seiner Schelling- und Husserlrezeption, p. 38.
} 
dos fundamentos teóricos que os organizam - sobretudo a filosofia do espírito, a teoria do sentido e a teoria dos símbolos. A teologia da cultura de Tillich é baseada em um conceito específico de espírito, cujas bases foram desenvolvidas ainda antes da Primeira Guerra, i.e., no transcurso de seus estudos sobre Fichte e Schelling e em sua Systematische Theologie de 1913. No entanto, foi somente por meio da virada teórica de sua abordagem sistemática, proporcionada pela apropriação do neokantismo e da fenomenologia de Husserl durante a Primeira Guerra - sobretudo da Intentionalitätstheorie que conforma a fenomenologia husserliana ${ }^{6}-$, que Tillich foi capaz de articular a base da filosofia do espírito sobre a qual seu esboço programático se encontra fundamentado. ${ }^{7}$ Nosso papel,

${ }^{6}$ Através da internalização de Intentionalitätstheorie de Husserl na determinação de seu conceito de religião como "direcionamento para o incondicionado", Tillich emprega o tema central da fenomenologia husserliana. Sobre a posição da teoria da intencionalidade no sistema de Husserl, veja STRÖKER, E. Intentionalität und Konstitution. Wandlungen des Intentionalitätskonzepts in der Philosophie Husserls. Dialectica, vol. 38, no. 2-3, 1984, p. 191: „Intentionalität ist das Generalthema der Philosophie Edmund Husserls. Wollte man die gleiche Rolle dem Bewusstsein zuschreiben, so wäre dies ebenso zutreffend. Denn für Husserl ist es die Intentionalität, durch welche Bewusstsein im prägnanten Sinne charakterisiert ist. Es ist also nicht wie ein Dinghaftes, Substantielles, sondern als Beziehung aufgefasst dergestalt, daß es nur mittels etwas bestimmt werden kann, das nicht es selbst ist, auf das vielmehr es «sich richtet) als auf seinen Gegenstand. Dieser ist primär nicht von der Art des Bewusstseins, sondern ihm gegenüber transzendent. Das Prädikat «intentional〉 könnte also bloss einen Pleonasmus ergeben, gälte es nicht, die darin ausgedrückte eigentümliche Beziehung des Bewusstseins zu thematisieren und analytisch zu erhellen". Sobre o papel da fenomenologia de Husserl no sistema de Tillich, veja BARTH, U. Religion und Sinn. In: DANZ, C.; SCHÜßLER, W. (Hg.). Religion - Kultur - Gesellschaft. Der frühe Tillich im Spiegel neuer Texte (1919-1920). Tillich-Studien: Band 20. Wien; Berlin: LIT Verlag, 2008, p. 197-213, especialmente a nota 28 da p. 207: ,,Richtung auf" bzw. ,sich richten auf" sind Tillichs Verdeutschung von Husserls ,Intentionalität““. Apesar da centralidade da teoria da intencionalidade de Husserl na determinação do conceito de religião de Tillich, ainda não há uma investigação propriamente exegética da recepção de Husserl por Tillich. Considerações iniciais sobre esse tema podem ser encontradas, no entanto, nos seguintes estudos: GRUBE, D.-M. Unbegründbarkeit Gottes? Tillichs und Barths Erkenntnistheorien im Horizont der gegenwärtigen Philosophie. Marburg: N. G. Elwert Verlag, 1998, p. 63-71; BARTH, U. Die sinntheoretischen Grundlagen des Religionsbegriffs. Problemgeschichtliche Hintergründe zum frühen Tillich, p. 89-123; MOXTER, M. Kritischer Intuitionismus. Tillichs Religionsphilosophie zwischen Neukantianismus und Phänomenologie. In: DANZ, C.; SCHÜßLER, W. (Hg.). Religion Kultur - Gesellschaft. Der frühe Tillich im Spiegel neuer Texte (1919-1920), p. 173-195; NEUGEBAUER, G. Die geistphilosophischen Grundlagen der Kulturtheologie Tillichs vor dem Hintergrund seiner Schelling- und Husserlrezeption, p. 47-63; DANZ, C. Zwischen Transzendentalphilosophie und Phänomenologie. Die methodischen Grundlagen der Religionstheorien bei Otto und Tillich. In: LAUSTER, J.; SCHÜZ, P.; BARTH, R.; DANZ, C. (Hg.). Rudolf Otto. Theologie - Religionsphilosophie - Religionsgeschichte. Berlin; Boston: Walter de Gruyter GmbH, 2014, p. 341-345; HEINEMANN, L. C. Sinn - Geist - Symbol: Eine systematisch-genetische Rekonstruktion der frühen Symboltheorie Paul Tillichs. TillichForschungen: Band 10. Berlin; Boston: Walter de Gruyter GmbH, 2017, p. 335-348.

${ }^{7}$ Diferentemente da já mencionada análise de G. Neugebauer, o presente estudo não se preocupará, entretanto, com a tarefa de demarcar os contornos da teologia da cultura de Tillich no período anterior à Primeira Guerra Mundial. Em vez disso, minha preocupação aqui é a de 
aqui, não pode ser outro senão o de deslindar, nos limites das presentes páginas, os contornos centrais da filosofia do espírito e do sentido que fundamentam seu programa. A teoria dos símbolos, que somente alcança sua forma final a partir do texto Das religiöse Symbol, de $1928,{ }^{8}$ será tematizada através de um incurso na estrutura dessa base teórico-conceitual fundante.

Em linhas gerais, pode-se dizer que o programa teológico-cultural de Tillich intenciona oferecer uma superação da antítese entre religião e cultura por meio da reivindicação de uma cultura religiosa an sich ${ }^{9}$ Como pano de fundo desse programa, encontra-se a tentativa de integração do processo de autodiferenciação da cultura moderna autônoma em distintos subsistemas ${ }^{10} \mathrm{a}$ partir de uma nova fundamentação do sistema teológico. Para esse fim, e sob o prisma de uma teoria da consciência, Tillich emprega o conceito de incondicionado como a função básica para a articulação dos conceitos de religião e cultura. Em seu texto Rechtfertigung und Zweifel, de 1919, ${ }^{11}$ que opera como pressuposição da palestra programática proferida nesse mesmo ano na Sociedade Kantiana de Berlim, Tillich demonstra como a determinação paradoxal e antinômica de seu novo conceito de espírito - i.e., o incondicionado

fornecer uma análise sistemática da Kulturtheologie de Tillich em sua forma madura e já plenamente desenvolvida. Para considerações sobre a teologia da cultura de Tillich no período anterior à Primeira Guerra Mundial, veja NEUGEBAUER, G. Tillichs frühe Christologie. Eine Untersuchung zu Offenbarung und Geschichte bei Tillich vor dem Hintergrund seiner Schellingrezeption. Berlin; New York: Walter de Gruyter GmbH \& Co. KG, 2007, p. 146-292; DIENSTBECK, S. Transzendentale Strukturtheorie. Stadien der Systembildung Paul Tillichs. Göttingen: Vandenhoeck \& Ruprecht GmbH \& Co. KG, 2011, p. 37-234; STURM, E. Die Genese von Tillichs Kulturtheologie in seinen frühesten Texten. In: DANZ, C.; SCHÜßLER, W. (Hg.). Paul Tillichs Theologie der Kultur: Aspekte, Probleme, Perspektiven, p. 64-93; HEINEMANN, L. C. Sinn - Geist - Symbol: Eine systematisch-genetische Rekonstruktion der frühen Symboltheorie Paul Tillichs, p. 65-172.

${ }^{8}$ Veja TILLICH, P. Das religiöse Symbol. (1928). In: CLAYTON, J. P. (Hg.). Main Works Hauptwerke. Band 4: Religionsphilosophische Schriften. Berlin; New York: Walter de Gruyter; Evangelisches Verlagswerk, 1987, p. 213-228.

${ }^{9}$ STURM, E. Die Genese von Tillichs Kulturtheologie in seinen frühesten Texten, 64: „Der Schlüsselbegriff dieses Vortrags ist der Begriff ,Kultursynthese“ (GW IX, 22) bzw. ,Einheitskultur' (GW IX, 30.31)“.

${ }^{10}$ Veja LUHMANN, N. Die Ausdifferenzierung der Religion. In: Gesellschaftsstruktur und Semantik. Studien zur Wissenssoziologie der modernen Gesellschaft. Band 3. Frankfurt am Main: Surhkamp Verlag, 1989, p. 259-357; WAGNER, F. Kann die Religion der Moderne die Moderne der Religion ertragen? Religionssoziologische und theologisch-philosophische Erwägungen im Anschlus an Niklas Luhmann. In: DANZ, C.; DIERKEN, J.; MURRMANNKAHL, M. (Hg.). Religion zwischen Rechtfertigung und Kritik. Perspektiven philosophischer Theologie. Frankfurt am Main: Peter Lang GmbH; Internationaler Verlag der Wissenschaften, 2005, p. 173-201.

${ }^{11}$ Veja TILLICH, P. Rechtfertigung und Zweifel. (1919). 1. und 2. Version. In: STURM, E. (Hg.). Ergänzungs- und Nachlaßbände zu den Gesammelten Werken von Paul Tillich. Band X: Religion, Kultur, Gesellschaft. Unveröffentlichte Texte aus der deutschen Zeit (19081933). Erster Teil. Berlin; New York: Walter de Gruyter GmbH \& Co. KG, 1999, p. 127-185 (1. Version), p. 185-230 (2. Version). 
- habilita a reflexão teológico-crítica a não apenas apropriar-se da determinação autônoma da cultura moderna, como também a sujeitá-la a um juízo incondicional. ${ }^{12}$ Essa determinação antinômica do espírito a partir do conceito de incondicionado, esboçada já em sua correspondência com Emanuel Hirsch entre os anos de 1917 e 1918, fundamenta a dinâmica de apropriação e superação - ou crítica e formação (Kritik und Gestaltung) ${ }^{13}$ - da consciência autônoma a partir do binômio "justificação e dúvida". O programa teológico de Tillich interioriza, dessa forma, a crítica esclarecida da religião como um momento de fundamentação de um conceito de religião que seja capaz de respeitar as "condições de possibilidade" impostas pela modernidade. A subjetividade moderna, que assume cada determinação conteudística como um ato de autoposição e produção do espírito humano, torna-se, assim, o ponto de partida da reflexão teológica. Em seu programa teológico-cultural, Tillich descreve a teologia como um modo elementar e autorreferencial de autoapresentação da autorrelação da consciência, a qual apreende a si mesma na historicidade de seu desvelamento reflexivo (reflexiver Erschlossenheit). Por meio da negação da concretude das determinações condicionadas, ou melhor, do juízo incondicional intrínseco à dúvida radical, a transparência do ato reflexivo em que se baseiam todos os atos de determinação conteudística do espírito - i.e., a incondicionalidade da autorrelação - é elevada à consciência.

A partir dessas considerações preliminares, a estrutura da presente exposição já se encontra delineada. Nossas considerações baseiam-se na tese de que o modo da relação entre religião e cultura no programa teológicocultural de Tillich é não apenas mediado por uma filosofia do espírito e do sentido, como também reivindica uma teoria dos símbolos plenamente delineada. À parte de uma elucidação dos fundamentos de sua filosofia do espírito, sua teoria do sentido e sua teoria dos símbolos não é possível oferecer, portanto, qualquer reconstrução da teologia da cultura de Tillich. Isso quer dizer que o programa de uma teologia da cultura, enquanto um modo de autoapresentação e interpretação da realidade sob o ponto de vista do incondicionado, não pode ser analisado com base em sua Kulturvortrag apenas. ${ }^{14} \mathrm{Se}$, conforme afirmado, a determinação do conceito de religião e o

\footnotetext{
12 TILLICH, P. Rechtfertigung und Zweifel, p. 187: „Es bleibt nur noch der andere Weg, von dem Prinzip des Protestantismus auszugehen, es in immanenter Dialektik zu entfalten und auf einen Punkt zu führen, durch den es zum religiösen Prinzip des modernen Kulturbewußtseins werden kann. Wir können demnach unsere Aufgabe so bestimmen: Es soll gezeigt werden, daß das Prinzip des Protestantismus in sich ein Moment enthält, durch dessen Entfaltung es in Einheit kommt mit einem auf Autonomie aufgebauten Geistesleben“.

${ }^{13}$ Veja TILLICH, P. Der Protestantismus als kritisches und gestaltendes Prinzip. (1929). In: HUMMEL, G. (Hg.). Main Works - Hauptwerke. Band 6: Theologische Schriften. Berlin; New York: Walter de Gruyter; Evangelisches Verlagswerk, 1992, p. 127-149.

${ }^{14}$ Aqui, contra, por exemplo, as análises de GABUS, J.-P. Introduction à la théologie de la culture de Paul Tillich. Paris: Presses Universitaires de France, 1969; GRONDIN, N. Genèse de l'idée d'une théologie de la culture. In: DESPLAND, M.; PETIT, J.-C.; RICHARD, J. (Éd.).
} 
modo de interrelação entre religião e cultura são dependentes de sua filosofia do espírito e do sentido, por um lado, e da teoria dos símbolos que irrompe dessa fundamentação filosófica, por outro, então uma análise do conceito de sentido na determinação de sua teoria da consciência se torna um ponto de partida inescapável. A análise da filosofia do espírito e do sentido de Tillich será desenvolvida na primeira parte de nossa exposição (1). A partir da elucidação de sua filosofia do espírito e do sentido, o conceito de religião, enquanto direcionamento ao incondicionado, poderá ser apresentado em sua natureza mais própria. A tarefa de exposição do conceito de religião compreende o conteúdo da segunda parte desse artigo (2). Na terceira e última parte de nosso estudo, uma análise da função do conceito de símbolo para uma delimitação mais precisa de sua teologia da cultura será oferecida (3). Como se tornará perceptível, é a partir do conceito de símbolo que a forma própria do relacionamento entre religião e cultura, i.e., entre o condicionado e o incondicionado, é articulada. Somente assim a verdadeira substância de uma das fórmulas mais conhecidas de Tillich - a saber, "a religião é a substância da cultura e a cultura é a forma da religião" 15 - poderá ser descrita de forma adequada. É, pois, para os contornos fundamentais de sua filosofia do espírito e do sentido que devemos, agora, voltar nossa atenção. Para tanto, faremos uso não apenas da Kulturvortrag, mas também de textos indispensáveis produzidos no transcurso da década de 20 do século passado.

1. Espírito e sentido; ou, a estrutura de cumprimento de sentido (Sinnerfüllungsstruktur)

Em sua Religionsphilosophie de $1925,{ }^{16}$ Tillich descreve a estreita conexão entre os conceitos de espírito e de sentido de uma forma transparente.

Religion et culture: Actes du colloque international du centenaire Paul Tillich Université Laval, Québec, 18 août 1986. Québec: Les Presses de l'Université Laval; Éditions du Cerf, 1987, p. 207-216; SCHWEIKER, W. Theology of Culture and its Future. In: MANNING, R. R. The Cambridge Companion to Paul Tillich. New York: Cambridge University Press, 2009, p. 138151.

${ }^{15}$ TILliCH, P. Religion and Secular Culture. In: PALMER, M. (Hg.). Main Works Hauptwerke. Band 2: Kulturphilosophische Schriften, p. 199: "A theonomous culture expresses in its creations an ultimate concern and a transcending meaning not as something strange but as its own spiritual ground. "Religion is the substance of culture and culture the form of religion'. This was the most precise statement of theonomy". Essa fórmula já pode ser encontrada no estudo Kirche und Kultur elaborado por Tillich em 1924, e que é empregada como título desse artigo. Para essa referência, veja TILLICH, P. Kirche und Kultur. In: PALMER, M. (Hg.). Main Works - Hauptwerke. Band 2: Kulturphilosophische Schriften, p. 110: ,denn der tragende Gehalt der Kultur ist die Religion und die notwendige Form der Religion ist die Kultur".

${ }^{16}$ TILLICH, P. Religionsphilosophie. In: CLAYTON, J. P. (Hg.). Main Works - Hauptwerke. Band 4: Religionsphilosophische Schriften, p. 117-170. 
Todo ato espiritual é um ato de sentido; não importa se a teoria realista do conhecimento fala de uma recepção de sentido, ou se a teoria idealista do conhecimento fala de uma doação de sentido, ou se o método metalógico fala de um ato de cumprimento de sentido; não importa, portanto, como a relação entre sujeito e objeto é pensada no ato espiritual; o espírito é sempre atualização de sentido e aquilo que é intencionado pelo espírito é o contexto de interconexão de sentido. ${ }^{17}$

De acordo com a descrição de Tillich, todo ato do espírito é um ato de sentido e a vida espiritual é a vida no sentido. ${ }^{18}$ Não obstante, a compreensão de Tillich do espírito ainda não se encontra plenamente descrita. Há dois aspectos fundamentais ausentes. Em primeiro lugar, o espírito não se autopõe em sua atualização apenas como sentido e não intenciona apenas o contexto de interconexão de sentido. Antes, em seu ato de autoposição, o espírito apreende a si mesmo. Ao espírito pertence, portanto, também sua autorrelação constitutiva. "Esta consciência, esta autocontemplação [Sich-selbst-Zuschauen] e autodeterminação [Sich-selbst-Bestimmen] do pensamento no ato criativo é a característica fundamental do espiritual". ${ }^{19}$ Dessa determinação resulta, em segundo lugar, que o espírito é caracterizado em sua autoatualização por uma tensão irresolúvel. Essa é a tensão, em outras palavras, entre o universal e o individual. $\mathrm{O}$ espírito somente pode postar o universal como algo individual e determinado. "O ato espiritual pode se direcionar ao universal somente quando ele intui o universal em uma norma concreta, em uma realização individual do universal". ${ }^{20}$ Sobre a base dessa determinação do espírito, a compreensão de história de Tillich é construída. ${ }^{21}$ Isso quer dizer que o espírito já está sempre envolvido na história de um modo tal que ele sempre já encontra a si mesmo em

${ }^{17}$ TILLICH, P. Religionsphilosophie, p. 133.

18 Veja TILliCH, P. Paul Tillich an Emanuel Hirsch. 9. V. 1918. Die große religionsphilosophische Debatte. In: ALBRECHT, R.; TAUTMANN, R. (Hg.). Ergänzungsund Nachlaßbände zu den Gesammelten Werken von Paul Tillich. Band VI: Briefwechsel und Streitschriften. Theologische, philosophische und politische Stellungnahmen und Gespräche. Frankfurt am Main: Evangelisches Verlagswerk, 1983, p. 125: „Geistiges Leben ist Leben im Sinn oder unablässige schöpferische Sinngebung. So geben wir der Welt einen logischen - ethischen - ästhetischen, so auch einen religiösen Sinn“".

${ }^{19}$ TILLICH, P. Das System der Wissenschaften nach Gegenständen und Methoden. (1923). In: WENZ, G. (Hg.). Main Works - Hauptwerke. Band 1: Philosophische Schriften. Berlin; New York: Walter de Gruyter; Evangelisches Verlagswerk, 1989, p. 201.

${ }^{20}$ TILLICH, P. Das System der Wissenschaften nach Gegenständen und Methoden, p. 200.

${ }^{21}$ TILLICH, P. Das System der Wissenschaften nach Gegenständen und Methoden, p. 200: „Die individuelle Substanz der geisttragenden Gestalt ist kein ungeformtes Chaos, denn die geisttragende Gestalt ist immer auch geistgeformte Gestalt; sie steht in einer historischen Folgereihe. Aus ihrer individuellen historischen Formung heraus schafft die geisttragende Gestalt. Diese Formung reicht zurück über ihren eigenen Gestaltanfang hinaus durch den Zusammenhang aller Gestalten bis zu der universalen und unendlichen Gestalt, die Idee ist und nicht Wirklichkeit. Es gibt keinen außergeschichtlichen Moment einer geschichtlichen Gestalt. Es gibt keinen Anfang des Geistes; denn jede geistige Schöpfung setzt Geist voraus“. 
cada ato concreto de autoposição. ${ }^{22}$ Como afirma em seu Wissenschaftssystem de 1923, "não há origem do espírito; pois, cada criação espiritual pressupõe o espírito". ${ }^{23}$ Uma "teoria da constituição", de acordo com a qual o espírito produz a realidade empírica como um mundo externo através da atividade da própria consciência, é, dessa forma, rejeitada. Antes, o espírito já se encontra sempre entrelaçado na realidade histórica, sem, obviamente, ser derivado dela. ${ }^{24} \mathrm{O}$ espírito é direcionado, em seus atos concretos e determinados de autoposição, à estrutura de cumprimento de sentido. Nessa estrutura, o espírito apreende a si mesmo enquanto espírito: ele se encontra para além de si, sem deixar, contudo, de permanecer, ao mesmo tempo, consigo mesmo.

A partir da determinação do conceito de espírito, os contornos fundamentais da teoria do sentido de Tillich se tornam perceptíveis. Afinal, o que Tillich quer dizer com o conceito de ato e estrutura de cumprimento de sentido? Com sua teoria do sentido, Tillich pretende suprassumir, fundamentalmente, a contraposição entre os modelos idealista e realista do conhecimento. $^{25}$

O método crítico-dialético pressupõe a autonomia do espiritual em contraposição a todo aquele-que-é imediatamente dado. Nesse sentido, ele não precisa representar um idealismo epistemológico; ele não deve supor que o espírito confere leis à natureza. Não obstante, ele certamente não pode admitir que um realismo epistemológico seja verdadeiro. Ele não pode supor que a natureza confere leis ao espírito. Ele deve pressupor que os princípios de sentido aos quais a consciência se submete no ato espiritual são, ao mesmo tempo, os princípios de sentido aos quais o ser está submetido. Ele deve pressupor que o sentido do ser alcança expressão na consciência formada pelo sentido. ${ }^{26}$

O método crítico-dialético deve supor tanto que os princípios de sentido aos quais a consciência se submete no ato espiritual são, ao mesmo tempo, princípios de sentido aos quais o ser está submetido quanto que o sentido do ser

\footnotetext{
${ }^{22}$ A partir da década de 30 , Tillich passa a se referir ao pertencimento inextricável do espírito à história a partir do termo heideggeriano "Geworfensein" ou "estar lançado". Sobre esse ponto, veja TILLICH, P. Die sozialistische Entscheidung. In: STURM, E. (Hg.). Main Works Hauptwerke. Band 3: Sozialphilosophische und ethische Scriften. Berlin; New York: Walter de Gruyter; Evangelisches Verlagswerk GmbH, 1998, p. 290.

${ }^{23}$ TILLICH, P. Das System der Wissenschaften nach Gegenständen und Methoden, p. 200.

24 Veja WITTEKIND, F. Gottesdienst als Handlungsraum. Zur symboltheoretischen Konstruktion des Kultes in Tillichs Religionsphilosophie. In: DANZ, C.; SCHÜßLER, W.; STURM, E. (Hg.). Internationales Jahrbuch für die Tillich-Forschung. Band 2: Das Symbol als Sprache der Religion. Berlin; Wien: LIT Verlag, 2007, p. 79.

${ }^{25}$ Veja TILLICH, P. Das System der Wissenschaften nach Gegenständen und Methoden, p. 204206; TILLICH, P. Religionsphilosophie, p. 124-133.

${ }^{26}$ TILLICH, P. Religionsphilosophie, p. 125.
} 
somente alcança expressão na consciência formada pelo sentido. ${ }^{27} \mathrm{~A}$ partir de uma reflexão crítica de suas performances, os modelos idealista e realista do conhecimento apresentam fragmentariedade e necessidade de complementação, na medida em que encontram problemas que não podem ser elucidados com base em seus próprios pressupostos. Para Tillich, assim como o realismo, como uma análise crítica de seus pressupostos epistemológicos demonstra, é incapaz de explicar como a natureza pode conferir leis ao espírito, o idealismo, por sua vez, é incapaz de explicar como uma substância desprovida de forma pode se tornar capaz de aceitar leis. Sob a perspectiva de sua teoria do sentido, ambos os modelos provam ser abstrações do reconhecimento fundamental que substância (Gehalt) e forma (Form) já configuram uma unidade em cada experiência de sentido. ${ }^{28}$ Como corolário de tais considerações tem-se que, para Tillich, a experiência de sentido não pode ser adequadamente descrita nem como doação de sentido, nem como apreensão de sentido, mas somente como "cumprimento de sentido". ${ }^{29}$

$\mathrm{O}$ conceito indica que as coisas permanecem em seu direcionamento à forma incondicionada e que esse direcionamento encontra seu cumprimento nas criações espirituais. Nem normas ideais, que jazem além do ser, nem uma realidade de sentido formada em contraposição ao espírito são portadoras de sentido. O sentido não é dado, quer de forma real ou ideal, mas ele é intencionado, e alcança seu cumprimento no espírito. ${ }^{30}$

O conceito de cumprimento de sentido encontra sua função epistêmica na medida em que pressupõe que, em cada processo de atualização da consciência, substância e forma já sempre configuram, por necessidade, uma unidade. ${ }^{31}$ Por outro lado, quanto mais o cumprimento de sentido aponta para

\footnotetext{
${ }^{27}$ TILLICH, P. Das System der Wissenschaften nach Gegenständen und Methoden, p. 204-205.

${ }^{28}$ TILLICH, P. Religionsphilosophie, p. 134.

${ }^{29}$ DANZ, C. Religion als Freiheitsbewußtsein. Eine Studie zur Theologie als Theorie der Konstitutionsbedingungen individueller Subjektivität bei Paul Tillich. Berlin; New York: Walter de Gruyter, 2000, 308.

${ }^{30}$ TILLICH, P. Zu Tillichs Systematik. Tillichs Antwort. Blätter für Religiösen Sozialismus, Jahrgang 5, No. 5-6, 1924, p. 19.

${ }^{31}$ TILLICH, P. Religionsphilosophie, p. 134. Como Tillich afirma nessa mesma página: „Form und Gehalt gehören zusammen; es ist sinnlos, das eine ohne das andere zu setzen“. O estabelecimento de uma diástase entre Form e Gehalt resulta, necessariamente, de toda interpretação ontologizante do pensamento de Tillich. Um típico exemplo, aqui, é o estudo de HERBERGER, K. Historismus und Kairos. Die Überwindung des Historismus bei Ernst Troeltsch und Paul Tillich. Theologische Blätter, vol. 14, no. 18, 1935, p. 129-141; p. 161-175; veja, igualmente, SCHÜßLER, W. Der philosophische Gottesgedanke im Frühwerk Paul Tillichs (1910 - 1933). Darstellung und Interpretation seiner Gedanken und Quellen. Würzburg: Königshausen \& Neumann, 1986, p. 49-67, que incorre no mesmo equívoco.
} 
uma estrutura performática unitária, tanto mais permite designar os momentos que são constitutivos do processo infinito de cumprimento de sentido. ${ }^{32}$

\begin{abstract}
A necessidade de formar conceitos independentes está em todos os lugares em que os elementos de uma realidade unitária provam ser independentemente variáveis. A formação dos conceitos, a emergência de determinados objetos do fluxo absolutamente uniforme da realidade, encontra sua base nesse fato. Agora, no entanto, há o fato que, tanto na ontologia quanto na filosofia da história, a forma do sentido (Sinnform) e a substância do sentido (Sinngehalt) permanecem, em todas as esferas da realidade, numa relação de tensão uma com a outra, e que nessa tensão jaz a riqueza tanto dos objetos quanto dos processos. Evidentemente, não há elementos isolados. A realidade está sempre em integração. ${ }^{33}$
\end{abstract}

A forma do sentido e a substância do sentido configuram os momentos estruturais que constituem o processo de cumprimento de sentido, e não quaisquer dados independentemente disponíveis. O relacionamento entre a forma do sentido e a substância do sentido deve ser entendido, consequentemente, como um de estrita interrelação. ${ }^{34}$ Segue-se que, assim como a forma do sentido jamais pode ser pensada sem a substância, por um lado, também a substância jamais pode ser pensada sem a forma do sentido, por

32 TILLICH, P. Paul Tillich an Emanuel Hirsch. 9. V. 1918. Die große religionsphilosophische Debatte, p. 125.

${ }^{33}$ TILLICH, P. Zu Tillichs Systematik. Tillichs Antwort, p. 19. Nesta conexão, afirma Tillich: „Aber es gibt [...] keine vollkommene Integration, keine absolute Synthese. Gäbe es sie, so wäre weder die Dynamik des Geschehens, noch die Möglichkeit der Verunwesung gegeben. Alles Geschehen, alle Lebendigkeit beruht auf der Spannung der Elemente, auf der Variabilität ihrer Relation. Wer darum die Dynamik des Werdens verstehen will, muß diese Elemente in abstracto herausgreifen und ihre Spannungsverhältnisse beobachten“.

34 TILLICH, P. Religionsphilosophie, p. 134. Em função do relacionamento de estrita copertença entre forma e substância, torna-se impossível operar uma identificação entre os conceitos de incondicionado e substância, por um lado, e os conceitos de forma e condicionado, por outro. Tal identificação equívoca pode ser encontrada, por exemplo, na análise do conceito de símbolo de Tillich desenvolvida por RINGLEBEN, J. Symbol und göttliches Sein. In: HUMMEL, G. (Ed.). God and Being: The Problem of Ontology in the Philosophical Theology of Paul Tillich. Contributions made to the II. International Paul Tillich Symposium held in Frankfurt 1988. Berlin; New York: Walter de Gruyter \& Co., 1989, p. 165-181, especialmente, p. 166 e 181. Se a interpretação do relacionamento de mútua pertença entre forma e substância operar uma identificação entre o incondicionado e a substância e entre o condicionado e a forma, então seria impossível visualizar como o conceito de símbolo poderia ser defendido frente às objeções críticas, levantadas por Ringleben, que identificam, no pensamento de Tillich, uma diástase entre o incondicionado e o condicionado. $\mathrm{O}$ ponto a ser aqui percebido é que as categorias forma e substância constituem, na dinâmica de sua copertença e interrelacionalidade, os meios a partir dos quais o incondicionado encontra expressão. Não há, pois, uma identificação na medida em que o incondicionado se expressa por meio da justaposição de forma e substância. Sobre esse ponto, cf. DANZ, C. Religion als Freiheitsbewußtsein. Eine Studie zur Theologie als Theorie der Konstitutionsbedingungen individueller Subjektivität bei Paul Tillich, p. 308309 , nota 17. 
outro. ${ }^{35}$ Caso essa tese de Tillich receba uma leitura mais ampla, deve-se seguramente afirmar, então, que toda forma de percepção é já dotada de sentido, assim como cada percepção de sentido é dependente da mediação através de uma forma. Entre os momentos estruturais do sentido, a saber, a forma do sentido e a substância do sentido, não há somente uma estrita interrelacionalidade contínua, mas uma interrelacionalidade tal que deve ser entendida como independentemente variável. Não se pode operar, portanto, sem o risco de drásticas consequências para a sistematicidade interna do pensamento de Tillich, nem uma identificação entre os conceitos de incondicionado e de substância, por um lado, nem entre os conceitos de condicionado e de forma, por outro. ${ }^{36}$

${ }^{35}$ TILLICH, P. Religionsphilosophie, p. 134.

${ }^{36}$ A questão do relacionamento entre o conceito de incondicionado e a polaridade entre forma e substância ainda constitui um tema de disputa e controvérsia nas pesquisas sobre Tillich. Conjuntamente com interpretações que determinam o incondicionado nos termos de uma descrição do relacionamento entre forma e substância, como o faz, por exemplo, ULRICH, T. Ontologie, Theologie, gesellschaftliche Praxis. Studien zum religiösen Sozialismus Paul Tillichs und Carl Mennickes. Zürich: Theologischer Verlag, 1971, p. 45, inúmeros autores pressupõem uma identificação entre os conceitos de incondicionado e o de substância. Para essa identificação, veja WAGNER, F. Absolute Positivität. Das Grundthema der Theologie Paul Tillichs. Neue Zeitschrift für Systematische Theologie und Religionsphilosophie, 15, 1973, p. 128, nota 8, que se posiciona contra Thomas Ulrich. Sobre esse ponto, cf., igualmente, REPP, M. Die Transzendierung des Theismus in der Religionsphilosophie Paul Tillichs. Frankfurt am Main; Bern; New York: Peter Lang, 1986, p. 180; p. 238. Na interpretação de SCHÜßLER, W. Der philosophische Gottesgedanke im Frühwerk Paul Tillichs (1910 - 1933). Darstellung und Interpretation seiner Gedanken und Quellen, p. 49-67, os termos se tornam, por sua vez, intercambiáveis; outra identificação é operada por Michael Palmer em sua introdução ao segundo volume dos Main Works - Hauptwerke de Tillich. Como afirma PALMER, Michael. Paul Tillich's Theology of Culture. In: PALMER, M. (Hg.). Main Works - Hauptwerke. Band 2: Kulturphilosophische Schriften, p. 14: “Import', in a word, is the name given to the unconditioned meaning intended in religion and presupposed in every cultural creation". Ainda sobre essa interpretação problemática, veja HAIGIS, P. Im Horizont der Zeit. Paul Tillichs Projekt einer Theologie der Kultur. Marburg: N. G. Elwert Verlag, 1998, p. 65; p. 94. Em que se pesem tais interpretações, no entanto, é preciso notar que, já em 1924, em seu artigo-réplica $\mathrm{Zu}$ Tillichs Systematik, Tillich se posiciona contra uma identificação entre o conceito de incondicionado e o conceito de substância. A partir de uma ênfase na interrelação estrita entre forma e substância, Tillich afirma que a identificação entre o incondicionado e a substância implica uma fuga em direção a "uma transcendência vazia [eine leere Transzendenz]". Cf., aqui, TILLICH, P. Zu Tillichs Systematik. Tillichs Antwort, p. 18. O teor dessa ressalva reverbera a crítica de Tillich à teologia de Emanuel Hirsch. Sobre esse ponto, cf. TILLICH, P. Paul Tillich an Emanuel Hirsch. 20. II. 1918. Die große religionsphilosophische Debatte, p. 116; p. 118; TILLICH, P. Paul Tillich an Emanuel Hirsch. 9. V. 1918. Die große religionsphilosophische Debatte, p. 124. Ainda sobre a identificação problemática entre incondicionado e substância, veja JAHR, H. Theologie als Gestaltmetaphysik. Die Vermittlung von Gott und Welt im Frühwerk Paul Tillichs. Berlin; New York: Walter de Gruyter, 1989, p. 70-85. Em sua interpretação dos escritos tillichianos da década de 20, JAHR, H. Theologie als Gestaltmetaphysik. Die Vermittlung von Gott und Welt im Frühwerk Paul Tillichs, p. 82 aponta, em contraposição à própria intenção de Tillich, que há "uma preponderância do significado do elemento da substância em contraposição à forma". Sobre a base do 
Se o cumprimento de sentido deve ser entendido como unidade entre forma do sentido e substância do sentido, então um momento, que não pode ser deduzido nem da forma do sentido nem da substância do sentido, é também sempre já reivindicado. Esse momento é a sintese entre forma e substância, síntese essa já sempre reivindicada no processo de cumprimento de sentido. Tillich tematizou esse terceiro momento, que se encontra sempre e invariavelmente operante em cada experiência de sentido, em diferentes estudos elaborados na década de vinte do século passado. Em seu Wissenschaftssystem e em sua Religionsphilosophie, Tillich dedica tanto o conceito de sentido quanto o conceito de espírito à determinação da síntese entre forma e substância. ${ }^{37}$ "A duplicidade de forma de sentido e substância de sentido é elementar para cada função de sentido. Essa duplicidade não é nenhum princípio de sentido, mas o próprio princípio do sentido". ${ }^{38}$ Em seu artigo Kairos und Logos. Eine Untersuchung zur Metaphysik der Erkenntnis, de 1926, ${ }^{39}$ Tillich descreve esse

relacionamento estrito entre forma e substância elaborado por Tillich, entretanto, não é possível identificar o que Tillich chama de substância com o incondicionado e o condicionado com a forma. Sobre esse ponto, veja TILLICH, P. „Die Kategorie des ,Heilige“ bei Rudolf Otto“. (1923). In: ALBRECHT, R. (Hg.). Gesammelte Werke. Band XII: Begegnungen. Paul Tillich über sich selbst und andere. Stuttgart: Evangelisches Verlagswerk, 1971, p. 185: „Das Unbedingte des Gehaltes und das Unbedingte der Form gehören wesenhaft zusammen“. Antes, como afirma DANZ, C. Religion als Freiheitsbewußtsein. Eine Studie zur Theologie als Theorie der Konstitutionsbedingungen individueller Subjektivität bei Paul Tillich, p. 308, nota 17, "substância e forma são simplesmente a expressão do incondicionado, sem que, com isso, o incondicionado coincida com a polaridade". Caso decida-se insistir nessa leitura da relação do conceito de incondicionado com a polaridade de substância e forma enquanto sistematicamente mais fundamental, então também a leitura daquelas passagens em que Tillich opera uma identificação equívoca entre os conceitos de incondicionado e o de substância resultaria em uma interpretação contrária aos interesses do próprio Tillich. Essa identificação, de fato, ocorre, ainda que de modo isolado. Sobre esse ponto, veja TILLICH, P. Das System der Wissenschaften nach Gegenständen und Methoden, p. 208; TILLICH, P. Religiöser Stil und religiöser Stoff in der bildenden Kunst. (1921). In: PALMER, M. (Hg.). Main Works - Hauptwerke. Band 2: Kulturphilosophische Schriften, p. 97. Em que se pesem essas contradições, os equívocos de Tillich encontram-se no processo de elaboração da teoria, e não no sistema teórico tomado em si mesmo. Uma identificação do incondicionado com a substância e do condicionado com a forma conduz a consequências imensuráveis para o conceito de símbolo e, nesse sentido, portanto, para a totalidade do pensamento de Tillich. É precisamente esse tipo de interpretação que, partindo da identificação do incondicionado com a substância e do condicionado com a forma, resulta numa desconstrução completa de sua teoria dos símbolos. Sobre esse ponto, cf. RINGLEBEN, J. Symbol und göttliches Sein, p. 165-181, aqui, sobretudo, p. 166 e p. 181. Sobre a base dessa identificação, o conceito de símbolo ensejaria uma diástase abstrata entre o sentido incondicionado e as formas condicionadas - tal como Ringleben acusa em Tillich -, em vez de uma mediação, como Tillich, de fato e de direito, intenciona.

37 TILLICH, P. Das System der Wissenschaften nach Gegenständen und Methoden, p. 214; TILLICH, P. Religionsphilosophie, p. 126.

${ }^{38}$ TILLICH, P. Das System der Wissenschaften nach Gegenständen und Methoden, p. 214.

${ }^{39}$ TILLICH, P. Kairos und Logos. Eine Untersuchung zur Metaphysik der Erkenntnis. (1926). In: WENZ, G. (Hg.). Main Works - Hauptwerke. Band 1: Philosophische Schriften, p. 265305. 
terceiro momento por meio dos termos "interpretação da essência", "entendimento espiritual da realidade", ou ainda, "decisão". ${ }^{40}$ Em aberta oposição a teorias realistas e idealistas do conhecimento, Tillich afirma: "uma tal doutrina do conhecimento negligencia, no entanto, um terceiro elemento da cognição que não é nem formal nem material, e que torna a cognição, dessa forma, um assunto primariamente espiritual". ${ }^{41}$

${ }^{40}$ TILLICH, P. Kairos und Logos. Eine Untersuchung zur Metaphysik der Erkenntnis, p. 279. Nessa mesma página, Tillich explica o terceiro elemento, isto é, o momento da síntese entre forma e substância, nos seguintes termos: „Es handelt sich nicht um die Anwendung der Form auf das Material, des Evidenten auf das Wahrscheinliche, also um die ,Urteilskraft'. Sie kann bis zur Genialität geisteigert sein, aber sie hört darum nicht auf, eine technische Funktion zu sein, die der Entscheidung in unserem Sinne entzogen ist. Das dritte Element, von dem wir reden, ist die Wesensdeutung, das geistige Verstehen der Wirklichkeit“. Sobre a apropriação de Tillich da Kritik der Urteilskraft de Kant, cf. DAVIDOCH, A. Religion as a Province of Meaning: The Kantian Foundations of Modern Theology. Minneapolis: Fortress Press, 1993, p. 221-303. Veja também LOVE, B. Tillich on Eros and the Beauty of Kant. Bulletin of the North American Paul Tillich Society, vol. 38, no. 4, 2012, p. 10-14. Em contraposição às interpretações de Tillich com base na terceira crítica de Kant, PERROTTET, C. Au-delà du criticisme kantien. La méthode critique-intuitive dans la première philosophie de la religion de Paul Tillich. 2008. Thèse (Doctorat en Théologie) - Université Laval (Faculté de Théologie et de Sciences Religieuses), Québec, 2008, p. 133 afirma o motivo de sua tese a partir de uma concentração na tarefa de interpretação do pensamento de Tillich a partir não da terceira, mas da primeira crítica kantiana: «j'avais annoncé dès le début de ma thèse que l'originalité de Tillich consiste en ce qu'il a cherché - et trouvé - le critère déterminant de la réalité religieuse dans la partie apparemment la plus séculière de l'oeuvre kantienne, la première Critique. La manière logique de terminer la discussion sur Kant, avant de passer à la méthode critiqueintuitive dans le prochain chapitre, est donc de montrer en quoi Tillich a fait sienne la notion kantienne de l'inconditionné à laquelle ma démarche a abouti». Contra as interpretações de Davidoch e de Perrottet, no entanto, BOSS, M. Which Kant? Whose Idealism? Paul Tillich's Philosophical Training Reappraised. In: MANNING, R. R.; SHEARN, S. (Ed.). Returning to Tillich: Theology and Legacy in Transition. Tillich-Forschungen: Band 13. Berlin; Boston: Walter de Gruyter GmbH, 2018, p. 14 afirma: "I shall contend that both claims are partly misguided insofar as they neglect the neo-Fichtean frame that shapes Tillich's early reception of Kant's philosophical program as a doctrine of freedom rooted in the Critique of Practical Reason. It is true that Tillich's affiliation with neo-Fichteanism has not yet received much attention, but if we look at the course of his philosophical training up to 1916, a period now well documented by the considerable amount of archival material published in the past fifteen years, it becomes unmistakably clear that Tillich's early writings, including his two doctoral dissertations on Schelling, find their impulse and purpose in the so-called Fichte-Renaissance introduced to Halle by his philosophical mentor Fritz Medicus". Para o tratamento de Boss da importância da segunda crítica kantiana para o pensamento sistemático de Tillich, cf. as p. 2325 desse mesmo estudo. Apesar do caráter ainda polêmico no que diz respeito à determinação precisa da influência de Kant na totalidade do pensamento de Tillich, o valor da terceira Crítica para o esclarecimento do momento de síntese entre forma e substância intrínseca à sua teoria do sentido é indiscutível. Sobre esse ponto, veja DANZ, C. Religion als Freiheitsbewußtsein. Eine Studie zur Theologie als Theorie der Konstitutionsbedingungen individueller Subjektivität bei Paul Tillich, p. 340, especialmente nota 80 .

${ }^{41}$ TILLICH, P. Kairos und Logos. Eine Untersuchung zur Metaphysik der Erkenntnis, p. 279. 
O conceito de sentido é, assim, erigido por Tillich através de uma estrutura que não pode mais ser adequadamente descrita por meio de uma relação que se quer binária, tal como o esquema sujeito-objeto. Isso porque foi precisamente esse modelo cognitivo binário que provocou, de acordo com Tillich, a alternativa entre idealismo e realismo. ${ }^{42}$ Uma superação dessa alternativa, tal como Tillich a reivindica com sua teoria do sentido, não pode mais operar dentro dos limites de relações binárias, mas deve se mover, por força de sua própria intenção sistemática, em direção ao estabelecimento de "relações triádicas". ${ }^{43}$ De outra forma, a reivindicação de Tillich de oferecer uma superação da alternativa teórico-cognitiva imposta pelos limites do idealismo e do realismo permaneceria não mais que uma mera promessa. Assim, a síntese entre forma e substância sistematiza, enquanto momento sempre já reivindicado no processo de cumprimento de sentido, o modo como a unidade entre a forma do sentido e a substância do sentido é alcançada pelo espírito. Pois, na medida em que não pode ser deduzida nem da forma do sentido nem da substância do sentido, a síntese constitui um momento terceiro que torna o processo de cognição "um assunto primariamente espiritual". ${ }^{44}$ Isso implica afirmar que Tillich assume, com sua teoria do sentido, a tarefa sistemática de percorrer o caminho espiritual que parte de uma relação binária em direção a uma relação triádica. Não obstante, assim como o modo de interrelação entre a forma do sentido e a substância do sentido não pode ser reduzido unilateralmente à forma ou à substância, tampouco pode a síntese, através da qual a forma do sentido e a substância do sentido constituem a experiência particular do sentido, ser reduzida a um dos polos dessa relação. ${ }^{45}$

Uma vez que o conceito de sentido é construído através da tríade forma, substância e síntese, a teoria do sentido de Tillich torna evidente o motivo pelo qual o conceito de sentido somente pode ser pensado nos termos de um encadeamento de sentido, ou melhor, como um conceito sequencial. A partir da assimilação do neokantismo, Tillich diferencia os atos do espírito em atos teóricos e práticos, e distingue os atos teóricos em ciência e artes e os atos práticos em lei e comunidade. Por meio dessas quatro funções de sentido, o esquema básico da cultura se encontra estruturado. Isso porque, para Tillich, a cultura não é outra coisa senão a realização dessas funções de sentido do espírito. A partir da determinação do conceito de cultura enquanto realização das funções teóricas e práticas de sentido, tem-se que, para Tillich, o espírito humano somente pode se realizar enquanto cultura, i.e., o incondicionado somente pode ser expresso por meio de formas condicionadas.

\footnotetext{
42 TILLICH, P. Das System der Wissenschaften nach Gegenständen und Methoden, p. 215-217; TILLICH, P. Religionsphilosophie, p. 125.

${ }^{43}$ DANZ, C. Religion als Freiheitsbewußtsein. Eine Studie zur Theologie als Theorie der Konstitutionsbedingungen individueller Subjektivität bei Paul Tillich, p. 310.

${ }^{44}$ TILLICH, P. Kairos und Logos. Eine Untersuchung zur Metaphysik der Erkenntnis, p. 279.

${ }^{45}$ TILLICH, P. Religionsphilosophie, p. 134.
} 
O sentido individual, que se torna experienciado e performado, permanece sempre em relação com outros sentidos; à parte desses, o sentido individual seria um frívolo aforisma. Sentido é sempre interconexão de sentido. A quintessência de todas as estruturas de interconexão de sentido é o que denominamos, de forma objetiva, mundo, e, de forma subjetiva, cultura. ${ }^{46}$

De acordo com essa citação, uma determinada experiência somente pode ser caracterizada como significativa se - e somente se - permanecer em uma relação de encadeamento sequencial e de interconexão com outras experiências de sentido. É precisamente através do avanço em direção a um contexto sequencial de sentido que uma experiência pode ser qualificada como dotada de sentido. Na medida em que essa experiência passa a ocupar uma posição determinada na estrutura de interconexão de sentido, ela se torna, assim, determinada, ao mesmo tempo, por essa estrutura. ${ }^{47}$ Por conseguinte, a experiência de sentido individual deve ser compreendida, de acordo com Tillich, como o modo de apresentação de uma relação de determinidade e indeterminidade. Somente quando for possível afirmar que cada experiência individual de sentido representa uma instância de indeterminidade e, desse modo, um excedente de sentido, torna-se possível discorrer sobre a necessidade inescapável do avanço em direção a um contexto de encadeamento sequencial de sentido. $O$ sentido individual deve sempre representar uma estrutura indeterminada de interconexão de sentido, por meio da qual uma atualização ulterior de sentido é alcançada. Em todas as formações, como Tillich afirma com precisão, tanto estéticas quanto lógicas, tanto sociais quanto legais, deve estar contida, portanto, "a reivindicação incondicional da formação absoluta". ${ }^{48}$ Em cada ato de sentido já se encontra posto um horizonte de significância (Sinnhaftigkeit) que não pode ser deduzido dos momentos estruturais forma e substância, mas que se deve, antes, à síntese que Tillich descreve por meio do conceito de sentido.

${ }^{46}$ TILLICH, P. Kirche und Kultur, p. 103. Cf., igualmente, TILLICH, P. Das System der Wissenschaften nach Gegenständen und Methoden, p. 205; TILLICH, P. Religionsphilosophie, p. 133-157.

${ }^{47}$ TILLICH, P. Das System der Wissenschaften nach Gegenständen und Methoden, p. 115: „Erkannt ist, was als notwendiges Glied einem Zusammenhang eingeordnet ist. Das Einzelne in seiner Vereinzelung ist kein Gegenstand der Erkenntnis“. Através de sua teoria da Gestalt, Tillich conceitua a precedência da estrutura de interconexão de sentido frente ao sentido individual, uma precedência que não pode se dar, entretanto, à custa do elemento individual de sentido. A estrutura de interconexão de sentido é construída por meio do encadeamento sequencial de cada experiência particular de sentido, e não à parte dessa. Sobre esse ponto, cf. JAHR, H. Theologie als Gestaltmetaphysik. Die Vermittlung von Gott und Welt im Frühwerk Paul Tillichs, p. 85-96; HARANT, M. Religion - Kultur - Theologie. Eine Untersuchung zu ihrer Verhältnisbestimmung im Werke Ernst Troeltschs und Paul Tillichs im Vergleich. Frankfurt am Main: Peter Lang GmbH, 2009, p. 142-159.

${ }^{48}$ TILLICH, P. Zu Tillichs Systematik. Tillichs Antwort, p. 20. 
A significância da estrutura de interconexão de sentido, que é correpresentada em cada sentido particular, não é, contudo, representável em si mesma.

É importante observar agora que esse aspecto não constitui algo que poderia se tornar objeto do conhecimento no próprio ato do conhecimento. Onde quer que isso seja intencionado, o terceiro elemento, que jaz além da forma e da matéria, se tornaria, ele mesmo, um material formado. Isso o privaria, no entanto, de seu sentido. $^{49}$

Com efeito, a significância de sentido já é reivindicada em cada ato de sentido, mas ela somente pode ser visualizada em uma forma determinada, e não como ela mesma. A síntese a priori, que é constitutiva para a própria atualização de sentido, somente pode ser tematizada pela consciência, por conseguinte, como síntese a posteriori. Assim, a significância de sentido não coincide, portanto, com os fatores estruturais correlativos forma e substância, muito embora seja ela reivindicada em cada performance atual de sentido.

2. A determinação do conceito transcendental de religião; ou, sobre a substância da fórmula Richtung auf das Unbedingte

A síntese entre forma e substância, enquanto momento já sempre reivindicado no processo de cumprimento de sentido, sistematiza, conforme visto, o modo como a unidade entre a forma do sentido e a substância do sentido é apreendida pelo espírito. Através desse avanço em direção a um contexto sequencial de sentido, triadicamente esquematizado, a experiência pode ser qualificada como dotada de sentido na medida em que passa a ocupar uma posição determinada na estrutura de interconexão de sentido. Por outro lado, a própria experiência se torna, dessa forma, determinada por essa mesma estrutura. De acordo com Tillich, a experiência de sentido individual deve ser compreendida nos termos do modo de apresentação de uma relação de determinidade e indeterminidade. A dialética que irrompe dessa relação é caracterizada como uma dialética de autoposição e autonegação. Na medida em que a consciência está ciente e tematiza essa relação, ela, a consciência, se torna propriamente religiosa. A significância, que já é reivindicada em cada ato de sentido, somente pode ser realizada, no entanto, em uma forma determinada, e não como ela mesma. É por esse motivo que a síntese a priori, que é constitutiva para a própria atualização de sentido, somente pode ser tematizada pela consciência como síntese a posteriori. ${ }^{50}$ Aqui, a determinação do conceito de religião no âmbito da teoria do sentido de Tillich se torna apreensível, na medida

${ }^{49}$ TILLICH, P. Kairos und Logos. Eine Untersuchung zur Metaphysik der Erkenntnis, p. 280.

${ }^{50}$ DANZ, C. Religion als Freiheitsbewußtsein. Eine Studie zur Theologie als Theorie der Konstitutionsbedingungen individueller Subjektivität bei Paul Tillich, p. 310-311. 
em que ela, a religião, constitui uma atitude qualitativa da intencionalidade da consciência. A religião se distingue da cultura na medida em que não apenas sabe da relação de determinidade e indeterminidade que deve ser entendida nos termos de uma dialética de autoposição e autonegação, mas também porque ela lida, de forma explícita, com essa dialética. Nesse contexto, a determinação do conceito de religião revela o motivo pelo qual o conceito de religião e o conceito de símbolo se pertencem mutuamente.

Religião é o direcionamento do espírito ao sentido incondicionado, cultura é o direcionamento do espírito às formas condicionadas. Ambas se encontram, no entanto, no direcionamento à unidade completa das formas de sentido. Essa unidade é para a cultura a conclusão, mas para a religião ela é um símbolo. Do ponto de vista do incondicionado, esse símbolo é afirmado e negado ao mesmo tempo: esse é o resultado geral da análise metalógica do sentido. ${ }^{51}$

Em termos programáticos e sistemáticos, a determinação do conceito de religião e da forma do relacionamento entre religião e cultura sobre a base de uma teoria do sentido faz uso de uma dupla intuição. ${ }^{52}$ Em primeiro lugar, a fórmula articulada por Tillich demarca o caráter autônomo e transcendental da religião: ela é, como ele afirma em seu Wissenschaftssystem, "o direcionamento imediato do espírito ao incondicionado". ${ }^{53}$ A demarcação do caráter transcendental da consciência religiosa atesta que a religião jamais pode ser completamente harmonizada com a cultura sem a estrita perda de sua unicidade distintiva. Antes, o que a fórmula de Tillich evidencia é que a religião se atualiza extrapolativamente na tematização simbólica e imediata da dimensão incondicional de sentido e unidade cuja gênese se encontra em um motivo interno à consciência de sentido.

Em segundo lugar, e em estreita correlação com a determinação transcendental da religião, a fórmula de Tillich impossibilita uma compreensão da religião nos termos simplistas de uma negação abstrata da cultura. Ao assegurar o caráter transcendental da religião enquanto direcionamento intencional ao sentido incondicionado, a fórmula de Tillich traz consigo, igualmente, a intuição de que a religião possui a função de nomear a irrupção (Durchbruch $)^{54}$ da unidade das funções transcendentais do espírito que se

\footnotetext{
${ }^{51}$ TILLICH, P. Religionsphilosophie, p. 141. Sobre os contornos do método metalógico de Tillich no escopo de seu Wissenschaftssystem, cf. TILLICH, P. Das System der Wissenschaften nach Gegenständen und Methoden, p. 211-217.

${ }_{52}$ TILLICH, P. Religionsphilosophie, p. 133-157.

53 TILLICH, P. Das System der Wissenschaften nach Gegenständen und Methoden, p. 209.

${ }^{54}$ Para uma breve reconstrução da metáfora "Durchbruch", cf. DANZ, C. Breakthrough of the Unconditional: Tillich's Concept of Revelation as an Answer to the Crisis of Historicism. Bulletin of the North American Paul Tillich Society, vol. 33, no. 2, 2007, p. 2-6; SCHARF, U. C. The Concept of the Breakthrough of Revelation in Tillich's Dogmatik of 1925. In: PARRElla, F. J. (Ed.). Paul Tillich's Theological Legacy: Spirit and Community.
} 
objetivam na cultura. Como Tillich assinala em sua Kulturvortrag de 1919, a religião não é uma função do espírito, mas uma atitude em todas as esferas de sentido "que conecta elementos práticos, teoréticos e intuitivos-emocionais em uma unidade complexa". ${ }^{55}$ Não há para Tillich, portanto, a possibilidade da afirmação de uma diástase entre religião e cultura. A copertença fundamental entre ambas se encontra na dimensão de incondicionalidade da consciência. $\mathrm{Na}$ medida em que a religião não pode ser compreendida como uma esfera especial de sentido, ${ }^{56}$ ou como uma entra outras funções transcendentais do espírito, ela somente é capaz de se atualizar por meio das formas culturais postas pelo espírito. Em sua acepção teórico-sistemática mais própria, a religião deve ser compreendida como o evento de autotransparência do espírito que irrompe por meio das formas culturais, muito embora, sob nenhuma hipótese, seja ela uma função particular de sentido entre outras. ${ }^{57}$ Tillich entende a religião como um modo de desvelamento reflexivo da consciência cultural que dissolve seu caráter como uma forma especial de cultura. Esse evento de autorreflexividade do espírito, implícito na fórmula direcionamento ao incondicionado, pode ser mais prontamente determinado como o evento em que o espírito se torna evidente para si mesmo em sua atividade cultural, i.e., o evento da "autotransparência na

International Paul Tillich Conference, New Harmony, 17-20 June 1993. Berlin; New York: Walter de Gruyter \& Co., 1995, p. 65-81.

${ }^{55}$ TILLICH, P. Über die Idee einer Theologie der Kultur, p. 73.

${ }^{56}$ TILLICH, P. Das System der Wissenschaften nach Gegenständen und Methoden, p. 209: „Voraussetzung dieser Auffassung ist die Erkenntnis, daß Religion ist keine Sinnsphäre neben den anderen ist, sondern eine Haltung in allen Sphären: die unmittelbare Richtung auf das Unbedingte. Wo die Unbedingtheit des Heiligen erfasst ist, kann seine Nebenordnung neben die übrigen Gebiete nicht in Frage kommen, auch nicht in Form der Überordnung“. Na determinação do conceito de religião formulado por Tillich, a influência de Windelband sobre seu pensamento é bastante evidente. Como afirma WINDELBAND, W. Kulturphilosophie und transzendentaler Idealismus. Logos: Zeitschrift für systematische Philosophie, Band. 1, Heft 2, 1910-1911, p. 193: „Ihre besonderen Funktionen, soweit sie ihre Vernunftgründe aus den logischen, ethischen oder ästhetischen Inhalten schöpfen, nehmen an deren transzendentalem Wesen teil, und der einzige Vernunftgrund, der der Religion selbständig eigen ist, besteht in dem Postulat, die Totalität aller Vernunftwerte in einer absoluten Einheit zu erleben, die von keiner der Formen unseres Bewußtseins erfaßt werden kann“. Para Windelband, portanto, a religião constitui o evento contingente da autotransparência do espírito em relação à esfera de validade transcendental em sua dimensão de unidade e totalidade, ou, como ele mesmo aponta, como o "postulado da consciência normal [Postulat des Normalbewußtseins]", que já se encontra presente nas três funções culturais apriorísticas da consciência. Sobre esse ponto, cf., igualmente, os seguintes estudos, já clássicos, de Windelband: WINDELBAND, W. Das Heilige. Skizze zur Religionsphilosophie. In: Präludien: Aufsätze und Reden zur Einleitung in die Philosophie. Tübingen: Verlag von J. C. B. Mohr (Paul Siebeck), 1907, p. 414-450; WINDELBAND, W. Einleitung in die Philosophie. Tübingen: Verlag von J. C. B. Mohr (Paul Siebeck), 1920, § 13, p. 246-257; § 20-21, p. 392-425. Sobre o Postulat des Normalbewußtseins em Windelband, cf. KEMPER, M. Geltung und Problem: Theorie und Geschichte im Kontext des Bildungsgedankens bei Wilhelm Windelband. Würzburg: Verlag Königshausen \& Neumann GmbH, 2006, p. 100-101.

${ }^{57}$ TILLICH, P. Das System der Wissenschaften nach Gegenständen und Methoden, p. 209. 
autorrelação da consciência e sua apresentação". ${ }^{58}$ No entanto, por mais que seja verdadeiro afirmar que a religião se torna atual por meio das formas culturais, é ainda mais importante perceber que a religião não pode ser deduzida ou criada na medida em que irrompe para a autoconsciência de um modo inderivável e sempre já concreto ${ }^{59} \mathrm{~A}$ determinação transcendental do conceito de religião revela que a subjetividade, em sua extrapolação religiosa, se atualiza através de uma assimilação que somente irrompe através das formas culturais, de um modo tal que a religião simultaneamente usa e nega essas formas.

A intuição do relacionamento de mútua coexistência e contraposição entre religião e cultura constitui o contexto a partir do qual Tillich introduz seu conceito de símbolo. A religião pode ser entendida, dessa forma, como "uma realização simbólica do sentido incondicionado". ${ }^{60}$ No símbolo de "Deus", a religião, ou consciência religiosa, realiza a significância de sentido já

${ }^{58}$ DANZ, C. Zwischen Transzendentalphilosophie und Phänomenologie. Die methodischen Grundlagen der Religionstheorien bei Otto und Tillich, p. 345. Para considerações mais entretidas sobre as implicações da determinação do conceito de religião a partir da fórmula Richtung auf das Unbedingte, cf. ABREU, F. H. "Richtung auf das Unbedingte" and "SelfTransparency": The Foundations of Paul Tillich's Philosophy of Spirit, Meaning, and Religion (1919-1925). Revista Eletrônica Correlatio, vol. 16, no. 1, 2017, p. 5-97.

${ }^{59}$ No contexto da disputa sobre o "paradoxo", a crítica que Karl Barth dirige à teologia de Tillich a partir da metáfora de um "Offenbarungswalze" revela-se, dessa forma, insustentável. Para a crítica de Barth, cf. BARTH, K. Von der Paradoxie des ,positiven Paradoxes“: Antworten und Fragen an Paul Tillich. In: ALBRECHT, R. (Hg.). Gesammelte Werke. Band VII: Der Protestantismus als Kritik und Gestaltung. Schriften zur Theologie I. Stuttgart: Evangelisches Verlagswerk, 1962, p. 226-239, especialmente, p. 234: ,[...] das von Tillich so großzügig geübte Generalisieren, dieses Beziehungen-Behaupten zwischen Gott und allem und jedem zwischen Himmel und Erde, diese breite allgemeine Glaubens- und Offenbarungswalze, die ich, ich kann mir nicht helfen, beim Lesen von Tillich alles und nichts ausrichtend über Häuser, Menschen und Tiere gehen sehe, als ob es sich wiederum von selbst verstünde, daß überall, überall Gericht und Gnade waltet, alles, einfach alles einbezogen ,ist ${ }^{\star}$ in den Streit und Frieden des ,positiven Paradoxes', das, so gehandhabt, bei aller ,Unanschaulichkeit' doch wirklich ein Paradox mehr ist, das mit dem Gotte Luthers und Kierkegaards keine, dafür aber mit dem Gotte Schleiermachers und Hegels eine ganz auffallende Ähnlichkeit hat". Sobre o debate entre Tillich e Barth no periódico Theologische Blätter, cf. GALLUS, P. Der Mensch zwischen Himmel und Erde. Der Glaubensbegriff bei Paul Tillich und Karl Barth. Leipzig: Evangelische Verlaganstalt, 2007, p. 555-564; SCHÜßLER, W. Paul Tillich und Karl Barth. Ihre erste Begegnung in den zwanziger Jahren. In: „Was uns unbedingt angeht“. Studien zur Theologie und Philosophie Paul Tillichs. Berlin; Münster: LIT Verlag, 2009, p. 119-129; DANZ, C. Die Religion in der Kultur. Karl Barth und Paul Tillich über die Grundlagen einer Theologie der Kultur. In: DANZ, C.; SCHÜßLER, W. (Hg.). Paul Tillichs Theologie der Kultur: Aspekte, Probleme Perspektiven, p. 211-227; WITTEKIND, Folkart. Grund- und Heilsoffenbarung. Zur Ausformung der Christologie Tillichs in der Auseinandersetzung mit Karl Barth. In: DANZ, C.; SCHÜßLER, W.; STURM, E. (Hg.). Internationales Jahrbuch für die Tillich-Forschung. Band 6: Jesus of Nazareth and the New Being in History. Berlin; Boston: Walter de Gruyter GmbH, 2013, p. 89-119; HEINEMANN, L. C. Sinn - Geist - Symbol: Eine systematischgenetische Rekonstruktion der frühen Symboltheorie Paul Tillichs, p. 437-454.

${ }^{60}$ DANZ, C. Religion als Freiheitsbewußtsein. Eine Studie zur Theologie als Theorie der Konstitutionsbedingungen individueller Subjektivität bei Paul Tillich, p. 341. 
reivindicada em cada ato de sentido. Com isso, está claro o modo pelo qual a religião se distingue das demais funções transcendentais do espírito: na medida em que a religião transpassa as funções culturais em seu direcionamento intencional à dimensão de profundidade ou de incondicionalidade de sentido, ela realiza simbolicamente o sentido incondicionado ou a significação de sentido. Em contraposição à consciência cultural, a religião é essencialmente, portanto, consciência simbólica. Muito embora a consciência simbólica assuma o sentido incondicionado como uma reivindicação evidentemente atemática, ela não simboliza o sentido incondicionado propriamente dito, mas, antes, modela a realidade através das funções teóricas e práticas.

A partir da determinação da religião como consciência simbólica, a diferença entre religião e cultura se torna apreensível. Essa diferença jaz no fato de que a cultura opera fundamentalmente, para dar lugar a conceitos kantianos, como "esquematização", ao passo que a religião constitui o âmbito próprio da "simbolização". ${ }^{61}$ Cultura e religião devem ser distintas, no entanto, na medida

${ }^{61}$ KANT, I. Kritik der Urteilskraft. In: WEISCHEDEL, W. (Hg.). Immanuel Kant. Werke in zehn Bänden. Sonderausgabe. Band 8: Kritik der Urteilskraft und Schriften zur Naturphilosophie. Darmstadt: Wissenschaftliche Buchgesellschaft, 1983, § 59, p. 458-463. O conceito de símbolo desenvolvido por Tillich segue fundamentalmente a distinção entre "simbolização" e "esquematização" tal como por Kant elaborada em sua Kritik der Urteilskraft. Para a distinção entre esquematização e simbolização, veja KANT, I. Kritik der Urteilskraft, § 59, p. 458-463. Sobre o conceito de símbolo em Kant, cf. SCHÖNRICH, G. Kategorien und transzendentale Argumentation. Kant und die Idee einer transzendentalen Semiotik. Frankfurt am Main: Suhrkamp Verlag, 1981, p. 237-242; DIERKSMEIER, C. Das Noumenon Religion. Eine Untersuchung zur Stellung der Religion im System der praktischen Philosophie Kants. Berlin; New York: Walter de Gruyter GmbH \& Co., 1998, p. 40-48; p. 85-96; BIELEFELDT, H. Symbolic Representation in Kant's Practical Philosophy. Cambridge: Cambridge University Press, 2003, p. 32-39; RECKI, B. Die Dialektik der ästhetischen Urteilskraft und die Methodenlehre des Geschmacks ( $\S 55-60)$. In: HÖFFE, O. (Hg.). Kritik der Urteilskraft. Berlin: Akademie Verlag GmbH, 2008, p. 189-210; MALY, S. Kant über die symbolische Erkenntnis Gottes. Berlin; Boston: Walter de Gruyter GmbH \& Co. KG, 2012, p. 21-30; p. 149-203. A confusão entre os conceitos kantianos de esquematização e simbolização na interpretação da teoria dos símbolos de Tillich não é desconhecida na literatura secundária. Um típico exemplo, nesse caso, é NÖRENBERG, K.-D. Analogia Imaginis. Der Symbolbegriff in der Theologie Paul Tillichs. Gütersloh: Gütersloher Verlagshaus Gerd Mohn, 1966, p. 175, que interpreta a teoria dos símbolos de Tillich não por meio do conceito kantiano de simbolização, mas, antes, pelo de esquematização. Essa interpretação termina por situar a teoria dos símbolos de Tillich precisamente no lugar que ela quer evitar. Como afirma NÖRENBERG, K.-D. Analogia Imaginis. Der Symbolbegriff in der Theologie Paul Tillichs, p. 175: „Die Schematisierung soll dem reinen transzendentalen Begriff eine empirisch fundierte Verbildlichung ermöglichen, denn wir können uns das Obersinnlich-Transzendente und Göttliche nur durch Analogie mit der empirischen Wirklichkeit, durch einen Schematismus der Analogie faßlich machen“. No contexto de sua interpretação do conceito de símbolo de Tillich, Nörenberg não expõe adequadamente o locus do conceito tillichiano de símbolo a partir da distinção kantiana entre esquematização e simbolização. Somente na introdução de seu estudo, que é dedicado à história do conceito de símbolo, Nörenberg contempla o conceito de símbolo de Kant a partir da terceira crítica. Não obstante, Nörenberg se equivoca ao tratar dos motivos da distinção kantiana entre esquematização e simbolização - a saber, a função do símbolo para 
em que a cultura constitui o direcionamento intencional do espírito às formas culturais condicionadas, ao passo que a religião é o direcionamento intencional do espírito ao sentido incondicionado. O sentido incondicionado, entretanto, somente pode ser simbolicamente - e não esquematicamente - realizado. ${ }^{62} \mathrm{As}$ objetivações do sentido incondicionado por meio das formas condicionadas sempre permanecem sob o juízo da própria dimensão de incondicionalidade constitutiva do espírito. Por conseguinte, o delineamento preciso da diferença entre religião e cultura, nos termos da distinção kantiana entre esquematização e simbolização, justifica, igualmente, a unidade essencial e a distinção atual presente em ambos os polos de intencionalidade para os quais a consciência se direciona. ${ }^{63}$ Isso porque a religião não possui outra forma para a realização do sentido incondicionado à parte das formas condicionadas. ${ }^{64}$ Segue-se que a diferença entre religião e cultura somente pode encontrar sua justificativa na atitude distintiva da consciência intencional no que diz respeito às formas

a filosofia prática - cf. KRÜGER, G. Philosophie und Moral in der kantischen Kritik. Tübingen: J. C. B. Mohr (Paul Siebeck), 1967, p. 83 - na medida em que avalia os contornos do conceito de símbolo em Kant a partir da doutrina da analogia entis. Sobre esse ponto, veja as p. 47-75 do estudo de Nörenberg. Nesse sentido, WENZ, G. Subjekt und Sein. Die Entwicklung der Theologie Paul Tillichs. München: Christian Kaiser Verlag, 1979, p. 161-190, especialmente, p. 182-183 criticou corretamente a abordagem de Nörenberg ao afirmar de forma categórica: „Die Funktion des Rekurses auf den Kantschen Schematiesierungsgedanken ist dabei keine andere, als diese These zu verdeutlichen. Freilich, mit Kant hat der Nörenbergsche Schematismus genausowenig etwas zu tun, wie der Begriff, transzendental ${ }^{\text {' mit einer }}$ übersinnlich-transzendenten Welt" (aqui, p. 182). Os pressupostos kantianos do conceito de símbolo de Tillich também são enfatizados por MÜLLER, W. W. Das Symbol in der dogmatische Theologie: eine symboltheologische Studie anhand der Theorien bei K. Rahner, P. Tillich, P. Ricoeur und J. Lacan. Frankfurt am Main; Bern; New York; Paris: Peter Lang $\mathrm{GmbH}$; Internationaler Verlag der Wissenschaften, 1990, p. 119. Sobre esse ponto, cf., igualmente, DANZ, C. Religion als Freiheitsbewußtsein. Eine Studie zur Theologie als Theorie der Konstitutionsbedingungen individueller Subjektivität bei Paul Tillich, p. 341-347; HEINEMANN, L. C. Sinn - Geist - Symbol: Eine systematisch-genetische Rekonstruktion der frühen Symboltheorie Paul Tillichs, p. 31-53.

${ }^{62}$ DANZ, C. Religion als Freiheitsbewußtsein. Eine Studie zur Theologie als Theorie der Konstitutionsbedingungen individueller Subjektivität bei Paul Tillich, p. 342. Aqui, obviamente, contra a já mencionada interpretação errônea de NÖRENBERG, K.-D. Analogia Imaginis. Der Symbolbegriff in der Theologie Paul Tillichs, p. 175.

${ }^{63}$ Cf. ABREU, F. H. "Richtung auf das Unbedingte" and "Self-Transparency": The Foundations of Paul Tillich's Philosophy of Spirit, Meaning, and Religion (1919-1925), p. 24-48. Nessa conexão, veja, igualmente, NEUGEBAUER, G. Die geistphilosophischen Grundlagen der Kulturtheologie Tillichs vor dem Hintergrund seiner Schelling- und Husserlrezeption, p. 38-63; CORDEMANN, C. Religion und Kultur. Paul Tillichs religionsphilosophische Grundlegung einer Theologie der Kultur. In: DANZ, C.; SCHÜßLER, W. (Hg.). Paul Tillichs Theologie der Kultur: Aspekte, Probleme, Perspektiven, p. 94-127; DANZ, C. Die Religion in der Kultur. Karl Barth und Paul Tillich über die Grundlagen einer Theologie der Kultur, p. 211-227.

${ }^{64}$ TILLICH, P. Das System der Wissenschaften nach Gegenständen und Methoden, p. 230. 
culturais condicionadas. A distinção entre ambas jaz, portanto, na qualidade da atitude de intencionalidade da consciência. ${ }^{65}$

Quando concebida como o direcionamento intencional ao incondicionado - ou como a "experiência viva da incondicionalidade [Unbedingtheitserlebnis]", ou "a relação incondicional com a realidade [unbedingte Realitätsbeziehung]", como Tillich a define em suas Berliner Vorlesungen do início da década de $1920-{ }^{66}$ a religião deve ser entendida como um acontecimento que se dá por meio das formas culturais. Isso porque é o espírito que posta, por meio de sua atividade espontânea, as formas culturais concretas e dá origem a um mundo cultural próprio. Nessa perspectiva, a cultura é entendida como uma objetivação do espírito humano. ${ }^{67} \mathrm{Na}$ medida em que o espírito individual reflete sobre suas próprias formas culturais condicionadas, ele se torna consciente não apenas de sua própria atividade criativa e espontânea, mas também de sua própria relação consigo mesmo. Nessa autorrelação, o espírito apreende a si mesmo em sua atividade cultural. A religião somente pode ser entendida, nesse sentido, como um evento de autodesvelamento reflexivo que ocorre no espírito e, assim, nas funções de sentido do espírito. Visto que o evento religioso do tornar-se evidente para si mesmo do espírito em sua reflexividade interna é um evento que só pode ocorrer por meio das funções culturais, segue-se que as próprias funções culturais, ou seja, as funções de sentido do espírito, se tornam o meio para a autoapreensão reflexiva da incondicionalidade que sustenta o espírito em sua autorrelacionalidade. ${ }^{68}$ As categorias de sentido Gehalt e Form descrevem precisamente o modo da autoapreensão espiritual. Tillich integra esses diferentes níveis de autoapreensão reflexiva a fim de delinear a estrutura de sua teoria da consciência de sentido. ${ }^{69}$ A categoria Gehalt descreve a autoapreensão do espírito na

\footnotetext{
${ }^{65}$ Cf. TILLICH, P. Rechtfertigung und Zweifel, p. 176: „Klärend für dieses Verhältnis ist der von der phänomenologischen Schule gebrauchte Begriff des ,Meinens'. Ein Begriff ,meint ${ }^{\star}$ etwas, zielt auf etwas hin, und dieses Gemeinte ist etwas ganz anderes als die Vorstellung, durch die hindurch gemeint wird. So wird das Unbedingte gemeint in bedingten Vorstellungen“"

${ }^{66}$ TILLICH, P. Religionsphilosophie. (Sommersemester 1920). In: STURM, E. (Hg.). Ergänzungs- und Nachlaßbände zu den Gesammelten Werken von Paul Tillich. Band XII: Berliner Vorlesungen I (1919-1920). Berlin; New York: Walter de Gruyter GmbH \& Co. KG, 2001, por exemplo, p. 405.

${ }^{67}$ CORDEMANN, C. Religion und Kultur. Paul Tillichs religionsphilosophische Grundlegung einer Theologie der Kultur, p. 103.

${ }^{68}$ Cf. CORDEMANN, C. Religion und Kultur. Paul Tillichs religionsphilosophische Grundlegung einer Theologie der Kultur, p. 122-124 [Sinn als Medium des Geistes].

${ }^{69}$ TILLICH, P. Das System der Wissenschaften nach Gegenständen und Methoden, p. 245-254; TILLICH, P. Religionsphilosophie, p. 150-157. Sobre esse ponto, veja também os estudos de HEINRICHS, J. Der Ort der Metaphysik im System der Wissenschaften bei Paul Tillich: Die Idee einer universalen Sinnhermeneutik. Zeitschrift für katholische Theologie, vol. 92, no. 3, 1970, p. 249-286; JAHR, H. Theologie als Gestaltmetaphysik. Die Vermittlung von Gott und Welt im Frühwerk Paul Tillichs, p. 74-76; MOXTER, M. Kultur als Lebenswelt: Studien zum Problem einer Kulturtheologie, especialmente, p. 67-69.
} 
reflexividade de sua atividade cultural, ao passo que a categoria Form representa as funções transcendentais do espírito, ou seja, a atividade autônoma do espírito em sua autorrelação interna. Assim, as categorias substância e forma constituem, na dinâmica de sua copertença e interrelacionalidade, os meios a partir dos quais o incondicionado encontra expressão. ${ }^{70}$

Enquanto um evento que ocorre no espírito e nas funções transcendentais do espírito, a religião deve ser entendida como um autodesvelamento reflexivo que é, contudo, sempre e invariavelmente histórico. "Toda criação espiritual", como Tillich afirma, "é orientada para a história". ${ }^{71}$ Isso significa que o evento religioso é sempre um autodesvelamento histórico, pois não há autoapreensão possível da autorrelação espiritual à parte de uma determinação histórica concreta. No ato religioso, o espírito humano se apreende em sua estrutura reflexiva e apresenta sua própria transparência em formas simbólicas. Em sua autoapreensão, o espírito já está necessariamente envolvido em uma história particular, de modo que somente é capaz de descrever seu autodesvelamento por meio de símbolos concretos e historicamente determinados. Nesse sentido, as formas, por meio das quais o espírito apresenta o evento de autotransparência espiritual, derivam necessariamente de uma cultura já desenvolvida historicamente. No entanto, cabe ressaltar, os símbolos religiosos não devem ser igualados aos símbolos culturais. Há uma diferença qualitativa entre eles. Os símbolos religiosos diferenciam-se das criações simbólicas culturais na medida em que possuem a função de apresentar o evento de autodesvelamento do espírito. A diferença entre símbolos religiosos e culturais reside apenas na autorrelação implícita nos símbolos religiosos. "Os símbolos religiosos são distintos dos demais na medida em que tornam passíveis de intuição [Veranschaulichung] aquilo que transcende incondicionalmente a esfera da intuição, o último intencionado pelo ato religioso [des im religiösen Akt Letztgemeinten], o incondicional-transcendente [des Unbedingt-Transzendenten]". ${ }^{72}$ Dessa forma, Tillich torna evidente que os símbolos religiosos buscam o esclarecimento da atividade cultural da consciência subjetiva e diferem, assim, de toda consciência teórica. A consciência religiosa é consciência intencional da dimensão incondicionada de sentido, ao passo que a consciência cultural intenciona as formas condicionadas

\footnotetext{
${ }^{70}$ Cf. DANZ, C. Religion als Freiheitsbewußtsein. Eine Studie zur Theologie als Theorie der Konstitutionsbedingungen individueller Subjektivität bei Paul Tillich, p. 308, nota 17.

${ }^{71}$ TILLICH, P. Das System der Wissenschaften nach Gegenständen und Methoden, p. 200: „Der geistige Akt kann sich auf das Allgemeine nur richten, wenn er es anschaut in einer konkreten Norm, in einer individuellen Verwirklichung des Allgemeinen. Darum ist alles geistige Schaffen der Geschichte zugewendet. Die stärksten geistigen Schöpfungen in theonomer und autonomer Kultur sind aufs nachdrücklichste auf die Vergangenheit gerichtet. Offenbarungsautoritäten, klassische Zeiten, romantische Rückwendungen bedeuten nichts anderes, als das Bewußtsein um die Gebundenheit alles geistigen Schaffens an die konkreten Verwirklichungen des Geistes, an die Geschichte“.

${ }^{72}$ TILLICH, P. Das religiöse Symbol, p. 214.
} 
de sentido. As formas culturais, conquanto esquemáticas, se tornam símbolos para a atividade cultural da consciência na medida em que em são expressão da autoapresentação da subjetividade em sua autonomia. Por conseguinte, é errôneo supor que os símbolos religiosos façam referência a uma esfera particular de objetos em que participam - ou mesmo a um "Deus" que independe da consciência reflexiva. Eles são, essencialmente, meios pelos quais o autodesvelamento do espírito alcança expressão. Ou, dito de forma mais direta, os símbolos religiosos são uma expressão do autodesvelamento reflexivo que é constitutivo para o espírito humano, i.e., constituem uma imagem que é, ao mesmo tempo, extraída do espírito e da qual esse, o espírito, fundamentalmente, se diferencia. Assim, os símbolos religiosos não apontam para quaisquer espécies de realidades positivas, mas dão expressão ao evento de autodesvelamento reflexivo que é, por força de sua própria natureza, interno à constituição transcendental da consciência de sentido. ${ }^{73}$

A religião é entendida na teologia da cultura de Tillich, portanto, como o evento em que a consciência cultural se torna compreensível, na cultura e por meio das formas culturais, em sua estrutura de profundidade. Enquanto tal, a religião não é idêntica, contudo, a nenhuma forma cultural. Há duas consequências oriundas dessa construção do modo do relacionamento entre religião e cultura que precisam ser sublinhadas. Em primeiro lugar, a construção do conceito de religião a partir dessa filosofia do espírito e do sentido resulta em um conceito duplo de religião. A partir da determinação da religião como um evento que ocorre nas funções de sentido do espírito, Tillich elabora uma distinção entre a religião enquanto um evento de autotransparência do espírito e a religião enquanto forma cultural. A religião enquanto forma cultural é criticada por Tillich como uma forma de religião em que a consciência da estrutura de profundidade do espírito é esvaziada. Em segundo lugar, a religião, entendida enquanto um evento nas formas culturais, é, para Tillich, conforme afirmado, um evento inderivável e sempre já concreto. Nesse sentido, a religião não pode, portanto, ser criada. Ela não é uma produção cultural, um epifenômeno, mas ocorre sempre somente como um evento inderivável em que a autotransparência da dimensão de incondicionalidade do espírito toma lugar.

3. A síntese a priori da consciência e o papel da teoria dos símbolos; ou, a simbolicidade da consciência e a apresentação do processo de atualização da consciência de sentido

\footnotetext{
${ }^{73}$ Veja, nessa conexão, TILLICH, P. Religionsphilosophie, p. 140: „Darum ist der Gegenstand der Religion nicht nur real, sondern er ist die Voraussetzung aller Realitätssetzung. Aber er ist nicht in dem Sinne real wie irgendeine Einzelsetzung. Auch die universale Synthesis ist keine Gegebenheit, sondern ein Symbol. Im wahren Symbol wird die Realität erfaßt; aber Symbol ist die uneigentliche Ausdrucksform, die immer da notwendig ist, wo ein eigentlicher Ausdruck wesensmäßig unmöglich ist“.
} 
A partir da determinação do conceito de religião como um evento de autodesvelamento reflexivo que irrompe nas funções transcendentais do espírito, Tillich dissolve a ideia da religião como uma esfera cultural própria. A religião se realiza no âmbito da consciência como sua dialética interna. A consciência religiosa é marcada por uma dialeticidade na medida em que nega suas formas culturais e religiosas e, por outro lado, não pode se realizar de outro modo senão aceitando essas formas. No entanto, a religião não é apenas a forma da performance dessa dialética, mas também a consciência dessa dialética. Ela é, nesse sentido, a consciência de que as formas produzidas pela própria consciência são as formas de expressão (Ausdrucksgestalten) historicamente mutáveis do incondicionado. A religião é essencialmente, portanto, consciência simbólica. Com a determinação da religião enquanto consciência simbólica ou realização simbólica do sentido incondicionado, a fundamentação da teoria da religião de Tillich no âmbito de sua teoria do sentido pode ser apreendida. $\mathrm{Na}$ medida em que o sentido individual deve sempre representar uma estrutura indeterminada de interconexão de sentido e, dessa forma, um excedente de sentido, a dimensão de significância última e unidade da realidade é simbolicamente tematizada pela consciência.

Em toda consciência de sentido estão contidos três elementos: primeiro, a consciência da interconexão de sentido na qual cada sentido particular permanece e sem a qual o sentido se perderia; segundo, a consciência da significância da interconexão de sentido e, com isso, de cada sentido particular, isto é, a consciência de um sentido incondicionado que está presente em cada sentido particular; terceiro, a consciência de uma reivindicação, sob a qual cada sentido particular permanece, de cumprir o sentido incondicionado. ${ }^{74}$

De acordo com a descrição teórica e sistemática da estrutura de interconexão de sentido explicitada, torna-se evidente que é precisamente essa significância sempre já reivindicada em cada ato de sentido que Tillich tematiza através de seu conceito de incondicionado. Como Tillich descreve em uma carta enviada em maio de 1918 a Hirsch, "o divino é sentido, não ser [ist Sinn, nicht Sein], e ele é "um outro sentido". ${ }^{75}$ Se for possível assumir, com Tillich, que a

\footnotetext{
${ }^{74}$ TILLICH, P. Religionsphilosophie, p. 133.

75 TILLICH, P. Paul Tillich an Emanuel Hirsch. 9. V. 1918. Die große religionsphilosophische Debatte, p. 126. Em seu artigo Rechtfertigung und Zweifel de 1919, Tillich afirma: „Das Unbedingte ist ein Sinn, aber nicht ein einzelner Sinn, denn jeder einzelne Sinn steht unter dem Zweifel und könnte den Zweifler nicht rechtfertigen. Das Unbedingte ist der Sinn schlechthin, der Ausdruck dafür, daß überhaupt ein Sinn ist, die Setzung der Sinnsphäre. Indem das Ich das Unbedingte bejaht, bejaht es zugleich sich selbst als sinnvoll, erhält es erst einen Sinn“. TILLICH, P. Rechtfertigung und Zweifel, p. 169-170; veja, igualmente, TILLICH, P. Über die Idee einer Theologie der Kultur, p. 74; TILLICH, P. Kirche und Kultur, p. 103-107; TILLICH, P. Religionsphilosophie, p. 133-141. Nesse sentido, cf. ainda os apontamentos de WAGNER, F. Absolute Positivität. Das Grundthema der Theologie Paul Tillichs, p. 181, nota 22: „Denn
} 
significância incondicionada já está reivindicada em cada experiência de sentido, sem que essa seja capaz, entretanto, de ser representada em si e por si mesma, segue-se que essa circunstância demanda uma forma ainda mais complexa da ideia do absoluto. Essa última deve levar em consideração não apenas a presença imediata do sentido incondicionado em todas as atualizações de sentido, mas também sua transcendência reflexiva. De acordo com Tillich, o dilema entre a presença imediata do sentido incondicionado em cada atualização de sentido e sua transcendência reflexiva não pode evadir qualquer autoesclarecimento ideativo da consciência. No entanto, caso se reconheça que esse dilema ocorre em cada autoesclarecimento conceitual da consciência, então se torna perceptível que ele se deve precisamente ao paradoxo que assinala a particularidade distintiva da própria ideia do absoluto. Em seu artigo Die Überwindung des Religionsbegriffs in der Religionsphilosophie, de 1922, ${ }^{76}$ Tillich explicita de forma inequívoca a transcendência reflexiva intrínseca à ideia do absoluto.

Agora, porém, há um ponto onde o paradoxo não se encontra fundamentado no sujeito, mas, antes, fundamenta-se completamente no objeto, um ponto onde o paradoxo é tão necessário à asseveração quanto a não-contraditoriedade é para cada asseveração científico-experiencial: o ponto em que o incondicionado se torna um objeto. $\mathrm{O}$ fato que o incondicionado se torna um objeto consiste precisamente no paradoxo originário (Urparadoxie), tendo-se em vista que, enquanto incondicionado,

der Zweifel kann sich überhaupt nur dann als Zweifel äußern, wenn er sich schon auf den bezweifelten, damit gleichwohl vorausgesetzten Sinn und Sinngrund bezieht. Mit dem Durchbruch der Gewißheit von Sinn, der Grundoffenbarung, durch den Zweifel an sich selber zweifelt“. No contexto de suas correspondências com Hirsch entre os anos de 1917 e 1918 , Tillich ainda opera uma identificação entre sentido e valor. Como ele afirma nessa mesma carta a Hirsch, "valor' e 'sentido' resultam, em uma análise mais profunda, como conceitos idênticos". Cf. TILLICH, P. Paul Tillich an Emanuel Hirsch. 9. V. 1918. Die große religionsphilosophische Debatte, p. 125. No entanto, Tillich os diferencia em seu Wissenschaftssystem, mais especificamente, em sua "Doutrina das normas do sentido ou Sistemática [Die Sinnormenlehre oder Systematik]". Cf. TILLICH, P. Das System der Wissenschaften nach Gegenständen und Methoden, p. 220-221. A distinção entre sentido e valor é central para o chamado neokantismo de Marburg, cujos representantes principais são Hermann Cohen, Paul Natorp e Ernst Cassirer, enquanto sua identificação é decisiva para a variante do neokantismo de Baden, tal como representada, sobretudo, por Wilhelm Windelband, Heinrich Rickert e Emil Lask. Sobre esse ponto, cf. ZIJDERVELD, A. C. Rickert's Relevance: The Ontological Nature and Epistemological Functions of Values. Leiden; Boston: Koninklijke Brill NV, 2006, p. 1-29; BEISER, F. C. The Genesis of Neo-Kantianism, 1796-1880. Oxford; New York: Oxford University Press, 2014, p. 1-9.

${ }^{76}$ TILLICH, P. Die Überwindung des Religionsbegriffs in der Religionsphilosophie. (1922). In: CLAYTON, J. P. (Hg.). Main Works - Hauptwerke. Band 4: Religionsphilosophische Schriften, p. 73-90. 
ele jaz, em essência, para além da contraposição entre sujeito e objeto. $^{77}$

Caso se procure dissecar conceitualmente o que se poderia dizer com a ideia do paradoxo original ou "profundo" do absoluto, que Tillich indica como a única forma conceitual adequada e possível de descrição do absoluto, é-se conduzido, então, a uma circunstância dupla. O que se torna evidente, com isso, é que, por um lado, Tillich intenciona assegurar a percepção, cum grano salis, kantiana que nega qualquer possibilidade de uma via do condicionado ao incondicionado, e que a reflexão é - por força dos próprios limites impostos à razão crítico-esclarecida - sempre, portanto, malsucedida. Por outro lado, a presença já sempre reivindicada do absoluto nas performances reflexivas da consciência deve ser, ipso facto, validada. A ideia de Tillich em relação ao paradoxo original do absoluto demanda, assim, não apenas a atualização imediata do absoluto, mas também que a transcendência reflexiva do absoluto seja pensada como pertencente ao próprio absoluto.

Como pode ser prontamente percebido, a versão dupla do absoluto que resulta dessa elaboração sistemática empreendida por Tillich é uma consequência direta da estrutura peculiar da consciência de sentido. À parte de sua realização concreta, bem como da sobreposição mútua e constante entre dois movimentos opostos que caracteriza o conceito de símbolo elaborado por Tillich, o absoluto jamais é intencionado. No entanto, "uma vez que a consciência não possui quaisquer outras formas além das formas condicionadas, segue-se, então, que ela deve empregá-las", como afirma Tillich, "para expressar o incondicionado através delas, isto é, deve empregar os conceitos científicos simbolicamente, e não literalmente". ${ }^{78}$ De acordo com a sentença de

77 TILLICH, P. Die Überwindung des Religionsbegriffs in der Religionsphilosophie, p. 73. Neste contexto, cf. TILLICH, P. Paul Tillich an Emanuel Hirsch. 20. II. 1918. Die große religionsphilosophische Debatte, p. 122. Sobre o problema do "duplo absoluto", veja KORSCH, D. Das doppelte Absolute. Der Geist als Medium von Reflexion und Religion. In: Dialektische Theologie nach Karl Barth. Tübingen: J. C. B. Mohr (Paul Siebeck), 1996, p. 241-272, especialmente, p. 242-245.

${ }_{78}^{7 I L L I C H, ~ P . ~ R e l i g i o n s p h i l o s o p h i e, ~ p . ~ 122 . ~ S o b r e ~ e s s e ~ p o n t o, ~ c f . ~ t a m b e ́ m ~ T I L L I C H, ~ P . ~ D a s ~}$ System der Wissenschaften nach Gegenständen und Methoden, p. 229-231. Como Tillich afirma em seu artigo Rechtfertigung und Zweifel, de 1919: „Sobald sich das Bewußtsein aber auf die Stufe des radikalen Zweifels erhoben hat, können jene Vergegenständlichungen in ihrer unreflektierten Anschaulichkeit nur als Symbole gelten für die Lebendigkeit und Konkretheit des absoluten Paradox. Auf dieser Stufe kann das Bewußtsein jene Symbole nur gebrauchen unter ständiger Erinnerung an ihren symbolischen Charakter und den Sinn, den sie zwar anschaulich und lebendig, aber doch inadäquat ausdrücken“. TILLICH, P. Rechtfertigung und Zweifel, 172. Contudo, na segunda versão desse estudo, o conceito de símbolo é abandonado. A revisão do estudo não apenas emprega conceitos cum grano salis hegelianos como Anschauung e Begriff para o problema das objetivações dos enunciados religiosos, como também insere o conceito de revelação (Offenbarung) como uma solução para a expressão da vitalidade e concretude do paradoxo absoluto. Sobre esse ponto, cf. TILLICH, P. Rechtfertigung und Zweifel, p. 185-230, aqui, p. 221: „Aber das Bewußtsein kann nicht umhin, das Unbedingte 
Tillich, pode-se inferir que o símbolo descreve uma ratio, uma relação de apresentação em que os conceitos científicos não são empregados em sua autenticidade, mas, antes, de forma abertamente inautêntica e indireta. ${ }^{79}$ Que os

in diesen drei Formen zu hypostasieren. Es liegt hier gewissermaßen ein Schweben zwischen Anschauung und Begriff vor, ein Vergegenständlichen des Sinnes zu einem Seienden durch die Anschauung und ein Entgegenständlichen des Seienden zu einen Sinn durch den Begriff [...] Sobald sich das Bewußtsein aber auf die Stufe des radikalen Zweifels erhoben hat, können jene Vergegenständlichungen nur als Offenbarungen gelten für die Lebendigkeit und Konkretheit des absoluten Paradox“.

${ }^{79}$ Em seu artigo Das religiöse Symbol, de 1928, Tillich afirma que a "inautenticidade [Uneigentlichkeit]" constitui "a primeira e fundamental característica do símbolo". De acordo com Tillich, a inautenticidade demonstra que o ato interno da consciência "que se direciona ao símbolo não intenciona o símbolo enquanto tal, mas, antes, aquilo que é simbolizado nele". Nesse caso, afirma Tillich, "o próprio simbolizado pode se tornar símbolo para uma categoria de status superior [höheren Ranges] que é simbolizado no símbolo". TILLICH, P. Das religiöse Symbol, p. 213. Não obstante, a demarcação do caráter de inautenticidade das expressões simbólicas deve ser desenvolvida em conjunto com seu caráter de indireticidade (Indirektheit). Sobre esse ponto, cf. HEINEMANN, L. C. Sinn - Geist - Symbol: Eine systematischgenetische Rekonstruktion der frühen Symboltheorie Paul Tillichs, p. 508-518. Tillich sublinha esse caráter de indireticidade das expressões simbólicas em suas Dogmatik-Vorlesungen proferidas em Dresden entre os anos de 1925 e 1927. No contexto da explicação da inefabilidade do incondicionado, Tillich afirma: „Da nun all unsere Worte ihren Gegenstand in diese Welt einreihen, so ist das Unbedingte zunächst das Unaussprechliche. Spricht es sich nun doch aus, so kann das nur in indirekten Worten, in Symbolen geschehen. Das Symbol hat die Tiefe, daß es die Verborgenheit achtet und doch real auf das Gemeinte hinweist. Auch das Wort Gott ist so ein Symbol“". TILLICH, P. Dogmatik-Vorlesung. (Dresden 1925-1927). In: SCHÜßLER, W.; STURM, E. (Hg.). Ergänzungs- und Nachlaßbände zu den Gesammelten Werken von Paul Tillich. Band XIV. Berlin; New York: Walter de Gruyter GmbH \& Co., KG, 2005, § 4, p. 17. $\mathrm{Na}$ condição de "indirekten Worten", os símbolos podem ser designados, desta forma, não apenas como "expressões inautênticas", mas também como "expressões indiretas". Nas características da inautenticidade e indireticidade constitutivas da teoria dos símbolos, a reserva intrínseca aos enunciados simbólicos se articula distintamente em contraste à transgressão sistemática do conceito de imediatidade. É precisamente por meio de sua teoria dos símbolos que o pensamento sistemático de Tillich pode ser "diferenciado das pretensões exageradas da imediatidade". HEINEMANN, L. C. Sinn - Geist - Symbol: Eine systematisch-genetische Rekonstruktion der frühen Symboltheorie Paul Tillichs, p. 517-518. Infelizmente, esse caráter de indireticidade da concepção simbólica apontado por Tillich não encontra maior reflexão nem em seu Wissenschaftssystem e em sua Religionsphilosophie, por um lado, nem em seu artigo Das religiöse Symbol, de 1928, por outro. Especialmente no que diz respeito a esse último artigo, uma identificação explícita da indireticidade enquanto característica constitutiva das expressões simbólicas - em conjunto com as outras características do símbolo apontadas por Tillich (cf. TILLICH, P. Das religiöse Symbol, p. 213-214) - teria contribuído para maior clareza na determinação conceitual de sua teoria dos símbolos. Para uma breve análise das características fundamentais dos símbolos apontadas por Tillich em seu artigo de 1928, cf. HEINEMANN, L. C. Sinn - Geist - Symbol: Eine systematisch-genetische Rekonstruktion der frühen Symboltheorie Paul Tillichs, p. 455-500; ABREU, F. H. Símbolo como linguagem da religião: fundamentos da teoria dos símbolos no âmbito da teoria da religião de Paul Tillich. In: TADA, E. S.; SOUZA, V. C. (Org.). Paul Tillich e a linguagem da religião. Santo André: Kapenke, 2018, p. 441-451. Além disso, como afirma HEINEMANN, L. C. Sinn - Geist - Symbol: Eine systematisch-genetische Rekonstruktion der frühen Symboltheorie Paul Tillichs, p. 518, a 
conceitos são empregados em sua inautenticidade e indireticidade é um fato que marca, em primeiro lugar, a diferença peculiar da construção da realidade empírica de sentido. Por outro lado, Tillich também reafirma essa diferença peculiar em seu discurso sobre uma intersecção e correlacionalidade entre o caráter de expressividade e o caráter de validade dos conceitos simbólicos. "Os conceitos metafísicos possuem caráter de expressão [Ausdruckscharakter] e, portanto, caráter de valor [Geltungscharakter], muito embora eles não possuam validade no mesmo sentido que os conceitos científicos possuem". ${ }^{80}$

Com esse conceito particular de símbolo, Tillich busca assegurar a dificuldade de especificar as condições precisas sob as quais se torna possível interpretar corretamente um conceito como o de símbolo. Posto de forma mais direta, se a consciência possui somente as formas condicionadas à disposição, então ela deve sempre já "saber" que, quando emprega conceitos para

elucidação da indireticidade das expressões simbólicas "teria prevenido a recepção equívoca de Tillich como o representante de um 'postulado da imediatidade' genuinamente epistemológico". A caracterização de Tillich como o representante de um "Unmittelbarkeitspostulat" epistemológico é desenvolvida por GRUBE, D.-M. Unbegründbarkeit Gottes? Tillichs und Barths Erkenntnistheorien im Horizont der gegenwärtigen Philosophie, p. $46-54$ no contexto de sua interpretação das obras estadunidenses de Tillich, especialmente em relação ao livro Dynamics of Faith, de 1957. Não obstante, no âmbito de uma reconstrução histórico-genética da teoria dos símbolos de Tillich, a determinação do caráter do conceito de símbolo expresso em suas últimas obras não pode ser simplesmente projetada, sem maior problematização, sobre o período de formação da teoria em análise. Sobre esse ponto, cf. HEINEMANN, L. C. Sinn Geist - Symbol: Eine systematisch-genetische Rekonstruktion der frühen Symboltheorie Paul Tillichs, p. 514; p. 548-549. Antes, uma investigação das obras ulteriores de Tillich deve tomar com a devida seriedade os contornos fundamentais do conceito de símbolo tal como estes são apresentados no contexto do desenvolvimento de sua teoria. Somente nessa complexidade pode a teoria dos símbolos de Tillich ser verdadeiramente reconstruída em sua profundidade sistêmica.

${ }^{80}$ TILLICH, P. Das System der Wissenschaften nach Gegenständen und Methoden, p. 230. A distinção tillichiana entre caráter de expressão e caráter de valor ressoa a distinção elaborada por MISCH, G. Lebensphilosophie und Phänomenologie. Eine Auseinandersetzung der Dilthey'schen Richtung mit Heidegger und Husserl. Leipzig; Berlin: Verlag und Druck von B. G. Teubner, 1931, p. 94-96 entre "fala discursiva" e "fala evocativa" a partir da Lebensphilosophie de Dilthey. Misch combina o programa de uma filosofia hermenêutica da vida com o conceito de "distinção", que retorna à definição de vida desenvolvida por Dilthey nos termos de uma combinação de inescrutabilidade e ponderação. De uma forma similar ao procedimento de Tillich no que diz respeito ao conceito de símbolo, Misch fixa na afirmação evocativa a relação fundamental entre determinidade e indeterminidade. Essa relação fundamental, que, de acordo com Misch, é constitutiva para o Logos (p. 51), torna-se não apenas o ponto de partida fundamental para a lógica, mas também a base para uma crítica da fenomenologia de Husserl e Heidegger. Para a distinção entre os conceitos de fala discursiva e evocativa, e para uma análise do caráter produtivo dessa tensão, cf. RODI, F. Der Logos des „getreuen Ausdrucks“. Georg Mischs Kritik der „Logik-Ontologie“ von Husserl und Heidegger. In: Erkenntnis des Erkannten: Zur Hermeneutik des 19. und 20. Jahrhunderts. Frankfurt am Main: Suhrkamp Verlag, 1990, p. 123-146; veja também SCHÜRMANN, V. Zur Struktur hermeneutischen Sprechens. Eine Bestimmung im Anschluß an Josef König. Freiburg; München: Verlag Karl Alber, 1999. 
representar o sentido incondicionado, ela assim o faz não de uma forma literal, mas sempre e invariavelmente simbólica. Explicar esse saber já pressuposto pela consciência é função da teoria do absoluto de Tillich. Assumindo-se a premissa que o processo de sentido deve ser inquestionável para a consciência - uma vez que a consciência é, ela mesma, abertura de sentido -, não pode haver qualquer possibilidade de que a consciência derive esse saber por meio de uma causa externa. Por essa razão, Tillich, em sua Religionsphilosophie, assume a tarefa de impulsionar a análise filosófica da consciência "até o ponto em que ela apreende a si mesma juntamente com a totalidade da cultura enquanto expressão do religioso". ${ }^{81}$ A percepção da indivisibilidade do condicionado corresponde à percepção da irredutível relação de reciprocidade entre o incondicionado e o condicionado. A construção perspicaz da indivisibilidade do condicionado constitui igualmente, dessa forma, uma construção do condicionado enquanto expressão do incondicionado. Esse saber, já sempre presente do condicionado, tomado em si mesmo como expressão do incondicionado, representa a condição indispensável para que a consciência possa entender signos como símbolos. Pois, somente quando a consciência já conhece a si mesma como expressão do incondicionado, pode ela empregar as formas condicionadas simbolicamente. ${ }^{82}$

\footnotetext{
${ }^{81}$ TILLICH, P. Religionsphilosophie, p. 142.

${ }^{82}$ Em seus escritos iniciais, a passagem sistemática em que esse "saber", que é reivindicado para o processo simbólico, deve ser explicado é relacionado com a figura da autoanulação do condicionado. De acordo com Tillich, para uma filosofia da história ciente do Kairos, a "dupla reivindicação" irrompe da tentativa "de unir a tensão do absoluto com o universalismo do relativo". Sobre esse ponto, cf. TILLICH, P. Kairos. (1922). In: CLAYTON, J. P. (Hg.). Main Works - Hauptwerke. Band 4: Religionsphilosophische Schriften, p. 53-72, aqui, p. 63. Essa reivindicação, conforme afirma Tillich, "contém um paradoxo: o que acontece no Kairos deve ser absoluto e, contudo, não-absoluto. Um ser histórico relativo (não no sentido simples, mas antes em sua acepção paradoxal) deve ser posto como absoluto" (p. 63). Não obstante, essa reivindicação somente se torna passível de redenção, como Tillich explica nessa mesma página, na medida em que se reconhece que "o condicionado anula a si mesmo e, dessa forma, faz de si mesmo um órgão para o incondicionado $[d a \beta$ das Bedingte sich selbst aufhebt und sich dadurch zum Organ macht für das Unbedingte]". TILLICH, P. Kairos, p. 63. O ponto dessa figura da autoanulação jaz não no fato absurdo de uma negação do condicionado, mas no fato de que o condicionado é agarrado pelo espírito como órgão do incondicionado. Um entendimento dessa autoanulação do condicionado, que subscreve, sob qualquer perspectiva, seu desaparecimento, resultaria numa abstração de que a autoanulação pressupõe, de um lado, uma instância que a implementa, e de que a própria autoanulação, de outro lado, deve constituir, ela mesmo, uma instância. A figura da autoanulação do condicionado constitui, portanto, uma expressão do reconhecimento da unidade e diferença entre o incondicionado e o condicionado. Isso porque $\mathrm{o}$ condicionado somente pode ser agarrado em sua condicionalidade através de uma oposição ao incondicionado. A relação entre o condicionado e o incondicionado é, de acordo com sua estrutura formal, uma relação de determinidade, e é precisamente essa relação que é pressuposta quando o condicionado é agarrado como um meio para o incondicionado. Contudo, quando o condicionado se torna ciente de si como um órgão do incondicionado, ele adquire um saber sobre si que o posiciona, mais especificamente, como um símbolo do incondicionado. Esse saber sobre si constitui, entretanto, a condição para que um símbolo possa ser interpretado como símbolo. Como afirma TILLICH, P. Kairos, p. 63: „Nicht im Bedingten an sich liegt der Grund,
} 
O símbolo se torna, pois, um conceito quando é interpretado pela consciência como apresentação da síntese a priori. Nesse procedimento, o conceito não é mais empregado para designar a construção da realidade de sentido, mas é a própria significância de sentido já reivindicada nesse procedimento de construção que deve, agora, ser apresentada. Essa diferença, que Tillich aponta como um processo de transição do caráter de valor dos conceitos para o seu caráter de expressão, pode ser explicada como a já mencionada diferença, apresentada por Kant, entre simbolização e esquematização. Tendo-se em vista que o sentido não é dado nem de forma ideal nem real, ${ }^{83}$ segue-se, portanto, que ele não pode ser esquematizado, mas somente simbolizado. A atualização da significância que a consciência já sempre reivindica em cada realização de sentido não pode depender, enquanto tal, da ajuda de qualquer intuição sensível. Isso porque essa significância não é, evidentemente, nenhuma instância empírica. Assim, a realização do sentido incondicionado somente pode acontecer na medida em que a própria estrutura da atualização do sentido se torna, ela mesma, uma apresentação. Para falar com Kant, trata-se de um modo intuitivo de apresentação, uma hipotipose, que, em contraste com o modo discursivo, encompassa, juntamente com a apresentação esquemática, também uma apresentação de caráter estritamente simbólico. Enquanto sensificação (Versinnlichung), o símbolo é, como afirma Kant em sua Kritik der Urteilskraft, um método ou procedimento de apresentação não esquemático, "já que o conceito é aquele que somente a razão pode pensar e ao

der zur absoluten Spannung treibt, sondem in der Richtung des Bedingten auf das Unbedingte, in der Hinwendung oder Abwendung. In jedem vollkommenen Geschichtsbewußtsein, in jedem vollkommenen Glauben an den Kairos liegt als letzte Tiefe die Hinwendung auf das Unbedingte; und welchen Inhalt das annimmt oder besser, welches Symbol es sich wählt, ob Kirche oder tausendjähriges Reich, ob Vernunftstaat oder drittes Zeitalter, das ist für das Wesen gleichgültig, wenn auch keineswegs für die geschichtlichen Wirkungen. Entscheidend aber ist, daß es als Symbol, als sekundäres Element, als Parodoxie durchschaut wird. Die absoluten lnhalte haben als hätte man sie nicht, das heißt sie paradox haben, in ihnen aber die Richtung auf das Unbedingte unbedingt bejahen, daß ist die Grundlage vollkommenen Kairos-Bewußtseins". A figura da autoanulação do condicionado empregada por Tillich possui um paralelo com a filosofia tardia de Fichte. Também para Fichte, a figura da autoanulação se faz presente na medida em que ele constata que há um lugar sistemático onde o saber possui a forma de um saber sobre si que não apenas não pode se autoproduzir sem cair num círculo, como também não pode proceder de uma instância externa ao próprio processo do saber. Sobre esse ponto, cf. DANZ, C. Atheismus und spekulative Theo-logie: Fichte und Schelling. In: KODALLE, K.-M; OHST, M. (Hg.). Fichtes Entlassung. Der Atheismusstreit in Jena vor 200 Jahren. Würzburg: Königshausen \& Neumann, 1999, p. 159-174, especialmente, p. 168-173; STOLZENBERG, J. Absolutes Wissen und Sein. Zu Fichtes Wissenschaftslehre von 1801/02. Fichte-Studien, Nr. 12, 1997, p. 307-322. Nessa conexão, veja ainda DANZ, C. Religion als Freiheitsbewußtsein. Eine Studie zur Theologie als Theorie der Konstitutionsbedingungen individueller Subjektivität bei Paul Tillich, p. 126-134.

${ }^{83}$ TILLICH, P. Zu Tillichs Systematik. Tillichs Antwort, p. 19. 
qual nenhuma intuição sensível pode ser adequada". ${ }^{84}$ Nesse último caso, como afirma Kant,

o conceito é fornecido com uma intuição tal que o procedimento da faculdade do juízo é simplesmente dado de forma analógica àquilo que ele observa na esquematização, isto é, vem em acordo com ele simplesmente em função da regra desse procedimento, não em função da própria intuição, e, consequentemente, apenas em função da forma da reflexão, não do conteúdo. ${ }^{85}$

Nessa direção, e em conformidade com uma perspectiva que poderia ser descrita, cum grano salis, como semiótica, pode-se afirmar, com base na propícia distinção kantiana entre simbolização e esquematização, que "o símbolo é um signo no qual o próprio emprego do signo opera como signo". ${ }^{86}$ A apresentação simbólica consiste, dessa forma, não na ilustração de uma realidade, mas na apresentação do próprio processo da atualização da consciência. ${ }^{87} \mathrm{O}$ que Tillich busca é, em outras palavras, nada menos que a

${ }^{84}$ KANT, I. Kritik der Urteilskraft, § 59, p. 459.

${ }^{85}$ KANT, I. Kritik der Urteilskraft, § 59, p. 459: „Alle Hypotypose (Darstellung, subiectio sub adspectum), als Versinnlichung, ist zwiefach: entweder schematisch, da einem Begriffe, den der Verstand faßt, die korrespondierende Anschauung a priori gegeben wird; oder symbolisch, da einem Begriffe, den nur die Vernunft denken, und dem keine sinnliche Anschauung angemessen sein kann, eine solche untergelegt wird, mit welcher das Verfahren der Urteilskraft demjenigen, was sie im Schematisieren beobachtet, bloß analogisch, d.i. mit ihm bloß der Regel dieses Verfahrens, nicht der Anschauung selbst, mithin bloß der Form der Reflexion, nicht dem Inhalte nach, übereinkommt“. Sobre esse ponto, cf. DIERKSMEIER, C. Das Noumenon Religion. Eine Untersuchung zur Stellung der Religion im System der praktischen Philosophie Kants, p. 42-43.

${ }^{86}$ DANZ, C. Religion als Freiheitsbewußtsein. Eine Studie zur Theologie als Theorie der Konstitutionsbedingungen individueller Subjektivität bei Paul Tillich, p. 346. Enquanto modo indireto de apresentação, a hipotipose simbólica faz uso de uma "analogia qualitativa" - cf. DIERKSMEIER, C. Das Noumenon Religion. Eine Untersuchung zur Stellung der Religion im System der praktischen Philosophie Kants, p. 41-43 - na medida em que não são os componentes intuíveis dos símbolos que são transferidos a outros objetos, mas a relação dos componentes com "os objetos suprassensíveis" intuídos nos símbolos. Como afirma Dierksmeier (1998, p. 43), "o símbolo não é, portanto, cumprido na intuição, mas na reflexão sobre essa relação". Sobre o método analógico em Kant, veja PIEPER, A. Kant und die Methode der Analogie. In: SCHÖNRICH, G.; KATO, Y. (Hg.). Kant in der Discussion der Moderne. Frankfurt am Main: Suhrkamp Verlag, p. 106. De acordo com sua apropriação da teoria dos símbolos de Kant, o conceito de símbolo elaborado por Tillich tem a função de apresentar, em sua própria performance de simbolização, o processo de atualização de sentido. Sobre esse ponto, veja, igualmente, HEINEMANN, L. C. Sinn - Geist - Symbol: Eine systematischgenetische Rekonstruktion der frühen Symboltheorie Paul Tillichs, p. 548-549.

${ }^{87}$ A proximidade entre a teoria dos símbolos de Tillich e a teoria dos símbolos de Kant é, nesse sentido, prontamente perceptível. Pois, também para Kant, como bem aponta Dierksmeier, o símbolo não encontra sua validade teórica em uma suposta apreensão de uma substância transcendente, mas em sua própria função transcendental de simbolização. Nas palavras de DIERKSMEIER, C. Das Noumenon Religion. Eine Untersuchung zur Stellung der Religion im System der praktischen Philosophie Kants, p. 92: „Denn das Symbol hat seine 
superação da clivagem irresolúvel entre o sentido incondicionado e o processo de cumprimento do sentido condicionado. Por essa razão, cada sentido contém um excedente de sentido, que Tillich descreve, aptamente, como "significado transcendente [transzendentes Bedeutung]". 88 "O sagrado não é inintuível [das Heilige ist nicht unanschaulich]. Contudo, ele não é objetivo. O sagrado é intuído de forma não-objetiva; ele é intuído como significado transcendente". ${ }^{89}$

À guisa de conclusão, devemos ressaltar que o conceito de símbolo elaborado por Tillich descreve um estado de coisas em que a significância reivindicada pelos sujeitos finitos em cada ato particular de sentido não pode ser realizada por si mesma. Antes, a significância encontra sua realização na própria apresentação do processo de atualização de sentido. Assim, na medida em que os símbolos religiosos são constituídos, enquanto tais, nas performances mentais da consciência religiosa, a teoria dos símbolos de Tillich demonstra ser, antes de tudo, uma "teoria da simbolização". ${ }^{90}$ Posto de outra forma, a tarefa da teoria dos símbolos de Tillich não consiste tanto em descrever a forma da participação referencial dos enunciados simbólicos. Antes, os símbolos descrevem, mais propriamente, a posição alterada da consciência reflexiva em relação a seus conteúdos concretos e determinados. A significância de sentido já reivindicada em cada ato de sentido é realizada na própria estrutura de apresentação do processo de atualização de sentido. Em sua transcendência interna, os símbolos devem ser considerados, ao mesmo tempo, como uma expressão da absoluta transcendência da ideia do incondicionado. No símbolo, enquanto modo de apresentação do próprio processo de atualização de sentido, a consciência realiza tanto a diferença quanto a unidade entre o incondicionado e o condicionado, i.e., a unidade essencial e a distinção atual entre religião e cultura. É no conceito de símbolo, portanto, que a verdadeira substância teórica da reformulação de Tillich da doutrina da justificação pela fé encontra sua expressão mais própria. A partir da determinação da religião como consciência simbólica, a objetividade e a condicionalidade dos enunciados religiosos são, ao mesmo tempo, justificadas em sua necessidade e submetidas ao escrutínio da dúvida radical. ${ }^{91}$ É somente assim, pois, que a religião pode não apenas ser determinada como a substância da cultura e a cultura como forma da religião,

geltungstheoretische Seinsquelle in seiner (transzendentalen) Funktion, nicht aber in einer ihm innewohnenden transzendenten Substanz". Sobre esse ponto, veja, igualmente, BIELEFELDT, H. Symbolic Representation in Kant's Practical Philosophy, p. 32-39.

${ }_{88}^{8 I}$ TILLICH, P. Der Protestantismus als kritisches und gestaltendes Prinzip, p. 138.

${ }^{89}$ TILLICH, P. Der Protestantismus als kritisches und gestaltendes Prinzip, p. 138.

${ }^{90}$ HEINEMANN, L. C. Sinn - Geist - Symbol: Eine systematisch-genetische Rekonstruktion der frühen Symboltheorie Paul Tillichs, 548.

${ }^{91}$ Sobre a reformulação da Rechtfertigungslehre operada por Tillich, cf. WITTEKIND, F. „Allein durch Glauben“. Tillichs sinntheoretische Umformulierung des Rechtfertigungsverständnisses 1919. In: DANZ, C.; SCHÜßLER, W. (Hg.). Religion - Kultur - Gesellschaft. Der frühe Tillich im Spiegel neuer Texte (1919-1920), p. 39-65. 
„denn der tragende Gehalt der Kultur ist die Religion und die notwendige

Form der Religion ist die Kultur“"

mas também como Richtung auf das Unbedingte - tal como Tillich formulou programaticamente há exatos cem anos.

\section{Referências}

\section{Obras de Paul Tillich}

TILLICH, Paul. $\mathrm{Zu}$ Tillichs Systematik. Tillichs Antwort. Blätter für Religiösen Sozialismus, Jahrgang 5, No. 5-6, p. 18-22, 1924.

. Über die Idee einer Theologie der Kultur. In: RADBRUCH, Gustav; TILLICH, Paul. (Hg.). Religionsphilosophie der Kultur. Zwei Entwürfe von Gustav Radbruch und Paul Tillich. Darmstadt: Wissenschaftliche Buchgesellschaft, 1968, p. 27-52.

. „Die Kategorie des „Heilige" bei Rudolf Otto“. (1923). In: ALBRECHT, Renate. (Hg.). Gesammelte Werke. Band XII: Begegnungen. Paul Tillich über sich selbst und andere. Stuttgart: Evangelisches Verlagswerk, 1971, p. 184-186.

. Paul Tillich - Emanuel Hirsch. Die große religionsphilosophische Debatte. In: ALBRECHT, Renate; TAUTMANN, René. (Hg.). Ergänzungsund Nachlaßbände zu den Gesammelten Werken von Paul Tillich. Band VI: Briefwechsel und Streitschriften. Theologische, philosophische und politische Stellungnahmen und Gespräche. Frankfurt am Main: Evangelisches Verlagswerk, 1983, p. 95-136.

. Kairos. (1922). In: CLAYTON, John Powell. (Hg.). Main Works Hauptwerke. Band 4: Religionsphilosophische Schriften. Berlin; New York: Walter de Gruyter; Evangelisches Verlagswerk, 1987, p. 53-72.

. Die Überwindung des Religionsbegriffs in der Religionsphilosophie. (1922). In: CLAYTON, John Powell. (Hg.). Main Works - Hauptwerke. Band 4: Religionsphilosophische Schriften. Berlin; New York: Walter de Gruyter; Evangelisches Verlagswerk, 1987, p. 73-90.

. Religionsphilosophie. (1925). In: CLAYTON, John Powell. (Hg.). Main Works - Hauptwerke. Band 4: Religionsphilosophische Schriften. Berlin; New York: Walter de Gruyter; Evangelisches Verlagswerk, 1987, p. 117-170. 
. Das religiöse Symbol. (1928). In: CLAYTON, John Powell. (Hg.). Main Works - Hauptwerke. Band 4: Religionsphilosophische Schriften. Berlin; New York: Walter de Gruyter; Evangelisches Verlagswerk, 1987, p. 213-228.

. Das System der Wissenschaften nach Gegenständen und Methoden. (1923). In: WENZ, Gunther. (Hg.). Main Works - Hauptwerke. Band 1: Philosophische Schriften. Berlin; New York: Walter de Gruyter; Evangelisches Verlagswerk, 1989, p. 113-263.

. Kairos und Logos. Eine Untersuchung zur Metaphysik der Erkenntnis. (1926). In: WENZ, Gunther. (Hg.). Main Works - Hauptwerke. Band 1: Philosophische Schriften. Berlin; New York: Walter de Gruyter; Evangelisches Verlagswerk, 1989, p. 265-305.

. Über die Idee einer Theologie der Kultur. (1919). In: PALMER, Michael. (Hg.). Main Works - Hauptwerke. Band 2: Kulturphilosophische Schriften. Berlin; New York: Walter de Gruyter; Evangelisches Verlagswerk, 1990, p. 69-85.

. Religiöser Stil und religiöser Stoff in der bildenden Kunst. (1921). In: PALMER, Michael. (Hg.). Main Works - Hauptwerke. Band 2: Kulturphilosophische Schriften. Berlin; New York: Walter de Gruyter; Evangelisches Verlagswerk, 1990, p. 87-99.

. Kirche und Kultur. (1924). In: PALMER, Michael. (Hg.). Main Works - Hauptwerke. Band 2: Kulturphilosophische Schriften. Berlin; New York: Walter de Gruyter; Evangelisches Verlagswerk, 1990, p. 101-114.

. Der Protestantismus als kritisches und gestaltendes Prinzip. (1929). In: HUMMEL, Gert. (Hg.). Main Works - Hauptwerke. Band 6: Theologische Schriften. Berlin; New York: Walter de Gruyter; Evangelisches Verlagswerk, 1992, p. 127-149.

. Die sozialistische Entscheidung. In: STURM, Erdmann. (Hg.). Main $\overline{\text { Works }}$ - Hauptwerke. Band 3: Sozialphilosophische und ethische Scriften. Berlin; New York: Walter de Gruyter; Evangelisches Verlagswerk GmbH, 1998, p. 273-419.

. Rechtfertigung und Zweifel. (1919). 1. und 2. Version. In: STURM, Erdmann. (Hg.). Ergänzungs- und Nachlaßbände zu den Gesammelten Werken von Paul Tillich. Band X: Religion, Kultur, Gesellschaft. 
„denn der tragende Gehalt der Kultur ist die Religion und die notwendige

Unveröffentlichte Texte aus der deutschen Zeit (1908-1933). Erster Teil. Berlin; New York: Walter de Gruyter GmbH \& Co. KG, 1999, p. 127-230.

. Religionsphilosophie. (Sommersemester 1920). In: STURM, Erdmann. (Hg.). Ergänzungs- und Nachlaßbände zu den Gesammelten Werken von Paul Tillich. Band XII: Berliner Vorlesungen I (1919-1920). Berlin; New York: Walter de Gruyter GmbH \& Co. KG, 2001, p. 333-584.

. Dogmatik-Vorlesung. (Dresden 1925-1927). In: SCHÜßLER, Werner; STURM, Erdmann. (Hg.). Ergänzungs- und Nachlaßbände zu den Gesammelten Werken von Paul Tillich. Band XIV. Berlin; New York: Walter de Gruyter GmbH \& Co., KG, 2005, p. 1-440.

\section{Literatura secundária}

ABREU, Fábio Henrique. "Richtung auf das Unbedingte" and "SelfTransparency": The Foundations of Paul Tillich's Philosophy of Spirit, Meaning, and Religion (1919-1925). Revista Eletrônica Correlatio, vol. 16, no. 1, p. 5-97, 2017.

. Símbolo como linguagem da religião: fundamentos da teoria dos símbolos no âmbito da teoria da religião de Paul Tillich. In: TADA, Elton Sadao; SOUZA, Vitor Chaves. (Org.). Paul Tillich e a linguagem da religião. Santo André: Kapenke, 2018, p. 365-582.

BARTH, Karl. Von der Paradoxie des ,positiven Paradoxes“: Antworten und Fragen an Paul Tillich. In: ALBRECHT, Renate. (Hg.). Gesammelte Werke. Band VII: Der Protestantismus als Kritik und Gestaltung. Schriften zur Theologie I. Stuttgart: Evangelisches Verlagswerk, 1962, p. 226-239.

BARTH, Ulrich. Die sinntheoretischen Grundlagen des Religionsbegriffs. Problemgeschichtliche Hintergründe zum frühen Tillich. In: Religion in der Moderne. Tübingen: J. C. B. Mohr (Paul Siebeck), 2003, p. 89-123.

Religion und Sinn. In: DANZ, Christian; SCHÜßLER, Werner. (Hg.). Religion - Kultur - Gesellschaft. Der frühe Tillich im Spiegel neuer Texte (1919-1920). Tillich-Studien: Band 20. Wien; Berlin: LIT Verlag, 2008, p. $197-$ 213.

BEISER, Frederick C. The Genesis of Neo-Kantianism, 1796-1880. Oxford; New York: Oxford University Press, 2014. 
BIELEFELDT, Heiner. Symbolic Representation in Kant's Practical Philosophy. Cambridge: Cambridge University Press, 2003.

BOSS, Marc. Which Kant? Whose Idealism? Paul Tillich's Philosophical Training Reappraised. In: MANNING, Russell Re; SHEARN, Samuel. (Ed.). Returning to Tillich: Theology and Legacy in Transition. Tillich-Forschungen: Band 13. Berlin; Boston: Walter de Gruyter GmbH, 2018, p. 13-30.

CORDEMANN, Claas. Religion und Kultur. Paul Tillichs religionsphilosophische Grundlegung einer Theologie der Kultur. In: DANZ, Christian; SCHÜßLER, Werner. (Hg.). Paul Tillichs Theologie der Kultur: Aspekte, Probleme, Perspektiven. Berlin; Boston: Walter de Gruyter GmbH \& Co. KG, 2011, p. 94-127.

DANZ, Christian. Atheismus und spekulative Theo-logie: Fichte und Schelling. In: KODALLE, Klaus-Michael; OHST, Martin. (Hg.). Fichtes Entlassung. Der Atheismusstreit in Jena vor 200 Jahren. Würzburg: Königshausen \& Neumann, 1999, p. 159-174.

. Religion als Freiheitsbewußtsein. Eine Studie zur Theologie als Theorie der Konstitutionsbedingungen individueller Subjektivität bei Paul Tillich. Berlin; New York: Walter de Gruyter, 2000.

. Breakthrough of the Unconditional: Tillich's Concept of Revelation as an Answer to the Crisis of Historicism. Bulletin of the North American Paul Tillich Society, vol. 33, no. 2, p. 2-6, 2007.

. Die Religion in der Kultur. Karl Barth und Paul Tillich über die Grundlagen einer Theologie der Kultur. In: DANZ, Christian; SCHÜßLER, Werner. (Hg.). Paul Tillichs Theologie der Kultur: Aspekte, Probleme Perspektiven. Berlin; Boston: Walter de Gruyter GmbH \& Co. KG, 2011, p. 211-227.

. Zwischen Transzendentalphilosophie und Phänomenologie. Die methodischen Grundlagen der Religionstheorien bei Otto und Tillich. In: LAUSTER, Jörg; SCHÜZ, Peter; BARTH, Roderich; DANZ, Christian. (Hg.). Rudolf Otto. Theologie - Religionsphilosophie - Religionsgeschichte. Berlin; Boston: Walter de Gruyter GmbH, 2014, p. 335-345.

DAVIDOCH, Adina. Religion as a Province of Meaning: The Kantian Foundations of Modern Theology. Minneapolis: Fortress Press, 1993. 
„denn der tragende Gehalt der Kultur ist die Religion und die notwendige Form der Religion ist die Kultur“"

DIENSTBECK, Stefan. Transzendentale Strukturtheorie. Stadien der Systembildung Paul Tillichs. Göttingen: Vandenhoeck \& Ruprecht GmbH \& Co. KG, 2011.

DIERKSMEIER, Claus. Das Noumenon Religion. Eine Untersuchung zur Stellung der Religion im System der praktischen Philosophie Kants. Berlin; New York: Walter de Gruyter GmbH \& Co., 1998.

GABUS, Jean-Paul. Introduction à la théologie de la culture de Paul Tillich. Paris: Presses Universitaires de France, 1969.

GALLUS, Petr. Der Mensch zwischen Himmel und Erde. Der Glaubensbegriff bei Paul Tillich und Karl Barth. Leipzig: Evangelische Verlaganstalt, 2007.

GRONDIN, Nicole. Genèse de l'idée d'une théologie de la culture. In: DESPLAND, Michel; PETIT, Jean-Claude.; RICHARD, Jean. (Éd.). Religion et culture: Actes du colloque international du centenaire Paul Tillich Université Laval, Québec, 18 août 1986. Québec: Les Presses de l'Université Laval; Éditions du Cerf, 1987, p. 207-216.

GRUBE, Dirk-Martin. Unbegründbarkeit Gottes? Tillichs und Barths Erkenntnistheorien im Horizont der gegenwärtigen Philosophie. Marburg: N. G. Elwert Verlag, 1998.

HAIGIS, Peter. Im Horizont der Zeit. Paul Tillichs Projekt einer Theologie der Kultur. Marburg: N. G. Elwert Verlag, 1998.

HARANT, Martin. Religion - Kultur - Theologie. Eine Untersuchung zu ihrer Verhältnisbestimmung im Werke Ernst Troeltschs und Paul Tillichs im Vergleich. Frankfurt am Main: Peter Lang GmbH, 2009.

HEINEMANN, Lars Christian. Sinn - Geist - Symbol: Eine systematischgenetische Rekonstruktion der frühen Symboltheorie Paul Tillichs. TillichForschungen: Band 10. Berlin; Boston: Walter de Gruyter GmbH, 2017.

HEINRICHS, Johannes. Der Ort der Metaphysik im System der Wissenschaften bei Paul Tillich: Die Idee einer universalen Sinnhermeneutik. Zeitschrift für katholische Theologie, vol. 92, no. 3, p. 249-286, p. 1970.

HERBERGER, Kurt. Historismus und Kairos. Die Überwindung des Historismus bei Ernst Troeltsch und Paul Tillich. Theologische Blätter, vol. 14, Nr. 18, p. 129-141; p. 161-175, 1935. 
JAHR, Hannelore. Theologie als Gestaltmetaphysik. Die Vermittlung von Gott und Welt im Frühwerk Paul Tillichs. Berlin; New York: Walter de Gruyter, 1989.

KANT, Immanuel. Kritik der Urteilskraft. In: WEISCHEDEL, Wilhelm. (Hg.). Immanuel Kant. Werke in zehn Bänden. Sonderausgabe. Band 8: Kritik der Urteilskraft und Schriften zur Naturphilosophie. Darmstadt: Wissenschaftliche Buchgesellschaft, 1983, p. 233-620.

KEMPER, Matthias. Geltung und Problem: Theorie und Geschichte im Kontext des Bildungsgedankens bei Wilhelm Windelband. Würzburg: Verlag Königshausen \& Neumann GmbH, 2006.

KORSCH, Dietrich. Das doppelte Absolute. Der Geist als Medium von Reflexion und Religion. In: Dialektische Theologie nach Karl Barth. Tübingen: J. C. B. Mohr (Paul Siebeck), 1996, p. 241-272.

KRÜGER, Gerhard. Philosophie und Moral in der kantischen Kritik. Tübingen: J. C. B. Mohr (Paul Siebeck), 1967.

LOVE, Brandon. Tillich on Eros and Logos and the Beauty of Kant. Bulletin of the North American Paul Tillich Society, vol. 38, no. 4, p. 10-14, 2012.

LUHMANN, Niklas. Die Ausdifferenzierung der Religion. In: Gesellschaftsstruktur und Semantik. Studien zur Wissenssoziologie der modernen Gesellschaft. Band 3. Frankfurt am Main: Surhkamp Verlag, 1989, p. 259-357.

MALY, Sebastian. Kant über die symbolische Erkenntnis Gottes. Berlin; Boston: Walter de Gruyter GmbH \& Co. KG, 2012.

MISCH, Georg. Lebensphilosophie und Phänomenologie. Eine Auseinandersetzung der Dilthey'schen Richtung mit Heidegger und Husserl. Leipzig; Berlin: Verlag und Druck von B. G. Teubner, 1931.

MOXTER, Michael. Kritischer Intuitionismus. Tillichs Religionsphilosophie zwischen Neukantianismus und Phänomenologie. In: DANZ, Christian; SCHÜßLER, Werner. (Hg.). Religion - Kultur - Gesellschaft. Der frühe Tillich im Spiegel neuer Texte (1919-1920). Tillich-Studien: Band 20. Wien; Berlin: LIT Verlag, 2008, p. 173-195. 
„denn der tragende Gehalt der Kultur ist die Religion und die notwendige Form der Religion ist die Kultur"

MÜLLER, Wolfgang W. Das Symbol in der dogmatische Theologie: eine symboltheologische Studie anhand der Theorien bei K. Rahner, P. Tillich, P. Ricoeur und J. Lacan. Frankfurt am Main; Bern; New York; Paris: Peter Lang GmbH; Internationaler Verlag der Wissenschaften, 1990.

NEUGEBAUER, Georg. Tillichs frühe Christologie. Eine Untersuchung zu Offenbarung und Geschichte bei Tillich vor dem Hintergrund seiner Schellingrezeption. Berlin; New York: Walter de Gruyter GmbH \& Co. KG, 2007.

. Die geistphilosophischen Grundlagen der Kulturtheologie Tillichs vor dem Hintergrund seiner Schelling- und Husserlrezeption. In: DANZ, Christian; SCHÜßLER, Werner. (Hg.). Paul Tillichs Theologie der Kultur: Aspekte, Probleme, Perspektiven. Berlin; Boston: Walter de Gruyter GmbH \& Co. KG, 2011, p. 38-63.

NÖRENBERG, Klaus-Dieter. Analogia Imaginis. Der Symbolbegriff in der Theologie Paul Tillichs. Gütersloh: Gütersloher Verlagshaus Gerd Mohn, 1966.

PALMER, Michael. Paul Tillich's Theology of Culture. In: PALMER, Michael. (Hg.). Main Works - Hauptwerke. Band 2: Kulturphilosophische Schriften. Berlin; New York: Walter de Gruyter; Evangelisches Verlagswerk, 1990, p. $1-31$.

PIEPER, Annemarie. Kant und die Methode der Analogie. In: SCHÖNRICH, Gerhard; KATO, Yasushi. (Hg.). Kant in der Discussion der Moderne. Frankfurt am Main: Suhrkamp Verlag, p. 92-112.

RECKI, Birgit. Die Dialektik der ästhetischen Urteilskraft und die Methodenlehre des Geschmacks ( $\S 55-60)$. In: HÖFFE, Otfried. (Hg.). Kritik der Urteilskraft. Berlin: Akademie Verlag GmbH, 2008, p. 189-210.

RENDTORFF, Trutz. In Richtung auf das Unbedingte. Religionsphilosophie der Postmoderne. In: FISCHER, Hermann. (Hg.). Paul Tillich: Studien zu einer Theologie der Moderne. Frankfurt am Main: Athenäum Verlag $\mathrm{GmbH}$, 1989, p. 335-356.

REPP, Martin. Die Transzendierung des Theismus in der Religionsphilosophie Paul Tillichs. Frankfurt am Main; Bern; New York: Peter Lang, 1986.

RINGLEBEN, Joachim. Symbol und göttliches Sein. In: HUMMEL, Gert. (Ed.). God and Being: The Problem of Ontology in the Philosophical Theology 
of Paul Tillich. Contributions made to the II. International Paul Tillich Symposium held in Frankfurt 1988. Berlin; New York: Walter de Gruyter \& Co., 1989, p. 165-181.

RODI, Frithjof. Der Logos des „getreuen Ausdrucks“. Georg Mischs Kritik der „Logik-Ontologie“ von Husserl und Heidegger. In: Erkenntnis des Erkannten: Zur Hermeneutik des 19. und 20. Jahrhunderts. Frankfurt am Main: Suhrkamp Verlag, 1990, p. 123-146.

SCHARF, Uwe Carsten. The Concept of the Breakthrough of Revelation in Tillich's Dogmatik of 1925. In: PARRELLA, Frederick J. (Ed.). Paul Tillich's Theological Legacy: Spirit and Community. International Paul Tillich Conference, New Harmony, 17-20 June 1993. Berlin; New York: Walter de Gruyter \& Co., 1995, p. 65-81.

SCHÖNRICH, Gerhard. Kategorien und transzendentale Argumentation. Kant und die Idee einer transzendentalen Semiotik. Frankfurt am Main: Suhrkamp Verlag, 1981.

SCHÜRMANN, Volker. Zur Struktur hermeneutischen Sprechens. Eine Bestimmung im Anschluß an Josef König. Freiburg; München: Verlag Karl Alber, 1999.

SCHÜßLER, Werner. Der philosophische Gottesgedanke im Frühwerk Paul Tillichs (1910 - 1933). Darstellung und Interpretation seiner Gedanken und Quellen. Würzburg: Königshausen \& Neumann, 1986.

. Paul Tillich und Karl Barth. Ihre erste Begegnung in den zwanziger Jahren. In: „Was uns unbedingt angeht". Studien zur Theologie und Philosophie Paul Tillichs. Berlin; Münster: LIT Verlag, 2009, p. 119-129.

SCHWEIKER, William. Theology of Culture and its Future. In: MANNING, Russell Re. The Cambridge Companion to Paul Tillich. New York: Cambridge University Press, 2009, p. 138-151.

STOLZENBERG, Jürgen. Absolutes Wissen und Sein. $\mathrm{Zu}$ Fichtes Wissenschaftslehre von 1801/02. Fichte-Studien, Nr. 12, p. 307-322, 1997.

STRÖKER, Elisabeth. Intentionalität und Konstitution. Wandlungen des Intentionalitätskonzepts in der Philosophie Husserls. Dialectica, vol. 38, no. 23, p. 191-208, 1984. 
„denn der tragende Gehalt der Kultur ist die Religion und die notwendige Form

STURM, Erdmann. Die Genese von Tillichs Kulturtheologie in seinen frühesten Texten. In: DANZ, Christian; SCHÜßLER, Werner. (Hg.). Paul Tillichs Theologie der Kultur: Aspekte, Probleme, Perspektiven. Berlin; Boston: Walter de Gruyter GmbH \& Co. KG, 2011, p. 64-93.

ULRICH, Thomas. Ontologie, Theologie, gesellschaftliche Praxis. Studien zum religiösen Sozialismus Paul Tillichs und Carl Mennickes. Zürich: Theologischer Verlag, 1971.

WAGNER, Falk. Absolute Positivität. Das Grundthema der Theologie Paul Tillichs. Neue Zeitschrift für Systematische Theologie und Religionsphilosophie, 15, p. 172-191, 1973.

. Kann die Religion der Moderne die Moderne der Religion ertragen? Religionssoziologische und theologisch-philosophische Erwägungen im Anschlus an Niklas Luhmann. In: DANZ, Christian; DIERKEN, Jörg; MURRMANN-KAHL, Michael. (Hg.). Religion zwischen Rechtfertigung und Kritik. Perspektiven philosophischer Theologie. Frankfurt am Main: Peter Lang GmbH; Internationaler Verlag der Wissenschaften, 2005, p. 173-201.

WENZ, Gunther. Subjekt und Sein. Die Entwicklung der Theologie Paul Tillichs. München: Christian Kaiser Verlag, 1979.

WINDELBAND, Wilhelm. Kulturphilosophie und transzendentaler Idealismus. Logos: Zeitschrift für systematische Philosophie, Band. 1, Heft 2, 1910-1911, p. 186-196.

. Das Heilige. Skizze zur Religionsphilosophie. In: Präludien: Aufsätze und Reden zur Einleitung in die Philosophie. Tübingen: Verlag von J. C. B. Mohr (Paul Siebeck), 1907, p. 414-450.

. Einleitung in die Philosophie. Tübingen: Verlag von J. C. B. Mohr (Paul Siebeck), 1920.

WITTEKIND, Folkart. Gottesdienst als Handlungsraum. Zur symboltheoretischen Konstruktion des Kultes in Tillichs Religionsphilosophie. In: DANZ, Christian; SCHÜßLER, Werner; STURM, Erdmann. (Hg.). Internationales Jahrbuch für die Tillich-Forschung. Band 2: Das Symbol als Sprache der Religion. Berlin; Wien: LIT Verlag, 2007, p. 77-100.

. „Allein durch Glauben“. Tillichs sinntheoretische Umformulierung des Rechtfertigungsverständnisses 1919. In: DANZ, Christian; SCHÜßLER, Werner. (Hg.). Religion - Kultur - Gesellschaft. Der frühe Tillich im Spiegel 
neuer Texte (1919-1920). Tillich-Studien: Band 20. Wien; Berlin: LIT Verlag, 2008, p. 39-65.

. Grund- und Heilsoffenbarung. Zur Ausformung der Christologie Tillichs in der Auseinandersetzung mit Karl Barth. In: DANZ, Christian; SCHÜßLER, Werner; STURM, Erdmann. (Hg.). Internationales Jahrbuch für die Tillich-Forschung. Band 6: Jesus of Nazareth and the New Being in History. Berlin; Boston: Walter de Gruyter GmbH, 2013, p. 89-119.

ZIJDERVELD, Anton C. Rickert's Relevance: The Ontological Nature and Epistemological Functions of Values. Leiden; Boston: Koninklijke Brill NV, 2006. 


\section{Réplica}

\section{Prof. Dr. Eduardo Gross (PPCIR-UFJF)}

Considerando a afirmação de alguns no sentido de que só haja sentidos particulares e nenhum incondicional (por exemplo, os pós-modernos):

Logicamente se poderia argumentar a respeito de uma incongruência fundamental, como faz Tillich em sua Filosofia da Religião, porque sentidos particulares pressupõem um sentido incondicional ou não fazem sentido. Dessa forma, é necessário pensar num sentido incondicional, se se pressupõe racionalidade no sentido (para mim, esse argumento de Tillich é afim ao formato do argumento ontológico de Anselmo; eu o considero um argumento muito bem construído, ao mesmo tempo que não acredito que ele venha a convencer ninguém da existência do sentido incondicional). Por outro lado, não se poderia dizer que haja também uma "decisão pelo sentido", uma "aposta no sentido", uma "fé no sentido incondicional"? Haveria na formulação de Tillich da Filosofia da Religião uma forma racionalizada de argumentação sobre a necessidade de um sentido incondicional, enquanto que esta segunda possibilidade acentuaria a dimensão da vontade - ou talvez do sentimento - na afirmação da existência do sentido incondicional? Haveria alguma primazia de alguma dessas formas de argumentação? Ou a partir de Tillich deveria ser acentuada uma necessária complementaridade entre elas? Será que a importância do conceito de símbolo aponta também para a inevitabilidade da fé para a afirmação de um sentido incondicional?

Essa questão é uma antiga questão minha a respeito do argumento presente na Filosofia da Religião de Tillich. A formulação em relação à palestra foi motivada pela citação feita à p. [4 no PDF da palestra]: "Ele [O método crítico-dialético] deve pressupor que os princípios de sentido aos quais a consciência se submete no ato espiritual são, ao mesmo tempo, os princípios de sentido aos quais o ser está submetido. Ele deve pressupor que o sentido do ser alcança expressão na consciência formada pelo sentido". Cf. também. p. [8 do PDF da palestra]: "O sentido individual deve sempre representar uma estrutura indeterminada de interconexão de sentido, por meio da qual uma atualização ulterior de sentido é alcançada". Ou seja, essa submissão é uma necessidade racional para evitar uma contradição, nesse argumento. A minha questão é se essa submissão enquanto necessidade racional efetivamente é suficientemente convincente.

Submetido em: 6-1-2022

Aceito em: 25-1-2022 


\title{
À guisa de uma tréplica: considerações sobre a história do problema da obra de Paul Tillich e o estatuto científico de sua teoria transcendental da religião
}

\author{
Prof. Dr. Fábio Henrique Abreu (Universität Wien)
}

A pergunta levantada pelo Prof. Dr. Eduardo Gross é excelente. Ela me confere uma oportunidade de tangenciar um dos aspectos mais fundamentais da teoria da subjetividade ou filosofia do espírito de Paul Tillich, para, a partir dessa base, tentar esclarecer alguns de seus conceitos mais centrais. Por outro lado, ela se conecta estreitamente com uma pergunta feita pelo Prof. Dr. Carlos Eduardo Calvani, do Programa de Pós-graduação em Ciências da Religião da Universidade Federal de Sergipe, que julgo extremamente pertinente, mas que acabei não tendo tempo para respondê-la durante a palestra - por motivos inúmeros. Tomo a liberdade, portanto, de reproduzir abaixo a pergunta elaborada pelo Prof. Calvani, até para ver em que medida as perguntas levantadas por ambos poderiam ser respondidas conjuntamente. Sobre o modo da relação entre religião e cultura, bem como em relação ao status da cultura popular no pensamento tillichiano, Calvani pergunta:

Às vezes me parece que, para Tillich, a cultura não existe por si mesma. Ela é a forma da religião, e a religião, por sua vez, é a substância da cultura. Essa é uma afirmação de fé. Ninguém pode experimentar isso como uma verdade histórica. $\mathrm{O}$ resultado desse pensamento seria a negação da cultura como uma realidade em si mesma. Ela precisa da substância da religião para existir. Se quisermos sustentar a posição de Tillich, chegaremos à conclusão paradoxal de que a religião é sua própria substância. Emendando com o tema do evento, que é sobre a atualidade da teologia da cultura, [faço uma consideração] sobre o status da cultura popular [no pensamento de Tillich]: o conceito de cultura de Tillich é extremamente limitado e elitista para ser aplicado ao contexto brasileiro. As palavras cultura e popular para Tillich não se combinam, e nunca aparecem juntas. É certo que nos escritos de maturidade, sua definição de cultura se torna mais abrangente, a criação de um universo de sentido em teoria e práxis, ou a autocriatividade da vida sob a dimensão do espírito, ou ainda, a totalidade da autointerpretação criativa do homem. Contudo, na prática, a autointerpretação criativa, privilegiada por Tillich, ou essa totalidade, sempre é aquela oriunda das elites ou das vanguardas artísticas, como o expressionismo. Isso não representa 

de 2021).

Tanto Gross quanto Calvani, e isso me chama a atenção, conectam algumas das consequências mais centrais da teoria da religião de Tillich com o conceito de fé. Gross fala em fé no sentido incondicionado, ao passo que Calvani sugere que a fórmula central oriunda da reconstrução do conceito de religião de Tillich na década de 1920 - a saber, "a religião é a substância da cultura e a cultura é forma da religião" - configura uma afirmação de fé, na medida em que ninguém poderia assumir essa determinação como "uma verdade histórica". No entanto, precisamente aqui, deveríamos nos perguntar se esse é realmente o caso. Será que Tillich, de fato, recorre à fé para sustentar a coerência interna de seu sistema? Ou será que não estaríamos aqui em outro âmbito, a saber, no domínio propriamente teórico de sua filosofia do espírito e da religião?

A fim de tentar contornar esse aparente problema, eu gostaria de chamar a atenção para uma distinção preliminar entre o âmbito propriamente teóricocientífico e o religioso. Em conformidade com a autodiferenciação moderna do sistema das ciências (Wissenschaftssystem), a teologia é e tem de ser distinta da religião. Já a teologia protestante esclarecida do século XVIII, a chamada Neologie, e, mais especificamente, Johann Salomo Semler, introduziu uma distinção fundamental entre teologia e religião vivida. Essa distinção permanece uma inflexão fundante da teologia enquanto ciência universitária e já deveria distingui-la de um discurso pura e simplesmente religioso - muito embora uma confusão entre esses dois âmbitos constitua uma marca pervasiva em nosso contexto de reflexão. Também a teoria da religião de Tillich assume essa distinção, de uma forma tal que não permite operar qualquer confusão entre teologia e religião vivida. Isso significa que, para todos os fins, a teoria da subjetividade e da religião de Tillich - bem como a totalidade de seu sistema teológico - não pode demandar uma justificação com base na fé subjetiva. Esse ponto é extremamente importante para que não apenas entendamos o estatuto científico da teologia de Tillich, mas também para que saibamos demarcar seu lugar no moderno sistema das ciências. Por outro lado, isso já ajuda a afastar a suspeita de que Tillich busque convencer seus leitores sobre a consistência interna de seu sistema a partir de um apelo à fé. Posto de outra forma, uma vez que sua teoria da subjetividade e da religião toma como seu fundamento e ponto de partida o conceito de incondicionado - que, a rigor, não é nem pode ser nenhum conceito -, Tillich sabe que não pode convidar seus leitores à fé no sentido incondicionado, ao mesmo tempo que também não busca uma justificação para a fórmula que sumariza o modo da interrelação entre religião e cultura em seu sistema a partir das virtudes da fé. Enquanto articulado no âmbito de uma teoria da subjetividade e da religião, o conceito de incondicionado deve ser suscetível à demonstração teórica. E, aqui, é importante que se afirme com toda a ênfase possível: Tillich não possui qualquer 
dificuldade em falar, nesse ínterim, de "ciência" - no sentido mais amplo de Wissenschaft, que, por vezes, tanto parece nos constranger. Nesse sentido, as sentenças iniciais da programática Kulturvortrag de 1919, que estabelecem uma distinção crucial entre as ciências da experiência ou empíricas (den Erfahrungswissenschaften) e as ciências sistemáticas da cultura (den systematischen Kulturwissenschaften), devem ser, aqui, relembradas. Como quer que entendamos o que Tillich se propõe a fazer a partir da construção de uma teoria da subjetividade e da religião - e essa teoria obviamente possui, em função de sua própria constituição, consequências lógicas para a compreensão do conceito de cultura, bem como para a totalidade da construção do sistema teológico -, não podemos nos esquecer que o que ele se propõe a fazer é, a rigor, ciência, i.e., uma construção teórica, metodicamente controlada, e que deve ser capaz de se sustentar a partir da coerência interna de seus próprios pressupostos, sem qualquer necessidade de um apelo à fé. Por esse motivo, penso que vincular o conceito de incondicionado e o modo da relação entre religião e cultura ao domínio da fé - e não ao domínio da ciência! - constitua um procedimento um tanto quanto problemático. Posto de outra forma, ninguém precisa decidir-se fideísticamente (ou a partir da fé) pela "existência [!] de um sentido incondicionado", assim como a fórmula da copertença entre religião e cultura não demanda nem poderia demandar qualquer "afirmação de fé". Ou Tillich é capaz de demonstrar, de uma forma sistemático-categorial, como a dimensão de incondicionalidade pode e deve ser tematizada como base para sua determinação dos conceitos de religião e cultura, ou seu empreendimento é natimorto.

Isso não significa afirmar, entretanto, que todos somos obrigados a concordar com seu empreendimento teórico do mesmo modo como somos obrigados a aceitar a lei da gravitação universal de Newton ou a teoria geral da relatividade de Einstein, responsável por descrever a gravidade não como uma força, mas como a curvatura do espaço-tempo causada pela distribuição desigual da massa, que faz com que as massas se movam ao longo das linhas geodésicas. O estatuto científico das ciências sistemáticas da cultura - numa palavra, filosofia - é outro, de uma forma tal que um empreendimento sistemático pode ser substituído por outro sistema cujos pressupostos internos julgamos, a partir de critérios objetivos e válidos, mais coerentes. A rigor, também aquilo que Tillich chama de ciências da experiência ou empíricas procedem de maneira similar, muito embora o ponto de partida na empiria e na evidência pressuponham a possibilidade de uma sua reprodutibilidade intersubjetiva irrestrita, o que contribui para a produção e acumulação de conhecimento reconhecido de forma universal (Heiner Schwenke). Em contrapartida, as ciências sistemáticas da cultura, ao menos aquelas que ainda assumem uma tradição que se quer rigorosa, a saber, "metafísica", partem decididamente de axiomas inverificáveis - o que, a rigor, é verdade até mesmo para a matemática (Kurt Gödel) -, como, por exemplo, as teorias da experiência religiosa. Afinal, 
como poderíamos verificar o que ocorre nas faculdades transcendentais da consciência numa dada experiência viva (Erlebnis) com o transcendente que assumimos como base - quando, de fato, evadimos a tentação de reduzi-la ao tabelionato da linguagem - de nossas teorias da religião? Já esse conceito de experiência religiosa confere à teologia, enquanto parte das ciências sistemáticas da cultura, seu caráter circular inescapável, como Tillich bem o sabia. Isso, no entanto, não as tornam menos rigorosas e científicas, mas certamente atestam que se trata de uma ciência que opera sob o prisma de um estatuto bastante distinto daquele assumido pelas ciências naturais. No caso das ciências sistemáticas da cultura, o princípio da reprodutibilidade intersubjetiva irrestrita é impossível e já de antemão indesejado. Afinal, como poderíamos reproduzir intersubjetivamente uma experiência religiosa sem, ao mesmo tempo, eliminarmos, precisamente com isso, seu caráter inderivável? Caso fôssemos capazes de reproduzi-la, certamente o faríamos - mas sem incorrer no burlesco de uma "neuroteologia", tal como o radiologista Andrew Newberg, entre outros, propõe. No entanto, por algum motivo fundamental, quiçá devido à própria irredutibilidade e inderivabilidade da religião - ou, numa palavra: sua autonomia! -, somos incapazes de reproduzi-la, criá-la. Também por esse motivo, a cientificidade das ciências sistemáticas da cultura deve ser mensurada a partir da coerência interna de seus pressupostos sob o prisma de certos princípios racionais metódica e sistematicamente estabelecidos. Mais do que isso, elas devem ser capazes de resistir à crítica pública oriunda da razão esclarecida. Não sem razão, portanto, a teologia protestante moderna adotou o salutar exercício de interiorização da crítica da religião (Religionskritik) como seu momento de justificação e fundamentação (Religionsbegründung). Obviamente, o princípio da coerência interna dos pressupostos de um determinado sistema abre margem para que outros sistemas de pensamento entrem em conflito e disputa em um domínio - que, em tese, ao menos, deveria ser - regulamentado pelo escrutínio da razão pública. No entanto, tais disputas não podem ser solucionadas, se de fato intencionam manter o exercício da arguição mútua em qualquer sentido minimamente aceitável, a partir de critérios puramente externos ao sistema verificado. Novamente, é a partir da coerência interna de seus próprios pressupostos que um determinado sistema de pensamento no âmbito das ciências sistemáticas da cultura pode ser mensurado e criticamente analisado em sua reivindicada cientificidade.

A análise da coerência interna dos pressupostos de um sistema filosófico e teológico não pode ser conduzida, no entanto, secundum omnium gustum. Antes, o exercício crítico intrassistêmico requer uma investigação cuidadosa e metodicamente controlada. Um sistema teológico, por exemplo, não pode, se de fato e de direito quiser permanecer inserido no sistema das ciências da modernidade, fazer um apelo à fé a fim de garantir, de antemão, seu estatuto científico. Isso configuraria uma verdadeira petitio principii autoautorizada. A rigor, a universidade não deveria aceitar esse tipo de procedimento, com o 
agravante risco de incorrer em obscuridade proselitista e, dessa forma, transmutar-se absolutamente. Tillich também estava ciente desse estado de coisas quando propôs os princípios da racionalidade semântica, lógica e metodológica como princípios constitutivos de qualquer sistema teológico digno do nome. Como afirma, "é função da forma sistemática garantir a consistência de afirmações cognitivas em todos os domínios do conhecimento metodológico". Por outro lado, assegurar o princípio da coerência interna de seus próprios pressupostos como critério de cientificidade das ciências sistemáticas da cultura impedem que críticas puramente externas possam servir como base para sua invalidação. Para todos os fins, o princípio que me parece mais prudente para o escrutínio de sistemas de pensamento ainda é o da crítica interna, imanente. É relativamente fácil elaborar uma crítica puramente externa - e essas estão presentes, ao menos em nosso cenário acadêmico, em todos os lugares. Contudo, caso assim procedamos, dificilmente poderemos escapar do juízo contra as "fillosofias das perspectivas" que Hegel impõe a seus críticos já no prefácio de sua Fenomenologia do Espírito, a saber, que seus críticos adotam a postura de juízes arrogantes e pensam estar sobre as coisas somente porque não estão nas coisas mesmas. Assumindo-se a crítica de Hegel como válida, poder-se-ia perguntar em relação à teoria da subjetividade e da religião de Tillich: o que, afinal de contas, é "essa coisa mesma" que não podemos criticar apenas externamente, como que numa Standpunktphilosophie?

Em meu entendimento, e eu já adianto que posso estar completamente equivocado, ambas as perguntas de Gross e Calvani revelam uma certa incompreensão acerca do que Tillich descreve a partir do conceito de incondicionado. Então, first things first! Nesse ponto, gostaria de levantar as seguintes perguntas: por que o incondicionado não demanda uma decisão pela fé para que possa ser tematizado com coerência? Por que não se trata de uma submissão enquanto necessidade racional a fim de se evitar uma contradição na construção teórica do sistema? Ou, para nos referirmos à pergunta de Calvani, por que a fundamentação da teoria da religião e da cultura de Tillich não repousa sobre "uma afirmação de fé"? A fim de tentar responder essas questões, peço licença, e já me desculpo de antemão, para elaborar uma espécie de excurso na intenção honesta de contextualizar minha resposta a partir da perspectiva da história dos problemas da obra (werkgeschichtliche Probleme) de Tillich. Após esse breve excurso, ao menos assim espero, poderei retornar às perguntas com mais propriedade e, quiçá, oferecer uma resposta com um grau mais elevado de inteligibilidade.

Como é possível perceber com bastante clareza a partir de um olhar histórico-genético de seu desenvolvimento intelectual, Tillich inicia seus estudos sob a influência da assim chamada teologia positiva-moderna, cujos principais expoentes são seus professores Adolf Schlatter e Wilhelm Lütgert. Composta por teólogos com ampla influência nos debates teológicos de seu tempo, a teologia positiva-moderna constituiu uma escola teológica que 
poderíamos chamar, cum grano salis, de "conservadora" - digo cum grano salis porque também os representantes da teologia positiva-moderna assumem a inflexão kantiana como ponto de partida, o que já deve servir para contornarmos a noção de "teologia conservadora" tanto em sua acepção no contexto intelectual norte-americano, como em nosso próprio contexto. Por volta do ano de 1900, as faculdades teológicas de Halle, Greifswald e Tübingen se tornaram os centros dessa versão da teologia protestante. $O$ ponto de partida teológico dessa escola encontra-se na reflexão a partir da história bíblica da salvação, não dos credos luteranos ligados a uma experiência religiosa, como fizeram os teólogos neoluteranos de Erlangen e Leipzig, nem da revelação de Deus em Jesus Cristo, como fizeram Albrecht Ritschl e sua escola. Jovens seguidores desses teólogos, tanto em suas teses doutorais como em seus trabalhos posteriores, conectaram os motivos da teologia positiva-moderna com a "constelação de problemas" (Dieter Henrich) do Idealismo Alemão. Basta lembrarmo-nos, aqui, de teólogos como Friedrich Brunstäd e Erich Schaeder, por exemplo, mas também do amigo íntimo de Tillich, Kurt Leese, que foi pupilo de Schaeder. Por outro lado, esse também é o contexto inicial da teologia de Tillich, para quem a teologia positivamoderna de Schlatter, Lütgert, mas também de seu pai Johannes Tillich, formaram o pano de fundo de seu próprio envolvimento com o Idealismo Alemão. De fato, Tillich emprega as filosofias de Fichte e do Schelling tardio a fim de oferecer uma interpretação da teologia de seus próprios professores.

O que torna a teologia de Schlatter e Lütgert tão importante para o jovem Tillich? A partir de uma apropriação de Franz von Baader, Schlatter, desde sua habilitação em Berna, em 1881, elabora o programa de uma "teologia empírica" - não no sentido usual de empírico, obviamente -, cujo objetivo principal é estabelecer as condições de possibilidade do conhecimento de Deus na natureza e na história. Seu "realismo teológico" consiste no fato de que ele posta o conceito de Deus como "causa" da natureza e da história. Assim, Deus já está sempre relacionado com a concretude do mundo enquanto seu fundamento de unidade. A alma, i.e., a consciência individual, se encontra sempre em contato real com o mundo já no momento de sua percepção. O conceito de percepção significa, aqui, uma espécie de "ser afetado" da alma pela realidade que se dá na consciência como imagens de memória e é processada, por esse motivo, em um duplo passo de análise e síntese. Na performance da fé, que é sempre inteiramente dependente da autorrevelação divina, Deus se abre ao homem como a causa do mundo e da história, para que ambos se tornem meios da autorrevelação de Deus. A teologia é, aqui, conhecimento de Deus, e somente é possível, enquanto tal, a partir do primado da autorrevelação divina.

$\mathrm{O}$ aluno de Schlatter, Wilhelm Lütgert, assume esse programa de uma "teologia realista". Como seu professor, ele também vincula todo o conhecimento de Deus à autorrevelação de Deus, ao mesmo tempo que distingue entre uma revelação universal da criação e uma revelação especial de salvação, sendo que a primeira é o pressuposto e a condição da última. O ponto 
de partida da teologia de Lütgert, assim como em seu mestre Schlatter, não se encontra na revelação de Deus em Jesus Cristo, mas, antes, na revelação de Deus na natureza e na cultura. A partir dessa concepção, Schlatter e Lütgert rejeitam a teologia de Albrecht Ritschl, que restringe a revelação de Deus à revelação especial em Jesus Cristo. Isso porque, conforme argumentam, caso somente possamos encontrar Deus através da revelação em Jesus Cristo, então tanto a natureza quanto a cultura não desempenham qualquer papel definitivo na teologia. Essa é a razão pela qual Schlatter e Lütgert elaboram concepções de teologia que partem da revelação universal de Deus e, em seguida, integram a revelação especial de Deus em Jesus Cristo no sistema teológico. Por outro lado, ambos os teólogos conectam explicitamente seus programas teológicos com motivos filosóficos derivados do Idealismo Alemão.

O jovem Tillich integrou essa abordagem e ponto de partida em sua própria construção teológica. Assim, com base na premissa de um conceito universal de revelação, Tillich critica a teologia dominante de Albrecht Ritschl e sua escola. Já em seu ensaio sobre o monismo (Monismusschrift), de 1908, Tillich critica a separação rígida de Ritschl entre teologia e metafísica. Mais tarde, em seus trabalhos posteriores à Primeira Guerra Mundial, Tillich continuou a trabalhar a partir desse mesmo quadro referencial. Aquilo que será por Tillich chamado - sobretudo a partir da disputa sobre o conceito de paradoxo travada com Karl Barth nas páginas do periódico Theologische Blätter na virada de 1923 para 1924, bem como na versão publicada de seu texto Rechtfertigung und Zweifel, de 1924, que é reformulado a partir dessa disputa - de "revelação fundamental" (Grundoffenbarung) e "revelação salvífica" (Heilsoffenbarung), e, posteriormente, de "pergunta e reposta" na Systematic Theology estadunidense, possui sua raiz histórico-genética nessa constelação de problemas conformada pelas teologias de Schlatter e Lütgert. Essa concepção do ponto de partida da reflexão teológica é muito distinta, por exemplo, daquela desenvolvida por Martin Kähler, a quem Tillich descreve, já conferindo estilisticamente demasiada importância em sua autobiografia, como "seu professor". Com efeito, Kähler também está inserido no quadro da assim chamada teologia positiva-moderna. No entanto, como sua obra principal claramente demonstra - refiro-me, aqui, ao livro Die Wissenschaft der christlichen Lehre -, Kähler começa sua teologia a partir do conceito de justificação, ou seja, da salvação em Jesus Cristo, que é precisamente o oposto daquilo que as teologias positivas de Schlatter e Lütgert procuram fazer ao adotar como ponto de partida a ideia de uma revelação universal de Deus no mundo. Por esse motivo, a influência do pensamento de Kähler no desenvolvimento intelectual de Tillich precisa ser cuidadosamente relativizada, a despeito do que o próprio Tillich afirma em sua autobiografia.

Conforme mencionado acima, Schlatter e Lütgert combinaram suas teologias com elementos do Idealismo Alemão. Essa conexão é ainda mais evidente em Lütgert, que se apropria da interpretação de Fichte elaborada por 
seu colega em Halle, o Privatdozent de filosofia Fritz Medicus, também professor de Tillich e cuja influência sobre seu pensamento é insofismável. Lütgert, em seu livro Die Religion des Deutschen Idealismus und ihr Ende, de 1923, que, como ele mesmo afirma, remonta às suas palestras proferidas em Halle, em 1908, apresenta uma descrição da filosofia de Fichte a partir do conceito-chave de "doutrina da convicção" (Überzeugungslehre). Essa é, porém, exatamente a interpretação oferecida por Fritz Medicus do pensamento de Fichte, desenvolvida em seu livro J. G. Fichte. Dreizehn Vorlesungen gehalten an der Universität Halle, de 1905 - livro publicado, vale dizer, apenas alguns meses antes da chegada de Tillich à Halle. Esse livro é decisivo para a compreensão de Tillich sobre o Idealismo Alemão, como facilmente notamos em seus primeiros textos acadêmicos do período de Halle. Para Medicus, o ponto central da filosofia de Fichte é o conceito de convicção (Überzeugung). No conceito de convicção, Medicus vê a importância decisiva da filosofia de Fichte para seu próprio tempo, especialmente para uma superação da "crise do historicismo" (Historismus). Tillich assume esse movimento de retorno ao Idealismo Alemão como uma alternativa ao historicismo de Troeltsch, muito embora, evidentemente, seu próprio sistema teológico tenha permanecido em estreitíssima conexão com o programa desenvolvido pelo "grande sistemático da escola da história da religião". Em contraposição a Troeltsch, Tillich constrói um conceito de história como uma história interna ao espírito, ao passo que a história, em Troeltsch, é externa.

Há três aspectos centrais na interpretação de Medicus da filosofia de Fichte que eu gostaria de destacar.

1). Em primeiro lugar, a compreensão do eu como convicção. Isso significa que o eu nada mais é do que um "estado de ação" (Tathandlung), i.e., um eu que possui um conhecimento autorreferencial e autorreflexivo de si mesmo. Em conformidade com o texto de Fichte Über den Begriff der Wissenschaftslehre oder der sogenannten Philosophie, Medicus faz uma distinção entre forma (Form) e substância (Gehalt), determinando o eu, portanto, ao mesmo tempo como estado de ação e substância. É precisamente nesse estado de ação que se encontra o fundamento da certeza do eu. No entanto, essa certeza somente está presente na consciência como forma (Form), ou melhor, como convicção da certeza enquanto autoposição e estado de ação. Contra o pano de fundo dessa estrutura, Medicus interpreta a convicção como o modo do autodesvelamento reflexivo do eu. A realização do eu se encontra em assumir o "não-eu" no "eu”. Em seu já mencionado livro sobre Fichte de 1905, Medicus lida não apenas com a Wissenschaftslehre de 1794. Antes, o filósofo e Privatdozent de Halle interpreta a Wissenschaftslehre tardia como um desenvolvimento adicional da concepção inicial da "doutrina da ciência". E, aqui, nos dirigimos para o segundo aspecto que penso ser importante destacar.

2). A filosofia tardia de Fichte, especialmente a Wissenschaftslehre de 1801/1802 e 1804, introduz uma distinção fundamental entre o absoluto e o 
"conhecimento absoluto" (absolutes Wissen). Para o Fichte tardio, o autodesvelamento reflexivo do eu é compreendido como substância (Gehalt), ao passo que o conhecimento é compreendido como forma (Form). O eu é a imagem (Bild) do absoluto. Medicus nomeia a filosofia fichteana tardia, com referência à interpretação fichteana do Evangelho de João, como o "período joanino" de Fichte. Por outro lado, é bastante significativo que Medicus tenha chegado à conclusão, a partir de uma citação do livro de Lütgert - a saber, Die johanneische Christologie -, que a interpretação de Fichte do Evangelho de João é uma interpretação equivocada. Em primeiro lugar, a compreensão de Fichte do pecado como ausência de autonomia é diferente daquela oferecida pelo Evangelho de João. Para Fichte, o pecado significa que o eu não consegue apreender a si mesmo como eu, ou seja, em seu estado de ação, o eu se desloca para trás de si mesmo enquanto autonomia no próprio ato de autoposição. Nesse sentido, Medicus, apoiado na interpretação de Lütgert, chega à conclusão que o Evangelho de João representa um contraponto na medida em que compreende o pecado não como algo negativo, mas, antes, como um ato dotado de positividade.

3). O terceiro aspecto central que eu gostaria de mencionar nesse contexto é a concepção de história de Fichte. Medicus interpreta a filosofia da história de Fichte como uma construção da consciência da história. Não há, no "Fichte de Medicus", uma conexão entre a história empírica e a filosofia da história. Em vez disso, a filosofia da história constrói uma história da autoconsciência (Geschichte des Selbstbewußtseins). O que se quer dizer com isso é que a filosofia da história estrutura o caminho da autoconsciência para sua própria autocompreensão reflexiva. Trata-se, em outras palavras, de uma história estritamente interna à consciência. $\mathrm{O}$ ponto mais relevante a ser percebido, aqui, é que o jovem Tillich se apropria dessa compreensão da história de seu professor Medicus. Assim como em Medicus, também em Tillich a história, enquanto uma história da autoconsciência, funciona como a base de uma filosofia da história que tem como objetivo central superar a crise do historicismo. Os escritos iniciais tillichianos revelam, precisamente por assumirem o absoluto como ponto de partida, que Tillich, em face da crise do historicismo, retorna à tradição idealista como uma alternativa ao programa teológico de Troeltsch. Não é de causar surpresa, portanto, o fato de que a tese de doutorado em filosofia de 1910 possuía originalmente por título Die Konstruktion der Religionsgeschichte und die Absolutheit des Christentums in Schellings ,positive 'Philosophie, como os "Tillich-Archives" da Universidade de Harvard demonstram. O título é uma clara referência ao Absolutheitsschrift de Troeltsch - a saber, Die Absolutheit des Christentums und die Religionsgeschichte (1902/1912). Por outro lado, a preocupação com o tema do caráter absoluto do cristianismo percorre, igualmente, sua pesquisa preparatória para a dissertação filosófica sobre Schelling, também escrita em 1910 - a saber, Gott und das Absolute bei Schelling, onde, vale dizer, a metáfora Durchbruch é 
empregada pela primeira vez como uma descrição do evento da revelação. Esses trabalhos iniciais de Tillich constituem não apenas contribuições singulares para a Idealismusrenaissance na Alemanha do início do século passado, mas também atestam sua própria tentativa de articular sua visão teológica original daquilo que o Idealismo Alemão, enquanto tradição viva, deveria ser. O que afirmamos aqui, em parcial conformidade com Marc Boss, é que Tillich, a partir da tradição filosófica inaugurada por Kant, intenciona, desde o início de sua formação, oferecer sua própria proposta para a retomada do Idealismo Alemão a partir de um ponto de vista original e, em grande medida, autônomo. No entanto, ao contrário de Boss, é preciso entender que a preocupação de Tillich jaz mais propriamente na fundamentação do sistema teológico e, de forma mais precisa, na construção de um conceito universal de revelação, do que na construção de um sistema filosófico - muito embora Tillich também tenha assumido essa tarefa, como seu Wissenschaftssystem, de 1923, prontamente atesta.

Com base nesse ponto de partida, podemos perceber a forma como Tillich constrói os alicerces de seu pensamento teológico. A partir de uma combinação bastante original das filosofias de Fichte e Schelling, Tillich lança os alicerces de sua teoria da subjetividade a fim de oferecer um suporte filosófico crítico (leia-se: científico) para a fundamentação de uma teologia universal da revelação na esteira dos influxos das teologias de Schlatter e Lütgert. Embora inicialmente ele tenha se esforçado por desenvolver, a partir de Fichte, um "monismo do espírito", e, posteriormente, tenha percorrido todo o caminho da construção especulativa do conceito de absoluto a partir da filosofia tardia de Schelling, Tillich altera essa teoria especulativa do absoluto por meio de uma apropriação das filosofias neokantianas e da fenomenologia de Husserl. Como diz Tillich com base numa sentença de Kähler, mas também em atitude claramente revisionista, "o absoluto é um ídolo". Com isso não se quer dizer, aqui, que o conceito de absoluto seja abandonado. Pelo contrário. A compreensão tillichiana do absoluto é modificada e transferida para a própria estrutura da autorrelação espiritual, que é exatamente a substância de seu conceito de incondicionado - a saber, Unbedingtheit im Selbstverhältnis. Isso já está indicado em sua tese de habilitação de 1915, onde o conceito de "Deus além de Deus" aparece pela primeira vez como categoria chave para a descrição da dimensão de incondicionalidade da autoconsciência. Em suas correspondências com Emanuel Hirsch entre os anos de 1917 e 1918, Tillich avança decisivamente em direção a um "monismo do sentido", onde precisamente o conceito de sentido (Sinn) - que, por sinal, não possui correlato quer no inglês, no francês ou no português - opera como uma descrição da consciência. Numa carta enviada a Hirsch, Tillich descreve seu monismo do sentido, numa linguagem que nos remete a Fichte, Paul Natorp e Emil Lask, nos seguintes termos: 
Também o ser, o puramente "factual", é por certo um conceito; por conseguinte, ele é o ser posto pelo contexto ou interconexão lógica de sentido (vom logischen Sinnzusammenhang), é produto de sentido ou de valor. O sentido põe o ser como seu "outro", no qual ele se realiza. Justamente por isso, o sentido põe o divino como seu "outro", pelo qual ele sabe que se realiza. Do mesmo modo, o sentido se delimita mediante o ser e o além-daquele-que-é (Überseiende). Ambos são atos de posição ou criação de sentido (Sinn-Setzungen). O ser não pode novamente "ser", e o alémdaquele-que-é tem sua essência no fato de não ser! Portanto, ensino o monismo do sentido, que se contrapõe ao contra-sentido ou absurdo, ao irracional, sob dois aspectos: o ser e o além-do-ser (das Sein und das Übersein).

Tillich, assim como Husserl, define a consciência como "abertura de sentido" (Sinnerschließung), i.e., a consciência opera estritamente a partir da criação e doação incessante de sentido. Esse aspecto é importante para que possamos compreender, com mais precisão, o que Tillich quer dizer, afinal de contas, com o conceito de incondicionado. Isso porque, muito embora a consciência seja abertura de sentido, essa mesma teoria do sentido, como a teoria da subjetividade de Tillich revela, precisa ser integrada ao conceito de espírito, que ainda não se encontra, entretanto, plenamente desenvolvido nesse período. Foi precisamente por esse motivo que escrevi o seguinte parágrafo em minha palestra:

Não obstante, a compreensão de Tillich do espírito ainda não se encontra plenamente descrita. Há dois aspectos fundamentais ausentes. Em primeiro lugar, o espírito não se autopõe em sua atualização apenas como sentido e não intenciona apenas o contexto de interconexão de sentido. Antes, em seu ato de autoposição, o espírito apreende a si mesmo. Ao espírito pertence, portanto, também sua autorrelação constitutiva. "Esta consciência, esta autocontemplação [Sich-selbst-Zuschauen] e autodeterminação [Sich-selbst-Bestimmen] do pensamento no ato criativo é a característica fundamental do espiritual". Dessa determinação resulta, em segundo lugar, que o espírito é caracterizado em sua autoatualização por uma tensão irresolúvel. Essa é a tensão, em outras palavras, entre o universal e o individual. $\mathrm{O}$ espírito somente pode postar o universal como algo individual e determinado. "O ato espiritual pode se direcionar ao universal somente quando ele intui o universal em uma norma concreta, em uma realização individual do universal". Sobre a base dessa determinação do espírito, a compreensão de história de Tillich é construída. Isso quer dizer que o espírito já está sempre envolvido na história de um modo tal que ele sempre já encontra a si mesmo em cada ato concreto de autoposição. Como afirma em seu Wissenschaftssystem de 1923, "não há origem do espirito; pois, cada criação espiritual pressupõe o espírito". Uma "teoria da constituição", de acordo com a qual o espírito produz a realidade 
empírica como um mundo externo através da atividade da própria consciência, é, dessa forma, rejeitada. Antes, o espírito já se encontra sempre entrelaçado na realidade histórica, sem, obviamente, ser derivado dela. O espírito é direcionado, em seus atos concretos e determinados de autoposição, à estrutura de cumprimento de sentido. Nessa estrutura, o espírito apreende a si mesmo enquanto espírito: ele se encontra para além de si, sem deixar, contudo, de permanecer, ao mesmo tempo, consigo mesmo.

Um ponto a ser destacado é o seguinte: ao mesmo tempo que o sentido descreve a natureza mais própria da consciência, o sentido que reflete sobre si mesmo - i.e., a autorreferencialidade da consciência -, e, dessa forma, dá origem à autorrelação constitutiva do espírito, i.e., à autocontemplação e à autodeterminação do pensamento no ato espiritual, descreve, igualmente, o estatuto do conceito de incondicionado - ou, se quisermos, absoluto. Há que se operar uma distinção conceitual entre consciência e autoconsciência (espírito). A consciência é abertura de sentido, ao passo que a autoconsciência é precisamente a autorrelação espiritual, i.e., a autorreflexividade da consciência que posta a si mesma e nesse ato de autoposição apreende a si mesma em sua autorrelacionalidade. Dessa autorrelação espiritual circular, autorreferencial e autorreflexiva, decorre que o espírito, enquanto autorreflexividade, torna-se ciente, na intuição intelectual, de sua própria incondicionalidade, ao mesmo tempo que sabe que somente pode apreender a si mesmo por meio de formas condicionadas, que são as únicas formas que ele tem à disposição. Essa antinomia interna do espírito, que Tillich chama de "paradoxo absoluto" ou "paradoxo originário do espírito", demarca o estatuto da filosofia do espírito de Tillich. Em outras palavras, o espírito é incondicionado, ou, novamente, se quisermos, absoluto, mas somente pode apreender a si mesmo de forma condicionada. Em sua autoposição, o espírito é ao mesmo tempo aquele que se posta (sujeito) e aquele que é posto (objeto). Essa circularidade da autoconsciência, para Tillich, inescapável, descreve o incondicionado como equiprimordialidade de fundamento e abismo de sentido. Por abismo de sentido não podemos entender outra coisa senão o fato de que o espírito, em seu ato de autoposição, não encontra sua origem, mas, antes, cai na circularidade daquele se põe e daquele que é posto. Novamente, como diz Tillich em seu Wissenschaftssystem de 1923, dedicado a Troeltsch, "não há origem do espírito; pois, cada criação espiritual pressupõe o espírito".

Por outro lado, na medida em que o espírito somente pode se apreender por meio de formas condicionadas, a consequência lógica dessa estruturação teórica é que o espírito somente pode se realizar enquanto cultura. É por isso que a cultura não possui outro estatuto para Tillich para além de "espírito objetivo". A cultura é, numa palavra, Geistesleben. Ou ainda, posto de outra forma, a cultura é o resultado do condicionamento necessário do incondicionado através de uma forma - e a categoria forma aponta para a estrutura 
transcendental da consciência de sentido. Por esse motivo, todos os atos concretos do espírito, i.e., todas as formas culturais, são inescapavelmente paradoxais, antinômicas, ambíguas - incluindo, evidentemente, a religião. A autoconsciência humana é uma unidade em oposição, uma autorrelação antinômica. É uma unidade, no entanto, que não pode se apreender como uma unidade. Daí que, a incondicionalidade da autorrelação do espírito, ou a "religião do paradoxo", somente pode ser elevada à consciência através de uma negação de suas formas concretas. Ou seja, mesmo a religião somente se torna religião na medida em que nega suas determinações concretas. Mas, na medida em que o espírito somente possui formas culturais ou condicionadas à disposição, ele precisa fazer uso dessas formas e negá-las ao mesmo tempo. É em função dessa antinomia interna do espírito que uma teoria dos símbolos é necessária. O símbolo liberta a consciência das objetivações necessárias que condicionam o incondicionado, ao passo que traz à consciência a vitalidade $\mathrm{e}$ concretude do paradoxo absoluto. Como afirma Tillich, "tão logo a consciência se eleve ao nível da dúvida radical, essas objetivações [Vergegenständlichungen] em sua intuitividade irrefletida somente podem ser consideradas como símbolos da vitalidade e concretude do paradoxo absoluto. Nesse estágio, a consciência somente pode usar esses símbolos sob a constante advertência e lembrança de seu caráter simbólico e de sentido que eles expressam de maneira intuitiva e vívida, mas inadequada". Por outro lado, o símbolo apresenta como unidade precisamente aquilo que é constitutivamente paradoxal. No entanto, a consciência simbólica está ciente de que os enunciados simbólicos são sempre necessariamente inautênticos e indiretos. A religião faz uso dos símbolos ao mesmo tempo que os nega.

Ora, é essa incondicionalidade da consciência reflexiva ou autoconsciência que Tillich usa para construir tanto sua teoria da subjetividade, por um lado, quanto sua teoria da religião e o conceito de Deus, por outro. Por esse motivo, toda a reformulação do conceito de religião operada por Tillich a partir da década de 1920 é marcada por uma antinomia, uma "paradoxalidade", que, posteriormente, ele descreve, sob o horizonte mais amplo de uma Lebensphilosophie, como as "ambiguidades da vida". Essa também é a substância de sua reformulação da doutrina da justificação pela fé, bem como a base não apenas paras os binômios "justificação e dúvida" (1919), "revelação fundamental e revelação salvífica" (1924), "coragem e melancolia" (1925), "coragem e angústia" (1952), mas também para a própria estruturação do método de correlação (1951), descrito a partir do binômio "pergunta e resposta" (1935). A substância do método de correlação de Tillich não pode ser corretamente compreendida como uma dinâmica entre "perguntas filosóficas" e "respostas teológicas", ou mesmo como um entrecruzamento entre ambas. Quem quer que tente descrever a substância e função do método de correlação nesses termos não consegue, de fato, compreendê-lo. A substância do método de correlação é retomar o ponto de partida do conceito universal de revelação - 
„denn der tragende Gehalt der Kultur ist die Religion und die notwendige

a condição de possibilidade da pergunta, como ele diz, de forma mais clássica, em sua Systematic Theology estadunidense - e sua apresentação simbólica concreta. Que a dialética entre pergunta e resposta descreva um problema contínuo na totalidade da obra de Tillich - a saber, o conceito geral de revelação e sua apresentação histórica concreta -, é algo que pode ser prontamente percebido no texto What is Wrong with "Dialectic" Theology?, de 1935, bem como em suas palestras sobre Natural and Revealed Religion, proferidas na Universidade de Harvard, no mesmo ano. É evidente que esses textos retomam a estrutura da revelação fundamental e da revelação salvífica a partir de uma nova terminologia. Por outro lado, os Advanced Problems in Systematic Theology. Courses at Union Theological Seminary, New York, 1936-1938, já em suas primeiras páginas, revelam essa preocupação pervasiva e programática de Tillich. Toda essa estruturação do sistema teológico se configura como um modo de autoapresentação simbólica das condições constitutivas da subjetividade individual, i.e., da estrutura antinômica e paradoxal do espírito humano. Dessa forma, a doutrina de Deus tem a função de descrever o caráter inderivável da estrutura do ato religioso, da performance da fé, ou melhor, ela aponta para a incondicionalidade da autorrelação espiritual. Por esse motivo, o incondicionado não é Deus. Antes, Deus é, mais propriamente, um símbolo para o incondicionado. A cristologia descreve a simbolicidade da consciência reflexiva e, assim, demarca a integração da fé na história. O símbolo do Cristo cumpre sua função precisamente ao apresentar uma imagem que é retirada da subjetividade e da qual ela, a subjetividade, ao mesmo tempo se distingue. $\mathrm{Ou}$ seja, o símbolo do Cristo é, em um sentido muito específico, uma imagem exteriorizada e invertida, espelhada, da própria subjetividade, com a qual a subjetividade se relaciona. Ao mesmo tempo, essa imagem se distingue da subjetividade na medida em que traz à apresentação o símbolo de uma unidade para aquilo que é originariamente antinômico. Esse modo simbólico de autoapresentação, cabe dizer, não possui qualquer paralelo com a teoria da projeção de Feuerbach, como um leitor desavisado poderia apressadamente inferir, mas, antes, encontra um forte paralelo em David Friedrich Strauss e no desenvolvimento da teologia protestante moderna. É por esse motivo que Tillich designa a cristologia, em suas preleções sobre Dogmática proferidas inicialmente em Marburg e logo continuadas em Dresden (1925-1927), como a "imagem real da fé" (Real-Bild). Não se trata, aqui, de projeção (Projektionstheorie), mas de apresentação (Darstellung). Com sua cristologia da imagem, Tillich se conecta à tradição teológica que remonta a Schleiermacher e sua cristologia da Urbild, mas também, e de forma mais forte, à teologia de Strauss. Isso porque a imagem de Cristo, ou a imagem real da fé, não é apenas a autoapresentação subjetiva da compreensão da história, mas também a apresentação do círculo metodológico da autointerpretação que está pressuposto em toda interpretação da história. Na imagem de Cristo, não apenas se demonstra a integração da fé em uma história concreta, uma história em que 
todo ato de interpretação da história já se encontra incluído, como também é apresentada a dependência que toda imagem histórica possui da interpretação. Tillich entende a imagem de Cristo como o meio a partir do qual a consciência se torna transparente para si em sua própria historicidade e esclarece a si mesma e sua autoposição na história. Desse modo, a cristologia dogmática é concebida por Tillich como uma autoimagem e uma autodescrição da autorrelação da consciência, i.e., uma autoimagem que se autoapreende em sua própria reflexividade e historicidade. Em sua realização revelatória, informada pela teologia da cruz, a cristologia apresenta a verdade da autorrelação na consciência como uma autointerpretação concreta, ou seja, a relação essencial entre o incondicionado e o condicionado. Para Tillich, no entanto, esse é o cerne da história, i.e., "o desdobramento da consciência em relação ao incondicionado. O cerne da história é a história da religião".

Desse modo, a cristologia se torna, no sistema de Tillich, um tipo particular de "filosofia teológica da história", se pudermos fazer uso dessa nomenclatura. O locus de autointerpretação da história, mesmo que essa autointerpretação somente seja possível em uma história específica e em um lugar histórico específico, certamente não coincide com a história empírica e não pode ser, de forma alguma, determinado. A imagem que a autorrelação da consciência humana tem de si mesma e de sua autocompreensão histórica não pode ser um dado que se poderia datar na história. Para Tillich, e isso já desde sua apropriação do Fichte de Medicus, há uma diferença estrita entre empirismo e autointerpretação da consciência, de modo que não é possível conectar os eventos da fé a um "Jesus histórico" que esconder-se-ia, por assim dizer, por trás da imagem do Cristo apresentada pela autointerpretação da fé. $\mathrm{Na}$ cristologia de Tillich, o Jesus histórico não possui a função de fornecer qualquer justificativa para a cristologia dogmática. Em outras palavras, o Jesus histórico não desempenha nenhuma função na cristologia. A despeito disso, porém, a fé possui um referencial necessário na pessoa histórica de Jesus de Nazaré. O homem Jesus não apenas simboliza a integração da fé na história, como também, e acima de tudo, demonstra que a fé é um evento pessoal que toma lugar na história. Embora a pesquisa histórica não possa, desse modo, justificar a fé, Tillich a relaciona à imagem da fé em sua própria história de uma forma tal que ele a equilibra com os resultados da investigação empírica da história.

A doutrina do Espírito Santo, por sua vez, tem a função de apresentar a unidade última da consciência reflexiva em sua infindável busca por atualização. A pneumatologia, que somente alcança um desenvolvimento substantivo na Systematic Theology estadunidense - muito embora uma pneumatologia plenamente desenvolvida já possa ser encontrada na Systematische Theologie de 1913, ainda que sob o prisma de uma filosofia do espírito distinta -, descreve o símbolo do Espírito Santo sob a chave da "unidade transcendente da vida sem ambiguidades". Ou seja, os símbolos dogmáticos descrevem o modo como a subjetividade apresenta sua unidade como um 
projeto (!) da razão (Ulrich Barth) em sua busca por unidade última. Isso quer dizer que a consciência se volta noeticamente para um sentido incondicionado de unidade última que permanece, não obstante, inalcançável. A necessidade que a consciência possui de postular essa unidade última se encontra justificada em sua própria estrutura transcendental e antinômica. Posto de outra forma, o sistema teológico nada mais é do que isto: uma autoapresentação simbólicosistemática das condições constitutivas da subjetividade individual. Por esse motivo, a teologia sistemática pode ser descrita como um modo elementar de autointerpretação simbólica que apresenta, por meios de símbolos, o autodesvelamento da incondicionalidade da consciência. É precisamente isso que a fórmula Richtung auf das Unbedingte descreve. À parte de um incurso em sua filosofia do espírito, torna-se impossível entender a substância dessa fórmula de um modo minimamente adequado.

É a partir desses apontamentos gerais a partir da história dos problemas da obra de Tillich que pretendo retomar as perguntas feitas por Gross e Calvani. Tendo-se em vista essa descrição da teoria da subjetividade e da religião de Tillich, pergunto-me, seria realmente adequado pressupor que Tillich faz uso de um apelo à fé no sentido incondicionado ou mesmo afirmar que o modo da relação entre religião e cultura constitua uma afirmação de fé? A partir da apresentação dos contornos gerais da teoria da subjetividade e da religião de Tillich, resta claro que não. A dimensão de incondicionalidade da consciência não pode demandar uma "decisão pelo sentido" ou uma "aposta no sentido" precisamente porque a própria consciência é consciência de sentido. Por certo, a fé é um direcionamento para o incondicionado. Mas, novamente, a fé somente pode ser um voltar-se para o sentido incondicionado em função da própria dimensão de incondicionalidade da autorrelação. É verdade que o método crítico-dialético "deve pressupor que os princípios de sentido aos quais a consciência se submete no ato espiritual são, ao mesmo tempo, os princípios de sentido aos quais o ser está submetido. Ele deve pressupor que o sentido do ser alcança expressão na consciência formada pelo sentido". Mas, novamente, ele somente pressupõe que os princípios de sentido aos quais a consciência se submete no ato espiritual são, ao mesmo tempo, os princípios de sentido aos quais o ser está submetido porque, de fato, o princípio do ser somente pode alcançar expressão na consciência formada pelo sentido. Ao desenvolver um método ao mesmo crítico e dialético, i.e., metalógico, Tillich pretende justamente tematizar a dimensão incondicional da consciência que irrompe como uma consequência necessária da consciência que reflete sobre si mesma. Posto de outra forma, o método crítico-intuitivo intenciona trazer à expressão conceitual a incodicionalidade da autorrelação enquanto fundamento e abismo da consciência de sentido. Por outro lado, como a consciência é abertura, criação e doação incessante de sentido, ela sempre constrói estruturas de interconexão de sentido que, ao mesmo tempo, a determinam. É precisamente através do avanço em direção a um contexto sequencial de sentido que uma 
experiência pode ser qualificada como dotada de sentido. Na medida em que essa experiência passa a ocupar uma posição determinada na estrutura de interconexão de sentido, ela se torna, assim, determinada, ao mesmo tempo, por essa estrutura. Além disso, na medida em que a consciência de sentido é infinita, a finitude de suas formas é elevada à consciência. Esse é um paralelo idêntico à construção da consciência de infinitude e finitude em Fichte. Pois, na medida em que as formas da consciência são finitas, há sempre um excedente de sentido que ela não consegue apreender. Nesse direcionamento à infinitude, a consciência percebe, ao mesmo tempo, sua finitude. Por esse motivo, a consciência de sentido traz consigo, igualmente, uma dialética de determinidade e indeterminidade. É por isso que "o sentido individual deve sempre representar uma estrutura indeterminada de interconexão de sentido, por meio da qual uma atualização ulterior de sentido é alcançada". Em toda estrutura de interconexão de sentido está contida, ao mesmo tempo, "a reivindicação incondicional da formação absoluta". O ponto a ser percebido é que essa reivindicação incondicional da formação absoluta jamais pode ser realizada. Ela permanece, como diz Tillich, como a conclusão da consciência cultural, ao passo que para a consciência religiosa é e somente pode ser um símbolo. Os princípios de sentido aos quais a consciência se submete no ato espiritual são precisamente os princípios de sentido que a constituem. Não se trata, portanto, de uma submissão enquanto "necessidade racional para evitar uma contradição", mas uma consequência da própria estruturação da consciência de sentido que, enquanto infinita e incondicionada, somente pode se apreender de forma finita e já historicamente condicionada. Se essa descrição teórico-filosófica da consciência desenvolvida por Tillich deve ser aceita ou não, isso certamente já configura outra análise. No entanto, o princípio da coerência interna dos próprios pressupostos constitutivos do sistema deve ser mantido. O sistema deve ser analisado desde dentro, a partir de uma investigação crítica e imanente, e não a partir de uma crítica puramente externa. Tanto Gross quanto Calvani apontaram para uma possível inconsistência interna. No entanto, a partir de um exame mais exegético, essa aparente inconsistência desaparece. Por certo, todo sistema (fechado) de pensamento apresenta inconsistências. Mas, novamente, tais inconsistências devem ser demonstradas a partir de uma análise imanente da coerência interna dos pressupostos que sustentam a totalidade do sistema.

As considerações acima já devem bastar como resposta parcial às considerações de Calvani. De fato, a cultura, para Tillich, não existe em si mesma - e eu me perguntaria até que ponto a cultura não é, em qualquer sentido possível, um produto humano. Antes, sob o prisma de uma teoria da subjetividade ou filosofia do espírito - e não somente a de Tillich, vale dizer -, resta claro que a cultura somente é possível enquanto "imediatidade mediada", ou melhor, a cultura é a imediatidade da natureza tal como mediada pela consciência. À parte da consciência e de um sujeito consciente, não sei de que forma poderia haver "cultura" em sentido estrito. Para pôr de um modo mais 
simples, a cultura é uma natureza sui generis que colocamos sobre a natureza, como diria H. Richard Niebuhr. Na medida em que o Naturmensch não existe, i.e., na medida em que toda consciência se eleva frente à imediatidade da natureza e a apreende como algo que a confronta, a natureza somente pode ser concebida como cultura. Ou, para citar o neokantiano Heinrich Rickert, "a natureza é um produto da cultura".

Por outro lado, está claro que, para Tillich, a cultura somente pode ser pensada como a forma por meio da qual o espírito se realiza. Como dito anteriormente, $\mathrm{o}$ incondicionado somente pode se apreender por meio de formas condicionadas, que são as formas culturais. A fórmula de Tillich, a saber, "a religião é a substância da cultura e a cultura é a forma da religião", quer dizer precisamente isto: o espírito, em sua incondicionalidade, é a pressuposição de todas as coisas. No entanto, ele somente pode se apreender numa forma condicionada. É por isso que, para Tillich, o incondicionado subjaz como "substância" da cultura. Isso não quer dizer que o incondicionado esteja abaixo ou acima dela, mas tão-somente que o incondicionado, enquanto pressuposição de todas as coisas, é também, obviamente, a pressuposição da cultura. Para Tillich, o que distingue religião e cultura é apenas a qualidade do ato noético da consciência, i.e., para onde ela, a consciência, se volta em intencionalidade. A autodeterminação religiosa é, por conseguinte, estritamente contingente. Por outro lado, não podemos nos esquecer que a religião precisa das formas culturais para que possa se realizar. Religião e cultura estão unidas na imediatidade da incondicionalidade da autorrelação espiritual. No entanto, elas estão separadas em sua atualidade. Novamente, a religião usa e nega as formas culturais, porque sabe que o incondicionado não é nenhuma forma - nem nenhuma coisa - que possa ser apreendida pelo espírito. Aqui, não é tanto que a cultura precise da substância da religião para existir. Antes, a cultura precisa do incondicionado como sua pressuposição - que, por certo, é a base para a fundamentação do conceito de religião e de Deus. O que Tillich quer dizer é que, a partir de sua filosofia do espírito, todos os atos espirituais concretos somente são possíveis porque a consciência de sentido se articula a partir da polaridade forma (Form) e substância (Gehalt). Essas são categorias estruturantes da consciência de sentido e, à parte delas, não há "vida consciente" possível.

No entanto, é preciso reconhecer que, de fato, Tillich não se ocupou demasiadamente em oferecer uma interpretação da cultura popular. Mas, mesmo assim, não me parece correto determinar seu conceito de cultura como elitista. Se há uma consequência da estruturação da consciência de sentido a partir da determinação do conceito de incondicionado é que, para Tillich, todas as formas culturais são - across-the-board! - ambíguas. E, em momentos de euforia política e de ultravalorização do popular como instância "quase redentora", conquanto, por vezes, ingenuamente assumida como desprovida de ambiguidades, a contribuição de Tillich constitui um alerta importante na medida em que assume suas ambiguidades e contradições. A cultura popular é, 
para todos os fins, tão ambígua e tão dependente de redenção quanto a "alta cultura" (Hochkultur). Por outro lado, além de notáveis e influentes preocupações em oferecer uma interpretação de movimentos políticos e de massa, Tillich também se dedicou, ainda que em chave menor, ao status da cultura popular. Em sua palestra de habilitação, proferida em Halle, em 1916, sob o título Der Begriff des christilichen Volkes, por exemplo, Tillich fala, literalmente, não apenas em "cultura popular", como também em "igreja popular", "vida popular", "alma popular". Seria importante, talvez, estudar esses textos com mais cuidado para que possamos ver até que ponto o olhar de Tillich pode iluminar nossas próprias análises da cultura popular - em suas múltiplas formas. E, se a partir de um exame minucioso, sua interpretação se revelar "extremamente limitada e elitista para ser aplicada ao contexto brasileiro", é, então, mister criticá-lo com toda a pujança intelectual possível. No entanto, precisamente por nos oferecer um sistema compreensivo de pensamento e uma teoria da religião e da cultura muitíssimo bem delineados, penso que o programa teológico de Tillich, menos que um estorvo, pode, antes, nos oferecer chaves extremamente valiosas para uma interpretação de nosso contexto sob o ponto de vista vantajoso do incondicionado. Talvez, aqui, seja válido reproduzir o juízo de Ulrich Barth, que empreguei como epígrafe do presente artigo:

Que a busca de sentido seja uma necessidade básica de toda vida consciente; que o manejo do sentido seja uma das tarefas centrais dos sistemas sociais; e que a religião, tanto em sua forma individual quanto pública, tenha participação em ambas; é, hoje em dia, quase um lugar-comum. Isso nem sempre foi assim. Devemos a primeira construção do conceito de religião baseado numa teoria do sentido a Paul Tillich. Dessa forma, ele estabeleceu padrões de importância duradoura para o tratamento cultural-científico, sociológico, filosófico-religioso e teológico-sistemático do conceito de sentido.

Uma última palavra sobre o incondicionado. Seria completamente errôneo compreender o conceito de incondicionado como um conceito alternativo para o conceito de Deus, uma vez que esse entendimento reproduziria imediatamente as mesmas dificuldades que o conceito de incondicionado formulado por Tillich pretende superar. Antes, o conceito de incondicionado atesta a mudança de perspectiva fundamental operada por Tillich em seus escritos ulteriores à Primeira Guerra, na medida em que esse conceito intenciona apresentar a ideia, intrínseca à razão (Vernunft), de uma unidade final permanentemente intencionada pela subjetividade extrapolativa. Somente quando se limita esse conceito a um status puramente lógico é que se torna possível empregá-lo como uma solução efetiva para o problema da contraditoriedade presente no conceito de Deus. Se, contudo, um status diferente daquele de uma ideia transcendental é conferido a esse conceito, então a eficácia sistêmica que Tillich confere ao conceito de incondicionado como solução para 
o problema da contraditoriedade presente no conceito de Deus torna-se um placebo. Pois, enquanto uma "ideia da razão", o incondicionado aponta para a própria necessidade da unidade interna e última do pensamento, sendo, ele mesmo, seu próprio pressuposto e fundamento. Tillich expressa esse ponto de vista de forma cogente em seu texto Religion und Weltpolitik, escrito entre os anos de 1938 e 1939:

Nós vimos que o incondicionado aparece como tal, na consciência ética (sittlichen Bewußtsein), enquanto a reivindicação incondicional do eu-que-vem-ao-encontro de se tornar reconhecido como eu (des begegnenden Selbst, als Selbst anerkannt zu werden). Mas, esse "incondicionado" carece de hipostaziação teórica. Ele é um "caráter", não um ser. E o teórico somente pode conferir caráter negativo à hipostaziação enquanto conceito do incondicionado. Onde o teórico faz uma tentativa de conferir uma determinação conteudística, ele deve extraí-lo do material daqueles-que-são (Seienden), isto é, daquilo que deve ser transcendido no teórico. Por esse motivo, todos os conceitos metafísicos do ser possuem esse caráter flutuante que se justifica no fato de que, no princípio teórico, o sentido mítico se torna igualmente visível ao ser simultaneamente intencionado, uma vez que esse princípio possui, enquanto tal, a função de uma hipótese última.

A percepção de que a objetivação lógica do conceito de Deus é uma consequência necessária do próprio pensamento, e que também vale apenas para pensar em Deus e não para o absoluto em si, também advém dessa reflexão. Essa "apercepção transcendental" (Kant), que irrompe da reflexão sobre o pensamento do conceito de Deus como instância que é pensada, também foi considerada por Tillich em sua doutrina de Deus, conforme elaborou em sua Systematic Theology, por meio da distinção entre "objeto lógico e ontológico". A distinção categorial elaborada por Tillich, que tem um lugar único no conhecimento do conceito de Deus como "algo" que é percebido pela consciência, também pode ser identificada na parte propriamente normativa de sua doutrina de Deus. Como ele afirma: "Deus deve ser abordado cognitivamente através dos elementos estruturais do ser-em-si. Esses elementos fazem dele um Deus vivo, um Deus que pode ser a preocupação última do homem. Eles nos permitem usar símbolos que sabemos apontar para o fundamento da realidade". A determinação perspicaz de Deus como o ser-emsi na Systematic Theology, enquanto positividade absoluta, abre espaço para o conhecimento advindo da unidade transcendental da apercepção. Além disso, a solução do problema contraditório presente no conceito de Deus a partir do conceito de incondicionado como conceito dotado de um estatuto puramente lógico, bem como a identificação, operada por Tillich, entre o ser de Deus e o ser-em-si que, enquanto positividade absoluta, abre espaço para o conhecimento advindo da unidade transcendental da apercepção, tem o mérito de indicar, 
igualmente, a função constitutiva da hipótese de uma unidade final que assegura a unidade do saber.

Por fim, é preciso perguntar: é possível abandonar a teoria da religião de Tillich e adotar outra, que julgamos mais adequada, também a partir de nossos próprios gostos e preferências intelectuais? É evidente que sim. No entanto, enquanto uma teoria da religião, firmemente alicerçada sobre a tradição moderna e crítica, careceria ela de tamanha coerência interna a ponto de tentar sustentar-se por meio de um apelo à fé? É evidente que não. Por outro lado, será que seu rigor sistêmico-metodológico ainda é capaz de nos oferecer uma chave de interpretação para um fenômeno que, salvo violência, não pode ser reduzido? Em meu entendimento, a resposta me parece por demasiado clara para que seja, de antemão, rejeitada. E, no entanto, todo aquele que fala sobre Deus está "condenado" a justificar as condições de possibilidade a partir das quais o faz muito embora, também em nosso ambiente universitário, falemos de Deus, muitas das vezes, do mesmo modo como falamos sobre mesas e cadeiras, portas e janelas. A menos que Deus não seja mais que uma palavra em nosso léxico cotidiano, sua tematização precisa ser justificada. Também aqui, o empreendimento sistemático de Tillich talvez seja, de fato, não apenas útil, mas, quiçá, terminus a quo. 